The Free Internet Journal

for Organic Chemistry
Review

Arkivoc 2018, part i, 134-178

\title{
The chemistry of the himachalenes and atlantones from Cedrus
}

\section{Abdelouahd Oukhrib, ${ }^{a}$ Mohamed Zaki, ${ }^{* b}$ and Ahmed Benharref ${ }^{a}$}

a Laboratoire de Chimie Biomoléculaire, Substances Naturelles et réactivité, Unité Associé au CNRST (URAC16), Université Cadi Ayyad, Faculté des Sciences Semlalia, BP 2390, Bd My Abdellah, 40000 Marrakech, Morocco

${ }^{b}$ Institut de Chimie Organique et Analytique, University d'Orléans, UMR CNRS 7311, B.P. 6759,

45067 Orléans cedex 2, France

E-mail: mohamed.zaki@etu.univ-orleans.fr

Received 12-16-2017

Accepted 03-15-2018

Published on line $04-16-2018$

\section{Abstract}

Synthesis and functionalization of natural products are useful procedures to access and develop new and interesting molecules with biological properties. In this review we discuss the major sesquiterpenes isolated from the essential oil of cedar, which represents a family of abundant and inexpensive natural materials. Some total synthesis and chemical transformations described in the literature have been included.

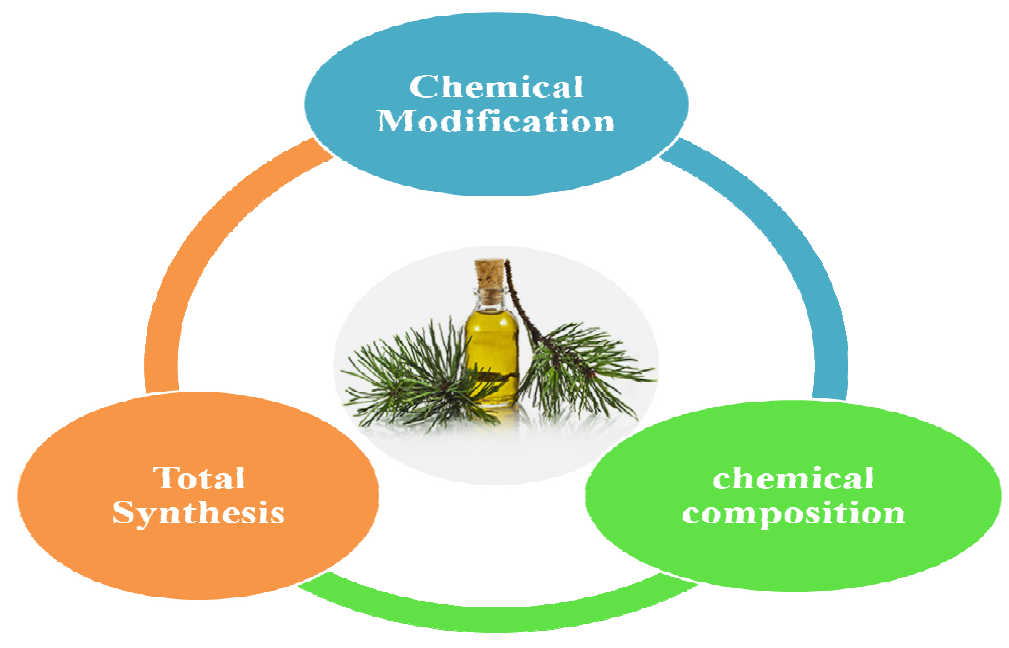

Keywords: Cedar (Cedrus), himachalenes, atlantones, hemisynthesis, total synthesis 


\section{Table of Contents}

1. Introduction

2. Chemical Composition of the Essential Oils of Cedar

3. Total Synthesis

3.1 Synthesis of himachalenes

3.2 Syntheses of ar-himachalene

3.3 Synthesis of $\alpha$-atlantones

4. Chemical Modifications of Major Compounds of the Essential Oil of Cedar

4.1 Hydrochlorination of himachalenes

4.2 Dehydrogenation

4.3 Oxidation of himachalenes

4.4 Cyclopropanation of $\beta$-himachalene

4.5 Rearrangements of epoxy-himachalenes

4.6 Amination of himachalenes

5. Synthesis of ar-Himachalene Derivatives

6. Reactivity of $\alpha$-Atlantones

6.1 Aromatization/Condensation with Thiosemicarbazone

6.2 Cyclocarbonylation of Atlantone Derivatives

6.3 Acylation of Atlantone Derivatives

7. Conclusions

References

\section{Introduction}

Plants have always been a vital source of medicines. Today the majority of the world's populations, particularly in developing countries, are treated only with traditional herbal remedies. The modern pharmaceutical industry is largely based on the diversity of secondary metabolites to find new molecules with new biological properties. ${ }^{1}$ The study of plants represents a huge potential for discovery of new substances or new "lead compounds" if we consider that each of these plants can contain hundreds or thousands of secondary metabolites. ${ }^{2}$ The largest pharmaceutical companies know that tropical forests and fields can become a potential sources of valuable drugs. They invest significant capital to find new substances to make drug candidates that can be commercialized. Research in this field becomes automated and pharmaceutical companies will soon have the opportunity to study millions of chemical substances per week. ${ }^{3}$

The genus Cedar belongs to the family Pinaceae. This kind of tree has existed since the tertiary era. In this review, the term "Cedar" refers to four species: Cedrus brevifolia, Cedrus deodara, Cedrus libani and Cedrus atlantica. The Atlas cedar (Cedrus atlantica) is endemic to North Africa, especially Morocco and Algeria. It is exposed to a bright and dry climate in summer. The Himalayan cedar (Cedrus deodara) remains the species most represented, with an estimated area of 500,000 hectares. It occurs in the regions of the Himalayas from Afghanistan to western Nepal where there is a sub-Mediterranean temperate and subtropical climate. Cedrus libani, the emblem of Lebanon, occupies large areas in the mountains of northern and central Lebanon.

This review covers the chemical composition of the essential oil of cedar, different routes to synthesis of major constituents of this oil and its chemical transformation. 


\section{Chemical Composition of the Essential Oils of Cedar}

Many chemical studies have been devoted to species of Pinaceae, but very few of them dealt with Cedrus. The studies reported in the literature essentially treated the two species: atlantica and deodara. We report the chemical composition classifying by family of compounds of three species: atlantica, deodara and libani.

The earliest work on the essential oils of cedar took place back in 1902, when the ketone 1 was isolated for the first time by Grimal. ${ }^{4}$ Pfau and Plattner ${ }^{5}$ showed the existence of two sesquiterpene ketones: $\alpha$-and $\gamma$ atlantone 2 and 3. Teisseire and Plattier ${ }^{6}$ identified an epoxide and two sesquiterpene ketones, namely $\beta$ epoxyhimachalene 5, 12,13-dehydro-trans- $\alpha$-atlantone 6 and 6,6,9-trimethylbicyclo[5.4.0]undec-8-en-2-one 4. Besides these products, Sukh Dev et al. ${ }^{7}$ isolated other sesquiterpenoid compounds, such as allohimachalol 7 and (+)-longiborneol 8 (Scheme 1).<smiles>CC(=O)C1C=CC(C)CC1</smiles>

1

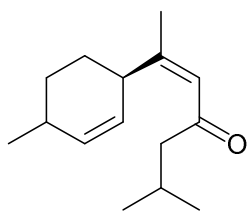

6 12,13-dehydro-trans$\alpha$-atlantone

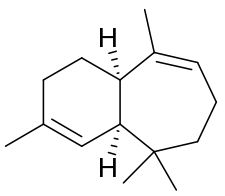

11 cis- $\gamma$-himachalene<smiles>CC1=C[C@@H]2[C@H](C[C@H]1O)[C@@H](O)CCCC2(C)C</smiles>

16 isocentdarol

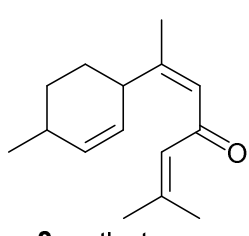

$2 \alpha$-atlantone

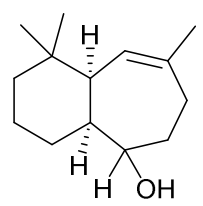

7 allohimachalo

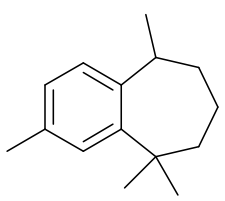

12 ar-himachalene

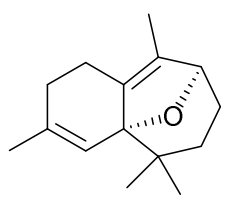

17 oxydohimachalene

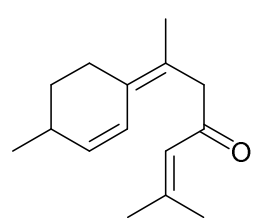

$3 \gamma$-atlantone

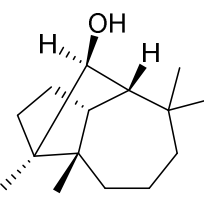

8 (+)-longiborneol

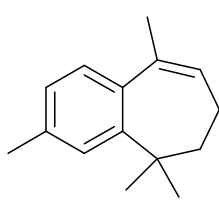

13 dehydro-7,8-arhimachalene<smiles>CC1=CC2C(=O)CCCC(C)(C)C2CC1</smiles>

4

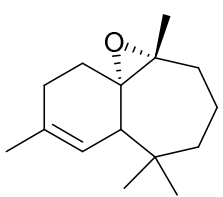

$5 \beta$-epoxyhimachalene

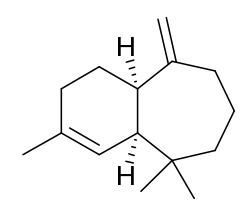

$9 \alpha$-himachalene

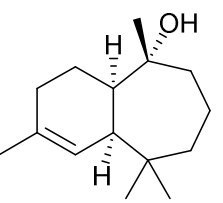

14 himachalol

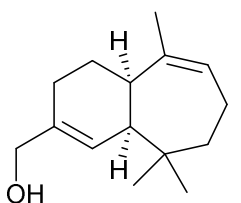

$19 \beta$-torsol

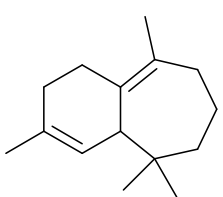

$10 \beta$-himachalene

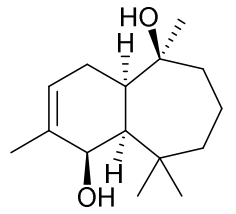

15 centdarol

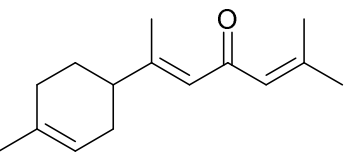

$20 \alpha$-trans-atlantone<smiles>CC1=CC[C@H]([C@H]2OC(C)(C)C=C(O)C2=O)CC1</smiles>

23 himasecolone

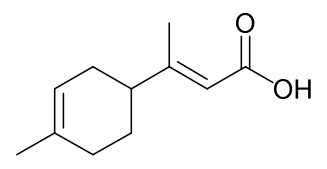

27 limonene carboxylic acid
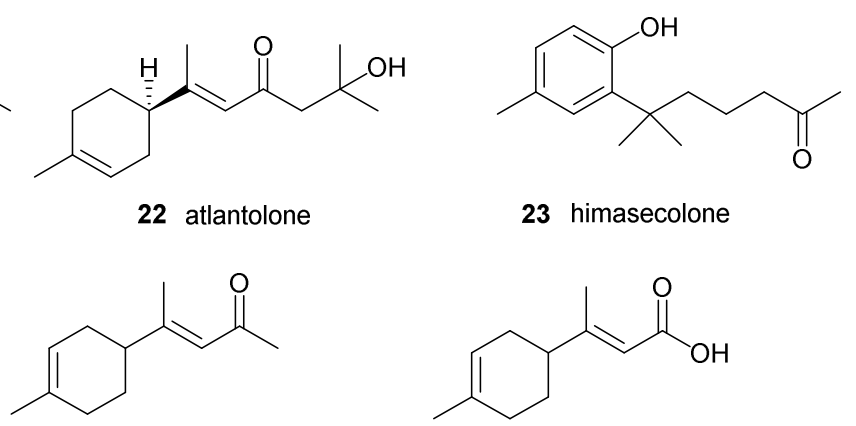

26 acetyldipentene
22 atlantolone

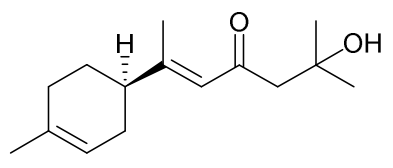

.

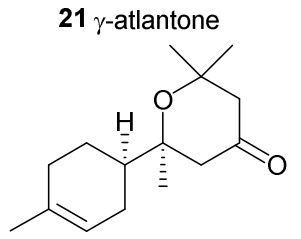

25 deodarone

Scheme 1. Compounds isolated from essential oil of cedar. 
Ruzička et al. ${ }^{8}$ discovered the existence of an optically inactive bicyclic sesquiterpene that could form a dihydrochloride by the action of gaseous hydrogen chloride in acetic acid. Rao et al. isolated two bicyclic optically active sesquiterpene hydrocarbons named $\alpha$ - and $\beta$-himachalene, $\mathbf{9}$ and 10 respectively (Scheme 1). ${ }^{9}$ The structures of these two sesquiterpenes were identified and confirmed by Joseph and Dev. ${ }^{10}$

In 1961, Bredenberg and Erdtman obtained similar sesquiterpenes from the essential oils of the wood of Cedrus atlantica and Cedrus libani by fractional distillation followed by chromatography on alumina. ${ }^{11}$ Moreover, Teisseire and Plattier ${ }^{12}$ isolated and identified three other sesquiterpene, cis- $\gamma$-himachalene 11, and two with the fully aromatic six-membered ring, ar-himachalene 12 and dehydro-7,8-ar-himachalene $\mathbf{1 3}$ (Scheme 1).

Other compounds were described, such as himachalol 14 oxydohimachalene 17, atlantolone 22, deodarone $\mathbf{2 5}$, deodardione $\mathbf{2 4},{ }^{13-17}$ centdarol $\mathbf{1 5}$, isocentdarol $\mathbf{1 6},{ }^{18,19} \alpha$-torsol $\mathbf{1 8}, \beta$-torsol $\mathbf{1 9}$, andirolactone $\mathbf{2 8},{ }^{20} \alpha$-trans-atlantone $\mathbf{2 0}, \gamma$-atlantone $\mathbf{2 1},{ }^{21}$ himasecolone $\mathbf{2 3},{ }^{22}$ acetyldipentene 26 and limonene carboxylic acid 27 (Scheme 1). ${ }^{17}$ In addition, the products mentioned above, recent studies have been discovered the existence of other compounds. ${ }^{23-27}$

\section{Total Synthesis}

\subsection{Synthesis of himachalenes}

A significant number of methods have been developed for the synthesis of himachalenes. The first was carried out by De Mayo et al. ${ }^{28,29}$ They realized a synthesis in seven steps to get the $\alpha$-trans and $\beta$-himachalenes (Scheme 2). Indeed, $\beta$-himachalene was prepared starting from 1,4-dioxaspiro[4.5]dec-6-ene 29 and enone acetate $\mathbf{3 0}$ according to the reaction scheme shown. Irradiation of both compounds in cyclohexane provided a tetracyclic ketone 31. The reduction of ketone function in the presence of sodium borohydride followed by conversion into the mesylate and hydrolysis with $\mathrm{NaOH}(0.7 \%)$ in mixture of solvent $\mathrm{H}_{2} \mathrm{O} /$ dioxane gave a tricyclic ketone 32 in $35 \%$ yield based on $\mathbf{3 1}$. The action of $\mathrm{CH}_{3} \mathrm{Mgl}$ followed by treatment with the SimmonsSmith reagent gave after hydrolysis a product 33 with a cyclopropane moiety. Then, alkylation was conducted with $\mathrm{CH}_{3} \mathrm{l} /\left(\mathrm{CH}_{3}\right)_{3} \mathrm{COK}$ in $t$-butyl alcohol-benzene followed by hydrogenation with (Pt/Rh) catalyst to gave 34 . Reduction of $\mathbf{3 4}$ with LiAlH4 gave a separable mixture of diols $\mathbf{3 5}$ and $\mathbf{3 6}$ Finally, dehydration in pyridine in presence of $\mathrm{POCl}_{3}$ provided a mixture of two isomers, $\alpha$-trans- and $\beta$-himachalene $\mathbf{3 8}$ and $\mathbf{1 0}$ respectively.

The second synthesis was conducted by Wenkert and Malmura. ${ }^{30}$ It is based on an intramolecular DielsAlder cycloaddition of trienone 40 (7,7,10-trimethyl-1,8,10-undecatrien-3-one) catalyzed by Lewis acid (Scheme 3). This derivative was obtained in its turn from 3,3,6-trimethyl-5-heptenal 39 in nine steps. Treatment of compound $\mathbf{4 0}$ with $\mathrm{AlCl}_{3}$ in toluene under reflux for $2 \mathrm{~h}$, then with methyllithium led to the formation of 7-isohimachalol 42; dehydration afforded a mixture of bicyclic dienes $\alpha$-cis and $\beta$-himachalenes.

Another trienone derivative $\mathbf{5 0}$ was also mentioned. ${ }^{31}$ This derivative is successfully prepared by addition $[1,2]$ of the enolate ester 43 with 3,3-dimethylacrolein 44 in THF at $-78{ }^{\circ} \mathrm{C}$. The allyl alcohol 45 so formed (72\%) was dehydrated in presence of $\mathrm{TsOH}$ to give trans-dienyl ester 46 (90\%). Simple reduction of the latter with $\mathrm{LiAlH}_{4}$ provided the corresponding alcohol, which is oxidized in its turn by PCC at $25{ }^{\circ} \mathrm{C}$ to obtain dienal 47 (82\%) (Scheme 4). Reaction of product 47 with complex 48 in THF at $-78{ }^{\circ} \mathrm{C}$ followed by protection of the alcohol formed with diethyl phosphochloridate $\mathrm{CIPO}(\mathrm{OEt})_{2}$ gave the trienyl phosphate $\mathbf{4 9}$ with a $85 \%$ yield. The cleavage of the silanol ether group in product 49 with potassium fluoride $\mathrm{KF}$ in methanol at $0{ }^{\circ} \mathrm{C}$ provided the product $\mathbf{5 0}$ in $\mathbf{8 5 \%}$ yield. Finally, an intramolecular cycloaddition [4+2] of the product $\mathbf{5 0}$ in benzene at reflux gave octahydrobenzocycloheptanone 41 (90\%). The same steps as previously described allow isolation of a mixture of the two isomers $\alpha$-cis- and $\beta$-himachalenes $\mathbf{9}$ and $\mathbf{1 0}$ from $\mathbf{4 2}$. 

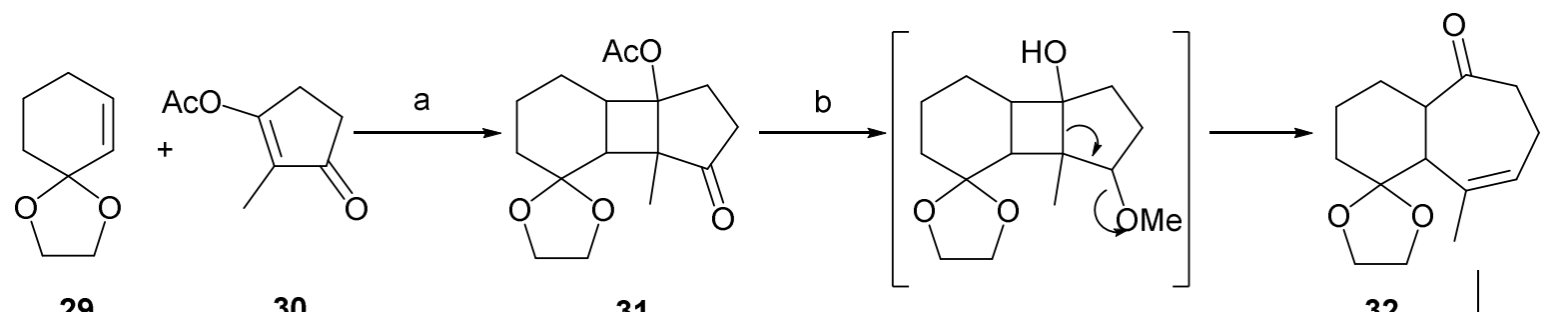

29

30

31

\section{2}

c<smiles>CC1=CC2C(=C(C)C1)CCC[C@H](C)[C@H]2O</smiles>

$10 \beta$-himachalene

$g \downarrow \uparrow \mathrm{h}$

36
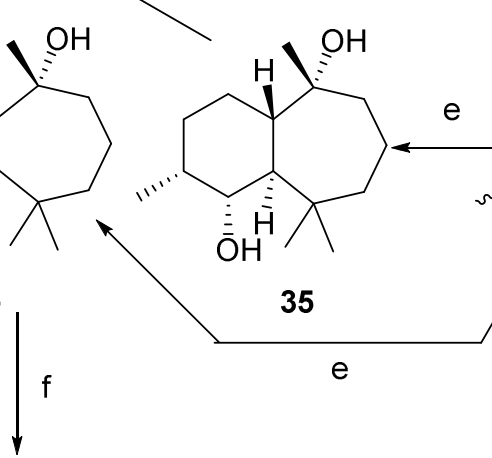

34

Н

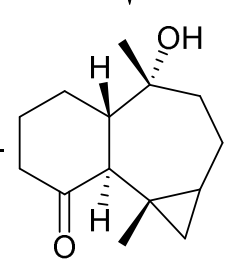

33<smiles>CC1(Cl)CC[C@@H]2[C@@H](C1)C(C)(C)CCCC2(C)Cl</smiles>

37

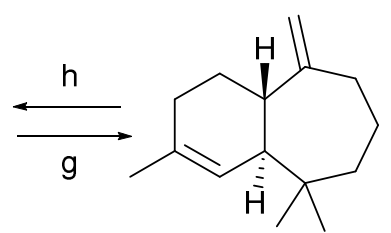

$38 \alpha$-trans-himachalene

a) irradiation, cyclohexane. b) 1: $\mathrm{NaBH}_{4} .2: \mathrm{MsCl}, \mathrm{NaOH}(0.7 \%), \mathrm{H}_{2} \mathrm{O} /$ dioxane. c) 1: $\mathrm{CH}_{3} \mathrm{Mgl}$, 2: Simmons-Smith reagent. d) 1: $\mathrm{CH}_{3} \mathrm{l} /\left(\mathrm{CH}_{3}\right)_{3} \mathrm{COK}$, t-butyl alcohol-benzene, 2: $\mathrm{Pt} / \mathrm{Rh}$. e) $\mathrm{LiAlH}_{4}$. f) $\mathrm{POCl}_{3}$, pyridine. g) $\mathrm{HCl}$. h) pyridine

Scheme 2. Total synthesis of $\alpha$-trans and $\beta$-himachalenes developed by De Mayo.

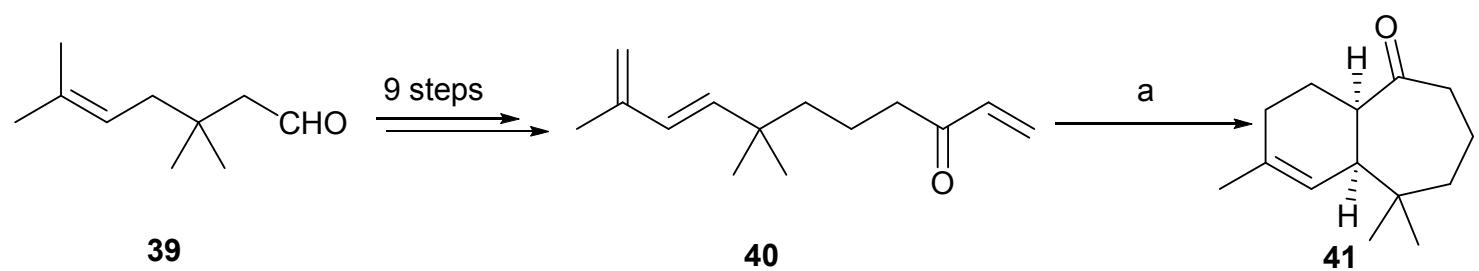

39

40

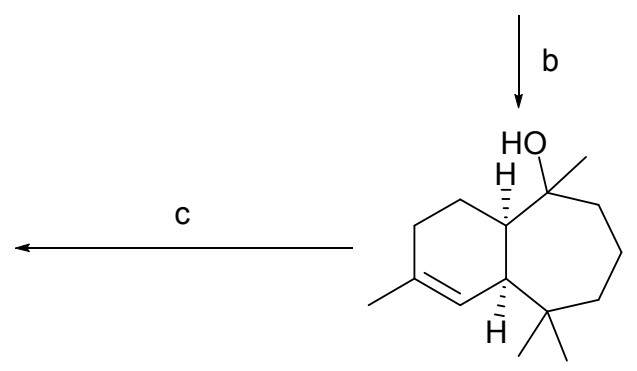

$9 \alpha$-cis-himachalene

$10 \beta$-himachalene

42 7-isohimachalol

a) $\mathrm{AlCl}_{3}, 110^{\circ} \mathrm{C}$. b) MeLi. c) $\mathrm{POCl}_{3} / \mathrm{Py}$

Scheme 3. Synthesis of $\alpha$-cis and $\beta$-himachalene by intramolecular Diels-Alder reaction. 


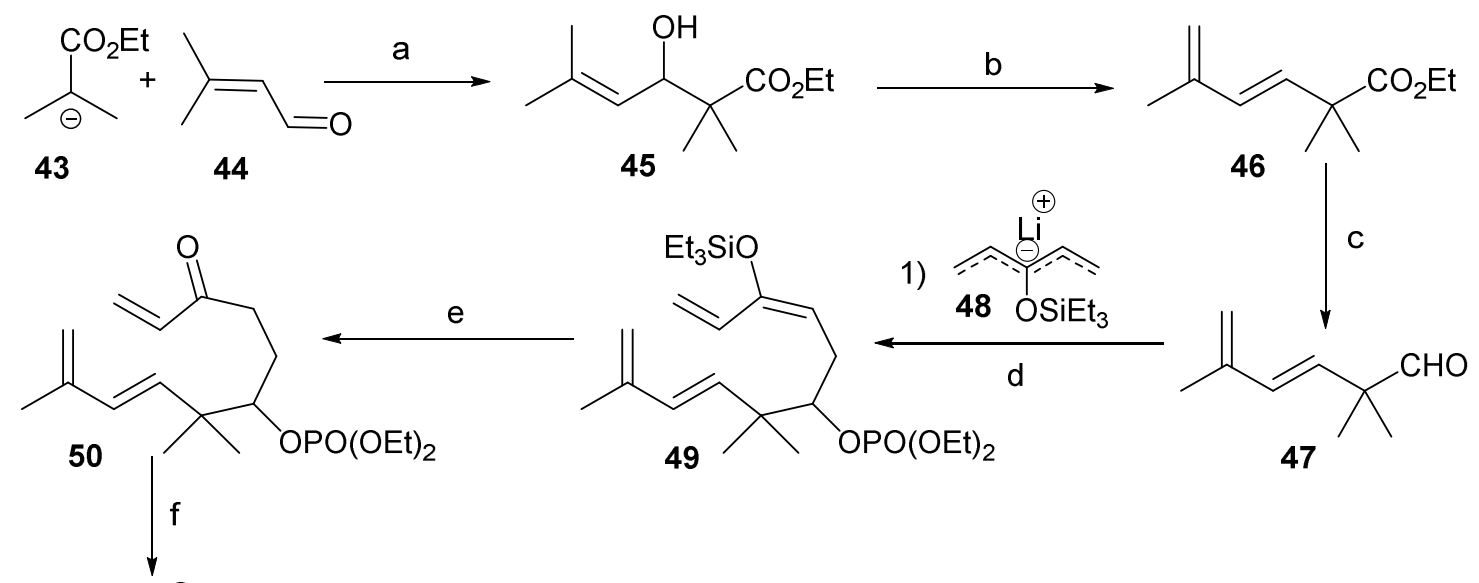

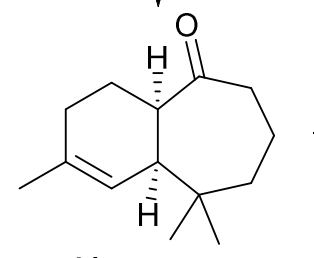

41

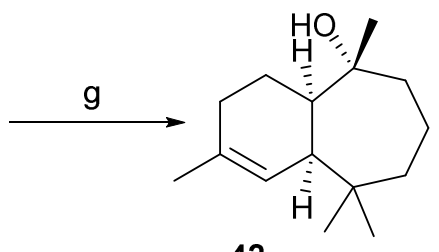

42

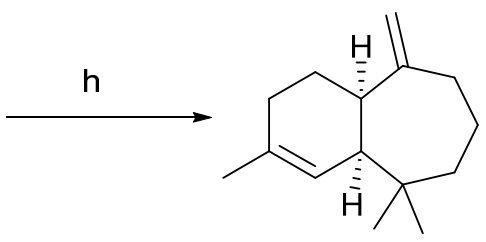

$9 \alpha$-cis-himachalenes

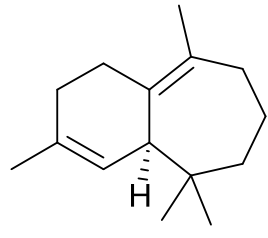

$10 \beta$-himachalenes

a) THF, $-78^{\circ} \mathrm{C}$. b) $\mathrm{TsOH} / 25^{\circ} \mathrm{C}$, c) 1: $\mathrm{LiAlH}_{4}, 2$ : PCC, $25^{\circ} \mathrm{C}$. d) complex 48, THF, $-78^{\circ} \mathrm{C}, 2: \mathrm{CIPO}(\mathrm{OEt})_{2 \cdot}$ e) $\mathrm{KF} / \mathrm{MeOH}, 0^{\circ} \mathrm{C}$. f) benzene, $80^{\circ} \mathrm{C} / 18 \mathrm{~h}$. g) MeLi. h) 1: $\mathrm{Li} / \mathrm{Et}_{3} \mathrm{~N}, 2: \mathrm{SOCl}_{2} / \mathrm{Py}$

Scheme 4. Synthesis $\alpha$-cis- and $\beta$-himachalene by intramolecular cyclization.

Evans et al. $^{32}$ used the same approach to synthesize cis- $\alpha$-himachalene starting from a chiral dienimide $\mathbf{5 1}$ (Scheme 5). Reaction of this chiral compound with acrolein leads stereoselectively to allylic alcohol 52 . $^{33}$ The latter undergoes Parikh-Doering oxidation to give the trienone 53. ${ }^{34}$ Intramolecular [4+2] cycloaddition of the trienone 53 in presence of $\mathrm{ZnBr}_{2}$ provides the product 54, which was converted into an $S$-ethyl $\beta$-ketothioester by action of LiSEt. Decarboxylation of the latter provides the ketone $\mathbf{4 1}$ and the synthesis is completed by treating with Tebbe reagent. ${ }^{35}$

Using an intermolecular Diels-Alder reaction, Brown and Liu achieved the synthesis of $\alpha$-cis- and $\beta$ himachalenes in eleven steps and in an effective overall yield of $21 \%$ from 4,4-dimethyl-2-cyclohexenone. ${ }^{36}$

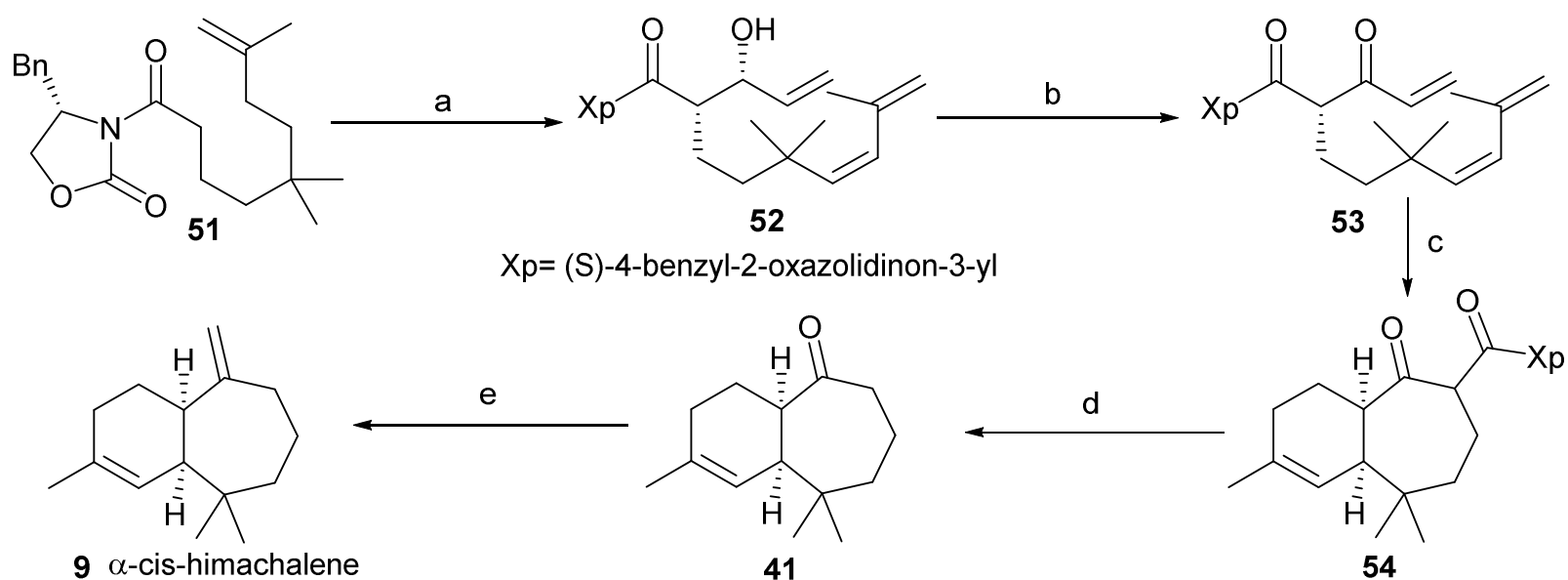

$9 \alpha$-cis-himachalene

41

54

a) $1: \mathrm{Bu}_{2} \mathrm{BOTf}, \mathrm{iPr}_{2} \mathrm{NEt}$, isoprene $0^{\circ} \mathrm{C}$. 2: Acrolein, $-78^{\circ} \mathrm{C}$. b) $\mathrm{SO}_{3} / \mathrm{Pyridine}, \mathrm{DMSO} / \mathrm{CH}_{2} \mathrm{Cl}_{2}, \mathrm{iPr}_{2} \mathrm{NEt},-10^{\circ} \mathrm{C}$. c) $\mathrm{ZnBr} 2$ $0^{\circ} \mathrm{C}$. d) 1: LiSEt. 2: $\mathrm{AgNO}_{3}$ 2,6-lutidine, $\mathrm{THF} / \mathrm{H}_{2} \mathrm{O} 70^{\circ} \mathrm{C}$. c) Tebbe reagent.

Scheme 5. Synthesis of $\alpha$-cis -himachalene from $N$-acyloxazolidinone 51. 
Another synthesis in seven steps was carried out by Mehta and Kapoor starting from the tricyclic sesquiterpene longifolene. ${ }^{37}$ This strategy allowed synthesis of (+)-himachalene dihydrochloride which is an intermediate that gave access to trans-himachalene derivatives and (+)-ar-himachalene (Scheme 6).

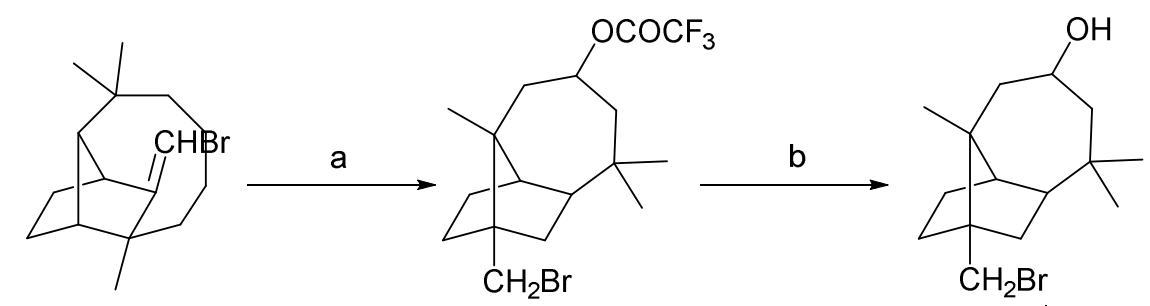

55 w-bromolongifolene

56
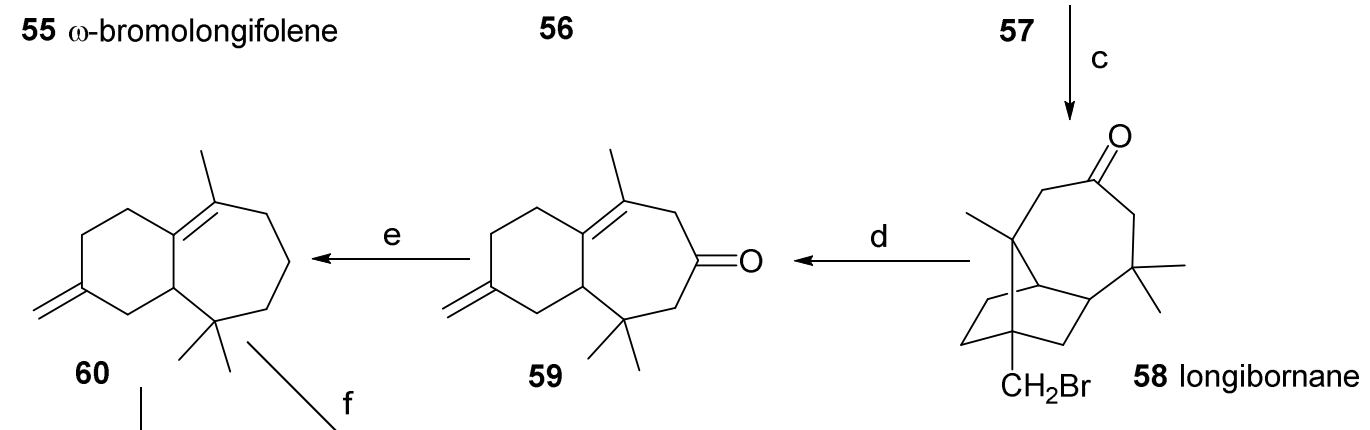

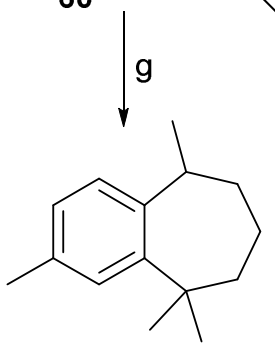

12 ar-himachalene

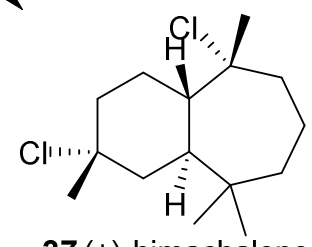

$37(+)$-himachalene dihydrochloride

a) $\mathrm{CF}_{3} \mathrm{COOH}$; b) $\mathrm{KOH} / \mathrm{EtOH}$; c) Jones reagent; d) Corey method; e) Wolff-Kishner; f) $\mathrm{HCl}($ gas) in acetic acid; g) Chloranil, $\mathrm{Pd} / \mathrm{C}$.

Scheme 6. Synthesis of (+)-trans-himachalenes.

The key step is the preparation of a bifunctional longibornane derivative $\mathbf{5 8}$ as the initial target. This was obtained from $\omega$-bromolongifolene $\mathbf{5 5}$ via an acid-catalyzed rearrangement involving an intramolecular 1,5hydride shift. The bicyclic ketone 59 was prepared from 58 using Corey reaction. ${ }^{38}$ Thus, Wolff-Kishner reduction of 59 and purification $\left(\mathrm{AgNO}_{3}\right.$-silica gel) gave the himachalene isomer $\mathbf{6 0}$. A stream of $\mathrm{HCl}$ gas through an acetic acid solution of 60 gave (+)-himachalene dihydrochloride $37 .^{39}$ The latter has already been converted into $\beta$-himachalene. Thus, the ar-himachalene was obtained from 60 by dehydrogenation with chloranil followed by aromatization with $\mathrm{Pd} / \mathrm{C}$.

In a similar way, a study of Dev and Shastri ${ }^{40}$ showed that $\alpha$ - and $\beta$-himachalene can be obtained by Wagner-Meerwein rearrangement of longipinene with a variety of acids $\left(\mathrm{BF}_{3} . \mathrm{Et}_{2} \mathrm{O}, \mathrm{HClO}_{4}\right.$ in aqueous dioxane, $\mathrm{H}_{2} \mathrm{NSO}_{2} \mathrm{OH}$ in acetone, and $\mathrm{H}_{2} \mathrm{SO}_{4}$ in glacial acetic acid). 


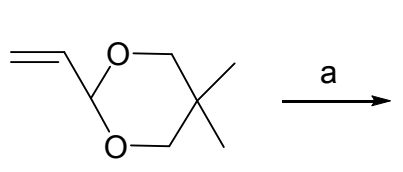

61

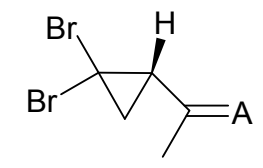

$62 \mathrm{~A}=\left(\mathrm{CH}_{3}\right) \mathrm{C}\left(\mathrm{CH}_{2} \mathrm{O}\right)_{2}$
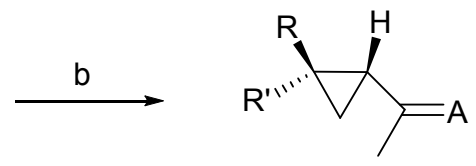

$63 \mathrm{R}=\mathrm{Br}, \quad \mathrm{R}^{\prime}=\mathrm{Me}$

$64 \mathrm{R}=\mathrm{Me}, \quad \mathrm{R}^{\prime}=\mathrm{Br}$

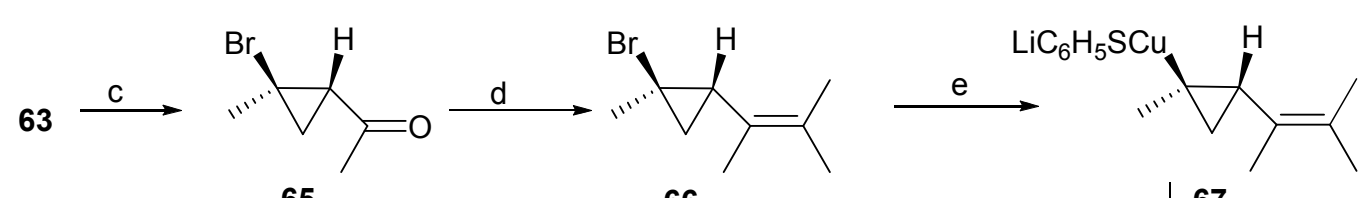

65

66
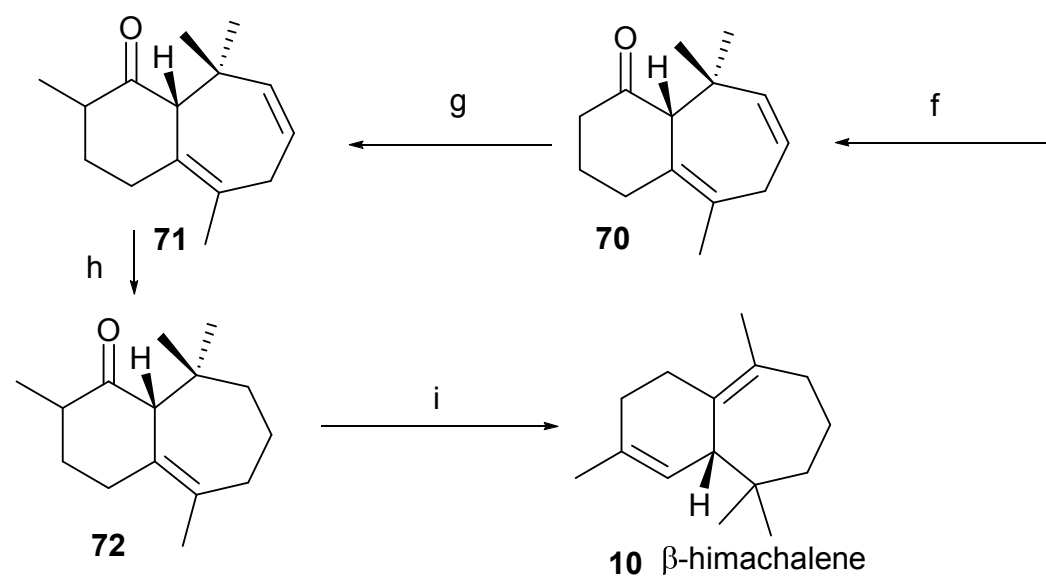

a) $\mathrm{CHBr}_{3}, \mathrm{NaOH}$. b) nBuLi, Mel. c) $\mathrm{HCO}_{2} \mathrm{H}$. d) $\mathrm{Ph}_{3} \mathrm{PC}\left(\mathrm{CH}_{3}\right)_{2}$. e) 1: nBuLi, 2: PhCuLiS, f)Xylene, reflux, g)1) LDA 2) Mel, h) $\left.\left(\mathrm{PPh}_{3}\right)_{3} \mathrm{RhCl}, \mathrm{i}\right)$ LDA.

Scheme 7. Synthesis of $\beta$-himachalene from 3-iodocyclohex-2-enone 68 and cuprate derivative 67.

Piers and Ruediger ${ }^{41}$ have described a total synthesis of $\beta$-himachalene $\mathbf{1 0}$ using cuprate $\mathbf{6 7}$ prepared from 5,5-dimethyl-2-vinyl-1,3-dioxane 61. The latter reacted with bromoform and sodium hydroxide in presence of a phase-transfer catalyst to give dibromocyclopropane 62. Treatment of the latter with $n$-butyllithium and methyl iodide gave a mixture of two epimers 63 (87-93\%) and 64 (7-13\%). The hydrolysis of product 63 with formic acid followed by Wittig reaction with isopropylidene triphenylphosphorane provided a brominated cyclopropane 66 which was converted into cuprate 67 by treatment with nBuLi/PhSCu. The interaction of 3iodocyclohex-2-enone $\mathbf{6 8}$ with a cuprate $\mathbf{6 7}$ followed by thermolysis (xylene reflux) provided dienone $\mathbf{7 0}$ in quantitative yield. Methylation of the latter gave the compound 71, which was converted into ketone 72 by hydrolysis in the presence of tris-triphenylphosphine rhodium chloride. The transformation of the ketone to the corresponding enol phosphate was followed by reduction to give $\beta$-himachalene 10 (Scheme 7).

$\alpha$-cis-Himachalene has also been prepared starting from tropone $\mathbf{7 3}$ as described by Rigby and McGuire. ${ }^{42}$ This strategy is based on a 1,8-addition-intramolecular cycloaddition protocol for construction of the bicyclo[5.4.0] undecane motif. The reaction of Grignard reagent $\mathbf{7 4}$ with tropone led to the formation of compound 75. Then, the oxidation and protection of the corresponding alcohol provided compound 76. The latter was then reacted with hydroxylamine hydrochloride under standard conditions. Conversion of the resultant oxime to the nitrile oxide by oxidation with sodium hypochlorite proceeded without incident and 
cycloaddition ensued to give the cis-fused bicyclic product 77. Reductive cleavage of the isoxazoline ring furnished amino alcohol 78 which was converted into $\alpha$-himachalene $\mathbf{9}^{30,36,43,44}$

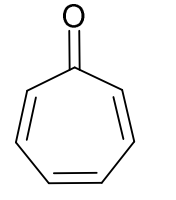

73 tropone

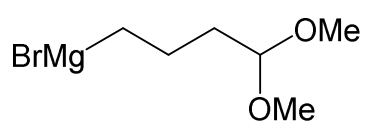

74

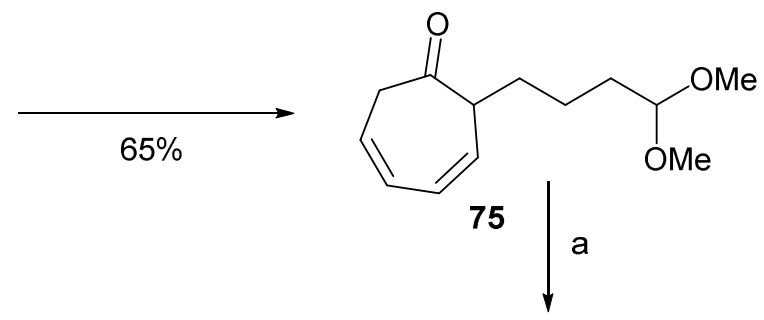

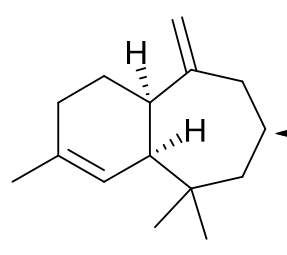

$9 \alpha$-cis-himachalene

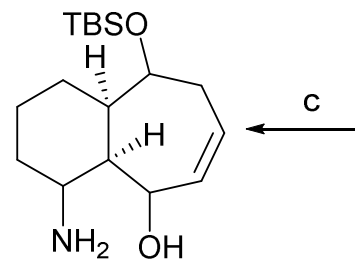

78

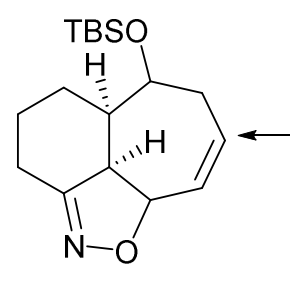

77

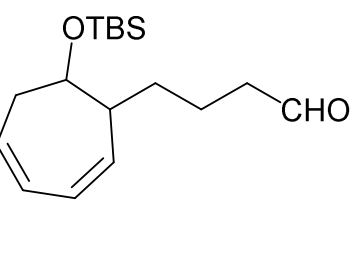

76

a) 1: $\mathrm{NaBH}_{4} / \mathrm{MeOH}, 2$ : TBDMSCI, imidazole, 3: TFA, aq acetone (36\%). b) 1: $\mathrm{NH}_{2} \mathrm{OH} \mathrm{HCl,} \mathrm{TEA,} \mathrm{2:}$ $\mathrm{NaOCl} / \mathrm{CH}_{2} \mathrm{Cl}_{2}$ (56\%). c) $\mathrm{LiAlH}_{4} / \mathrm{Et}_{2} \mathrm{O}(95 \%)$.

Scheme 8. Synthesis of $\alpha$-cis-himachalene from tropone.

An asymmetric version of the synthesis of $\alpha$-cis and $\beta$-himachalenes was recently reported by Ho and Chein, ${ }^{45}$ starting from $(1 S, 2 R)$-1,2-epoxy-p-menth-8-ene 79 in 15 or 16 steps with an overall yield of $6 \%$ (Scheme 10). The key steps include an Ireland-Claisen rearrangement, a Corey oxidative cyclization and a ring expansion.

The first step involves opening of the epoxide $\mathbf{7 9}$ followed by protection of the resulting alcohol $\mathbf{8 0}$ with isobutyric anhydride to obtain the product $\mathbf{8 1}$. Acid $\mathbf{8 2}$ was obtained by Ireland-Claisen rearrangement of $\mathbf{8 1 .}$ Then compound $\mathbf{8 2}$ was converted into $\mathbf{8 4}$ by a sequence of reactions involving $\mathrm{LiAlH}_{4}$ reduction to 83 followed by oxidation with pyridinium chlorochromate (PCC), ${ }^{46}$ and treatment with $\mathrm{TsOH}$ in benzene. Products $85 \mathrm{a}$ and $\mathbf{8 5 b}$ were obtained by treatment of $\mathbf{8 4}$ with ethylene glycol and trifluoroacetic acid respectively. The $\mathbf{8 5 b}$ was transformed to the bicyclic product 86b with expansion of the six-membered ring with $\mathrm{Me}_{2} \mathrm{SiCHN}_{2}$ and $\mathrm{BF}_{3}-$ $\mathrm{OEt}_{2} \cdot{ }^{47}$ The study showed that the last step was regioselective, providing only one product from the migration of the methylene group. Finally, treatment of the mixture $86 \mathrm{a} / \mathbf{8 6 b}$ with $\mathrm{Bu}_{4} \mathrm{NF}$ in MeCN provided $86 \mathrm{a}$. (+)- $\beta$ Himachalene was obtained by a reduction of $86 \mathrm{a}$, the first time with $\mathrm{NaBH}_{4}$ and then with $\mathrm{Li}$ in liquid ammonia.

$(+)-\beta$-Himachalene can be also obtained directly from $\mathbf{8 6 b}$ after reduction of the ketone function followed by syn-elimination of cis- $\alpha$-silylcycloheptenol derivative 87 by treatment with $\mathrm{KH} .{ }^{48}$ The resulting triene 88 was partially hydrogenated with $\mathrm{CoCl}_{2} / \mathrm{NaBH}_{4} / \mathrm{EtOH}$ (Scheme 9).

Recently, enantiospecific synthesis of (+)-trans- $\alpha$-himachalene was performed by Srikrishna and Kumar via an intramolecular type II carbonyl-ene reaction. ${ }^{49}$ Indeed, the (+)-trans- $\alpha$-himachalene was obtained from $(R)$ carvone 89. First step involves the preparation of compound $\mathbf{9 4}$. The latter was obtained from carvone $\mathbf{8 9}$ in five steps. Indeed, alkylation of carvone with methyl bromoacetate followed by reduction of keto ester $\mathbf{9 0}$, produce hydroxy ester 91, which was transformed into methoxyester $\mathbf{9 2}$ in the presence of sodium hydride and methyl iodide. Double alkylation of ester 92 using LDA and methyl iodide gave a compound 94 in $25 \%$ yield based on carvone. Accordingly, reduction with $\mathrm{LiAlH}_{4}$ followed by a mild oxidation with PCC/NaOAc 
furnished aldehyde $\mathbf{9 6}$. Wittig reaction with methoxymethylenetriphenylphosphorane provided enol ether $\mathbf{9 7}$ in a mixture of two isomers $Z$ and $E$ (1:1). Treatment with hydrochloric acid gave the aldehyde intermediate 98, which undergoes spontaneous intramolecular hetero-ene reaction to give a mixture of bicyclic alcohol 100 and diol 99 with high stereoselectivity. Thereafter, the alcohol 100 was mesylated with $\mathrm{MsCl}$. Thus, OMe and OMs groups are removed with lithium in liquid ammonia to obtain directly trans- $\alpha$-himachalene 38 with $12 \%$ yield based on 98 (Scheme 10).<smiles>C=C(C)C1C=C[C@](O)(CC#CC(=C)C2CC[C@@]3(C)O[C@H]3C2)CC1</smiles>

79

80

81

82

83 e

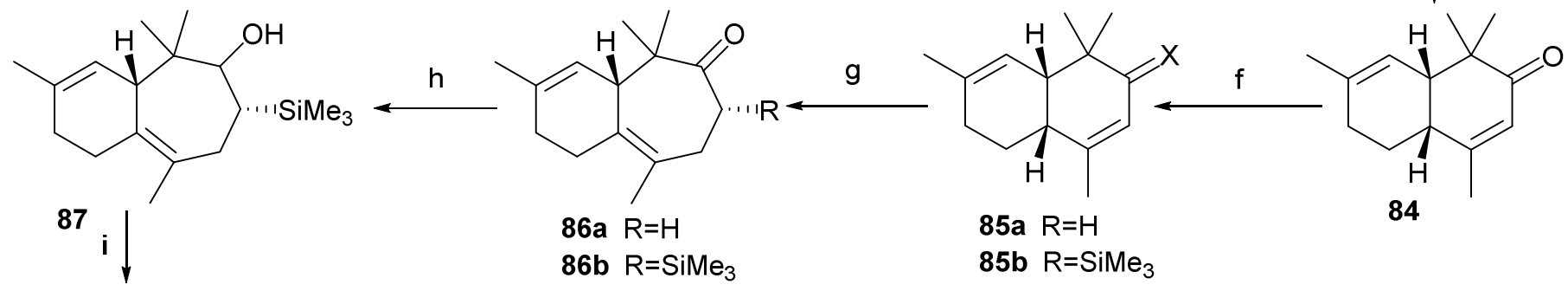<smiles>CC1=C[C@H]2C(=C(C)C1)C(C)=CC(C)(C)[C@H]2C</smiles>

a) 1: $\mathrm{Me}_{2} \mathrm{NH} 150^{\circ}, 18 \mathrm{~h}, 2: \mathrm{H}_{2} \mathrm{O}_{2} 150-180^{\circ}, 75 \%$. b) Isobutyric anhydride, $\mathrm{Et}{ }_{3} \mathrm{~N}$, DMAP; cat, $\mathrm{CH}_{2} \mathrm{Cl}_{2}, 25^{\circ}, 99 \%$. c) LDA, THF, $-78^{\circ}$, 1h, $-40^{\circ}, 30$ min; $\mathrm{Me}_{3} \mathrm{SiCl},-78^{\circ}$; PhMe, reflux, 36h, 68\%. d) $\mathrm{LiAlH}_{4}$, THF, reflux, 5h, 90\%. e) $\mathrm{PCC}, \mathrm{CH}_{2} \mathrm{Cl}_{2}$, r.t, $24 \mathrm{~h}$; TsOH, benzene, reflux, $1.5 \mathrm{~h}, 44.1 \%$. f) Ethylene glycol, TsOH (cat), Dean-Stark, reflux, $24 \mathrm{~h}, 92.1 \%$ of $87 \mathrm{a} ; 2.35 \% \mathrm{CF}_{3} \mathrm{COOH} / \mathrm{H}_{2} \mathrm{O}$, $\mathrm{CH}_{2} \mathrm{Cl}_{2}, 10-20^{\circ}, 98.8 \%$ of 87 b. g) $\mathrm{Me}_{2} \mathrm{SiCHN}_{2}, \mathrm{BF}_{3} \mathrm{OEt}_{2}, \mathrm{CH}_{2} \mathrm{Cl}_{2},-40^{\circ} \mathrm{C}, 2.5 \mathrm{~h}, 65.3 \%$. h) $\mathrm{NabH}_{4}, \mathrm{EtOH}, 25^{\circ}, 86.9 \%$. i) $\mathrm{KH}, \mathrm{THF}$, $25^{\circ}, 24 \mathrm{~h}, 72.3 \%$. j) $\mathrm{CoCl}_{3} 6 \mathrm{H}_{2} \mathrm{O}, \mathrm{NaBH}_{4}, \mathrm{EtOH}, 25^{\circ} \mathrm{C}, 24 \mathrm{~h}, 72.6 \%$.

Scheme 9. Enantioselective synthesis of (+)- $\beta$-himachalene.

Finally, it should be noted that the trans-himachalene isomer can be obtained from its isomer cishimachalene by hydrochlorination reaction with gaseous $\mathrm{HCl}$ followed by dehydrochloration/isomerization in pyridine or filtering on alumina. ${ }^{6,29,39,50,51}$ 
<smiles>C=C(C)C1CC=C(C)C(=O)C1</smiles>

$89(\mathrm{R})$-carvone

90

91<smiles>C=C(C)C1CC=C(C)C(OC)[C@H]1C(C)(C)C(C)C(C)C</smiles>

95

94

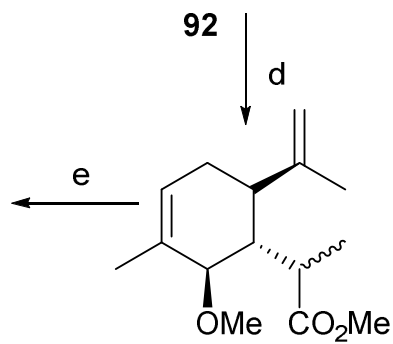

93<smiles>C=C(C)[C@H]1CC=C(C)[C@H](O[Ga])C1C(C)(C)/C=C\OC</smiles>

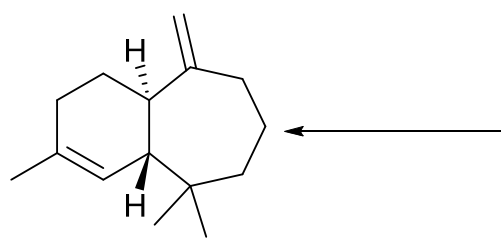

$38 \alpha$-trans-himachalene

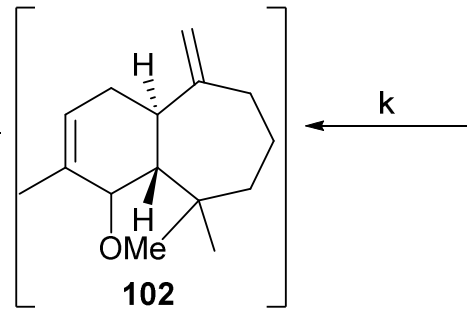

102

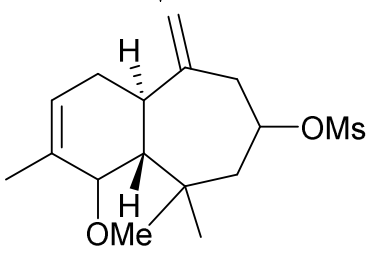

101

a) LDA/THF, $\mathrm{BrCH}_{2} \mathrm{CO}_{2} \mathrm{Me}, 75 \%$. b) $\mathrm{NaBH}_{4}, 79 \%$. c) $\mathrm{NaH}, \mathrm{Mel}, \mathrm{CH}_{2} \mathrm{~N}_{2}, 72 \%$. d) LDA, Mel, 82\%. e) LDA, Mel, 74\%. f) $\mathrm{LiAlH}_{4}, 86 \%$. g) PCC, NaOAc, 72\%. h) $\mathrm{Ph}_{3} \mathrm{P}=\mathrm{CHOMe}, 71 \%$. i) $3 \mathrm{~N} / \mathrm{HCl}, 66 \%$. j) MsCl, Pyridine, DMAP, $71 \%$. k) Li/ $/ \mathrm{NH}_{3}(\mathrm{l}), 57 \%$.

Scheme 10. Enantiospecific synthesis of (+)-trans- $\alpha$-himachalene.

Dufour et $a l^{52}$ have also reported the synthesis of $\alpha$-himachalene 9 starting from a commercially available mixture of ethyl chrysanthemate ester isomers 103 (Scheme 11). Reduction of 103 with $\mathrm{LiAlH}_{4}$ followed by catalytic TPAP (tetrapropylammonium Perruthenate) oxidation in presence of NMO (N-methylmorpholine-NOxide) gave aldehyde 104 (92\% two steps). Acid catalysed rearrangement with $p$-TsOH generated an aldehyde with the artemesyl carbon skeleton, ${ }^{53}$ which underwent Wittig reaction to give triene 105 ( $43 \% 2$ steps). 
<smiles>CCOC(=O)C1C(C=C(C)C)C1(C)C</smiles>
103

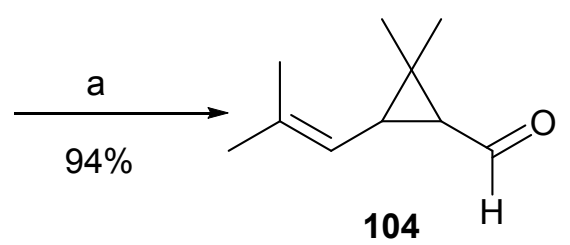

104

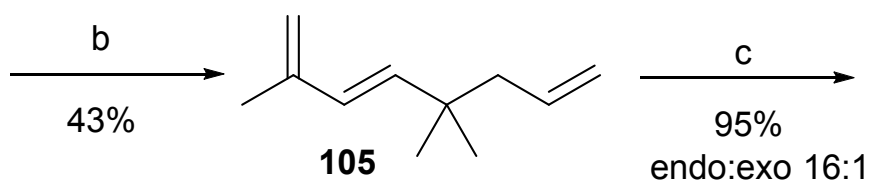<smiles>C=CCC(C)(C)C1C=C(C)CCC1C=O</smiles>

106-endo

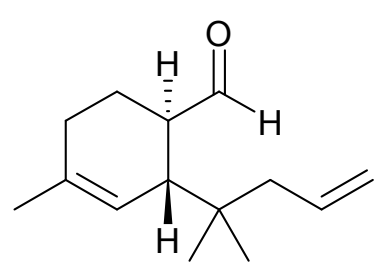

106-exo

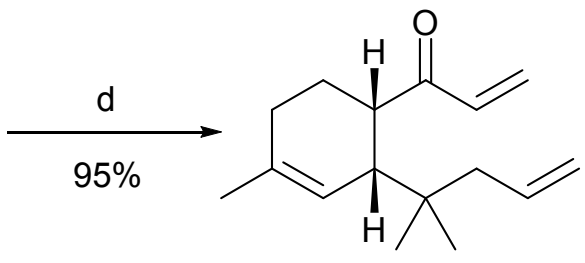

107

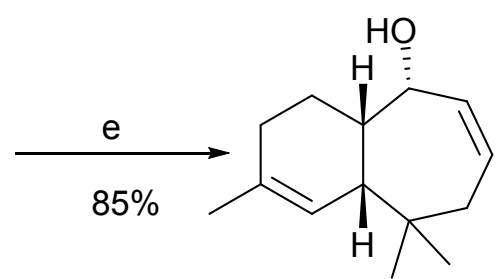

108

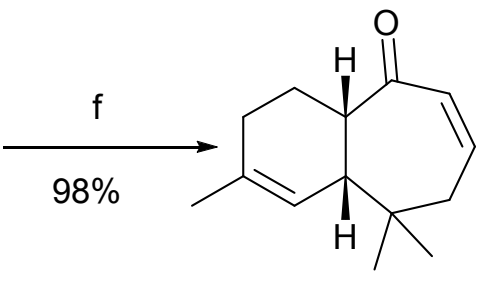

109

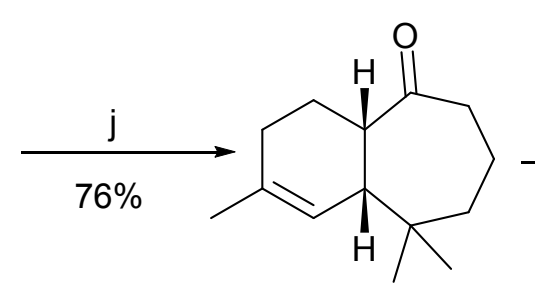

110

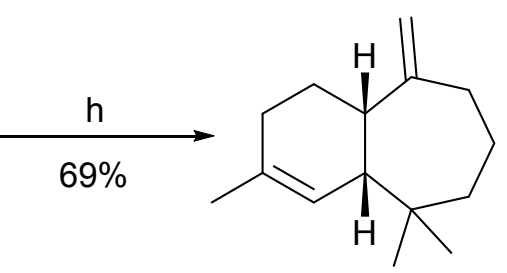

$9 \alpha$-cis-himachalene

a)1: $\mathrm{LiAlH}_{4}$, 2: TPAP, NMO; b) 1: $p$-TsOH, benzene, 2; $\mathrm{P}(\mathrm{Ph})_{3} \mathrm{CH}_{2}$; c) Acrolein, $20 \% \mathrm{ZnCl}_{2}, \mathrm{CH}_{2} \mathrm{Cl}_{2}$; d)

$\mathrm{CH}_{2} \mathrm{CHMgBr}$; e) Grubbs' first generation catalyst, benzene; f) TPAP, NMO; j) L-Selectride; h) Tebbe reagent.

Scheme 11. Synthesis of $\alpha$-himachalene from 103.

The Dielse Alder cyclization catalyzed by differents Lewis acids $\left(\mathrm{SnCl}_{4} \cdot 5 \mathrm{H}_{2} \mathrm{O}, \mathrm{ZnCl}_{2}\right.$ or $\left.\mathrm{ZnBr}_{2}\right)$, which all gave only one regioisomer and good diastereoselectivity. The best results were obtained with $\mathrm{ZnCl}_{2}$ as catalyst, which gave $95 \%$ yield and an endo/exo ratio of 16/1. Then, the endo isomer 106 was reacted with vinylmagnesium bromide followed by ring-closing metathesis using Grubbs' catalyst to give a bicyclic compound 108. The latter underwent an oxidation with TPAP and NMO followed by reduction of the double bond with L-Selectride to produce a compound $\mathbf{1 1 0}$ (Scheme 11). The last steps was methylenation with Tebbe reagent to obtain a disered product $\alpha$-himachalene 9 (in $12 \%$ overall).

\subsection{Synthesis of ar-himachalene}

Different approaches to synthesis the ar-himachalene were reported in the literature such as that by Kapoor and Mehta mentioned previously. ${ }^{37}$ The first total synthesis of ar-himachalene was reported by Dev's group in $1968 .^{54}$ It involved a synthesis in nine steps starting from $m$-methylacetophenone $\mathbf{1 1 1}$ according to scheme 12. Interaction of $m$-methylacetophenone with ethyl cyanoacetate furnished unsaturated ester 112, and then the addition of MeMgl to 112 gave a saturated cyano-ester 113. The latter was hydrolysed and decarboxylated to give 114 which was reduced to the corresponding alcohol 115. The chain extension by two carbon atoms was achieved with malonic ester to give 117, which readily underwent intramolecular acylation in polyphosphoric acid to obtain 5,5,7-trimethylbenzosubarone 118. Simple hydrogenation under $\mathrm{H}_{2}$ provided the required product 12. 


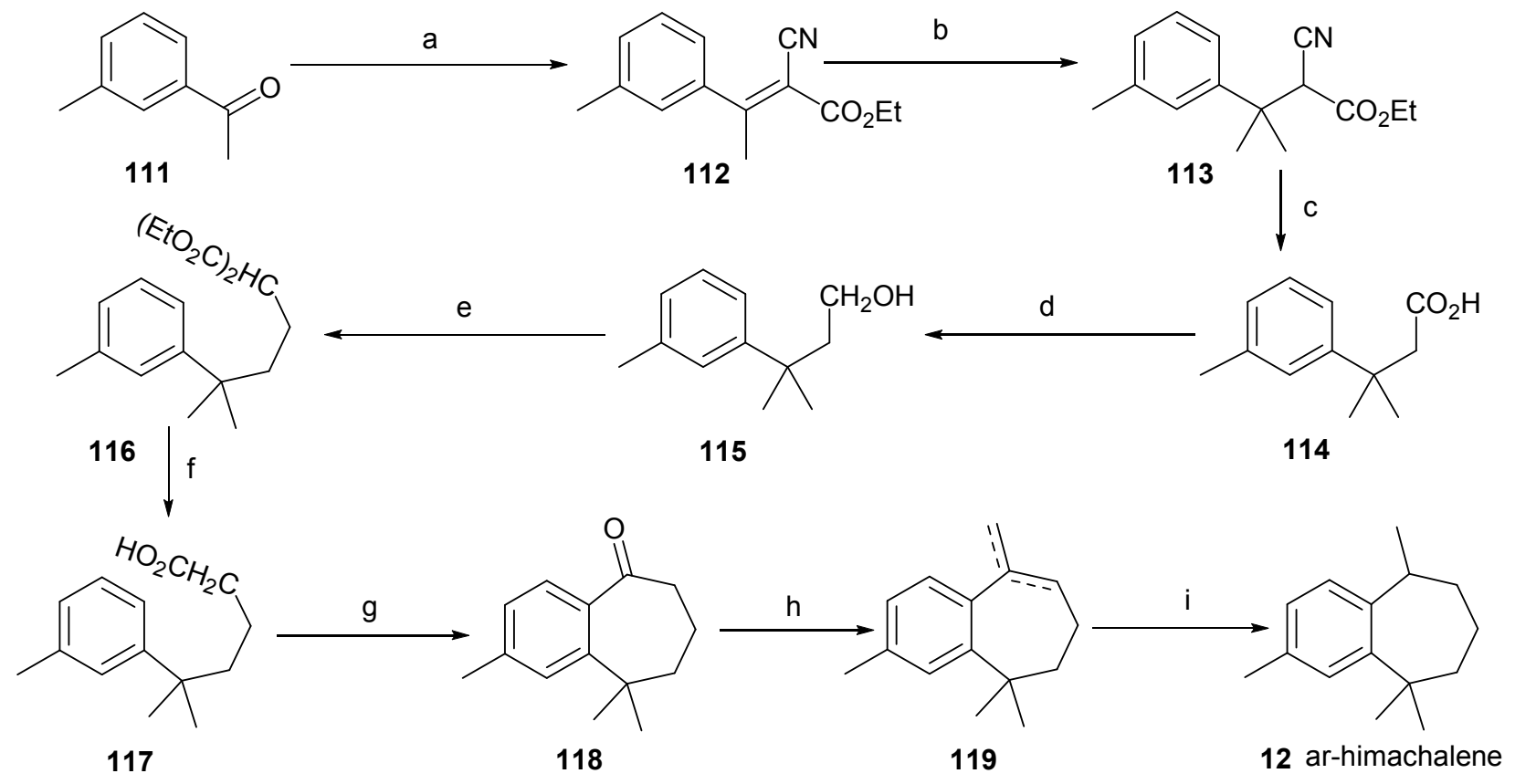

a) $\mathrm{CNCH}_{2} \mathrm{CO}_{2} \mathrm{Et}$. b) MeMgl. c) $\mathrm{MeOH}, / \mathrm{HCl}, 10 \% \mathrm{MeOH}-\mathrm{KOH}$. d) $\mathrm{MeOH}, \mathrm{H}_{2} \mathrm{SO}_{4}$, $\mathrm{LiAlH}_{4}$. e)1: TsCl, Pyridine, 2 : $\mathrm{CH}_{2}\left(\mathrm{CO}_{2} \mathrm{Et}\right)_{2}$, Na. f) $\mathrm{HCl}, \mathrm{AcOH}$. g) PPA. h) MeLi. i) $\mathrm{PtO}_{2}, \mathrm{AcOH}, \mathrm{H}_{2}$

Scheme 12. Synthesis of ar-himachalene from $m$-methylacetophenone 111.

A shorter and more efficient method was described by Sonawane et $a l^{55}$ (Scheme 13).

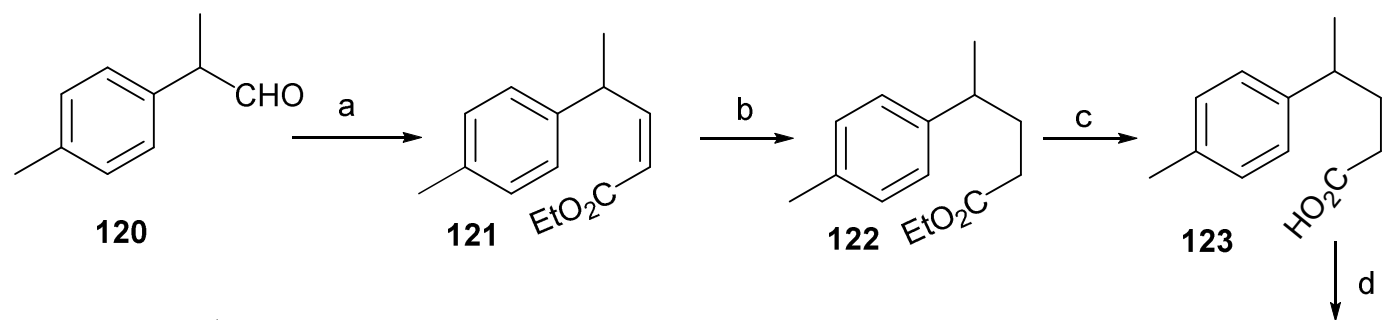<smiles>Cc1ccc([C@H](C)CC(=O)C=[W])cc1</smiles><smiles>Cc1ccc2c(c1)C(C)(C)CCCC2C</smiles>

a) $(\mathrm{Et})_{2} \mathrm{POCH}_{2} \mathrm{CO}_{2} \mathrm{Et}, \mathrm{NaH} /-5^{\circ} \mathrm{C}$. b) $\mathrm{H}_{2}$, Pd/C. c) $\mathrm{KOH} / \mathrm{MeOH}$. d) 1: $\mathrm{SOCl}_{2}$, 2: $\mathrm{CH}_{2} \mathrm{~N}_{2}$. e) $\mathrm{Rh}_{2}(\mathrm{OAC})_{2} / \mathrm{CH}_{2} \mathrm{Cl}_{2}$. f) $\mathrm{BF}{ }_{3} \mathrm{O}(\mathrm{Et})_{2} / \mathrm{CH}_{2} \mathrm{Cl}_{2}$. g) $\mathrm{t}-\mathrm{BuOK} / \mathrm{CH}_{3} \mathrm{I}, \mathrm{THF}$. h) $\mathrm{H}_{2} \mathrm{NNH}_{2} / \mathrm{MeONa}$

12 ar-himachalene

Scheme 13. Synthesis of ar-himachalene from the aldehyde $\mathbf{1 2 0 .}$

The key step of this method is based on the insertion of a carbenoid into an aromatic ring catalyzed by a rhodium complex. ${ }^{56,57}$ The resulting product undergoes an acid-catalyzed rearrangement to give the ketone 
125. The latter was demethylated and then reduced by a Wolff-Kishner reaction to achieve the arhimachalene 12 (Scheme 13).

A total synthesis performed by Momany et $a .^{58}$ provides a series of sesquiterpenes including arhimachalene. The route involved ten steps from cycloheptanone 128. Firstly, the latter was dimethylated with $\mathrm{Mel}$ and $t$-BuOK in $t$-BuOH under Ireland-Marshall conditions. ${ }^{59}$ Bromination of the resulting product 129 followed by $\mathrm{HBr}$ elimination using $\mathrm{LiBr}-\mathrm{Li}_{2} \mathrm{CO}_{3}$ in $\mathrm{DMF}$, provided enone 131. ${ }^{60}$ Interaction of the latter with $\mathrm{Me}_{2} \mathrm{CuLi}$ followed by Michael addition in the presence of silyl ketone 132 gave silyl diketone $133{ }^{61}$ The silyl group was removed by treatment with ethanolic $\mathrm{KOH}$ and the resulting compound 133 was cyclized to the bicyclic products 135 and 136 in a 97/3 ratio. The predominant compound 135 reacted with MeLi to give a mixture of two diastereoisomers 137 and 138 (19:81). Both alcohols were converted into the corresponding olefin products 139 and 140 by the action of Dowex 50W-X4. Finally, aromatization with chloranil provided the desired product 12 (Scheme 14).

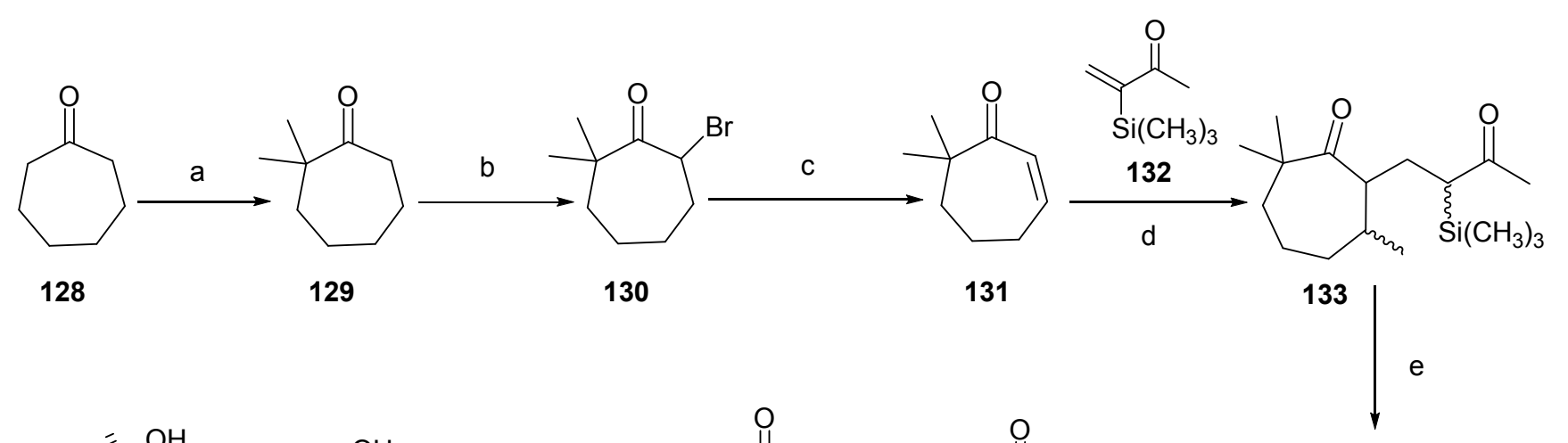

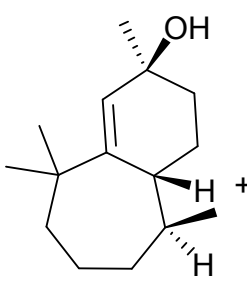

138

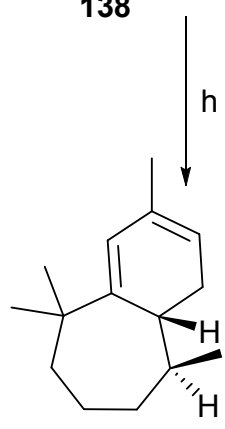

139

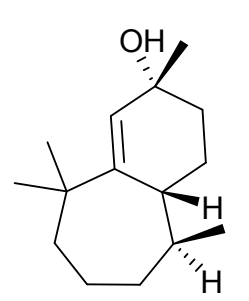

137

g

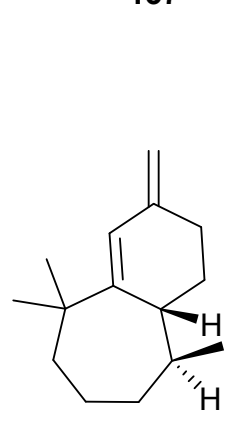

140

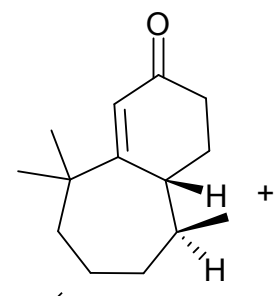

136

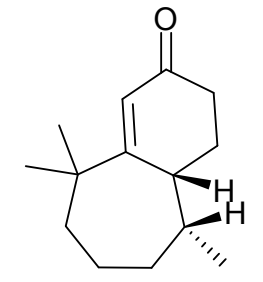

135

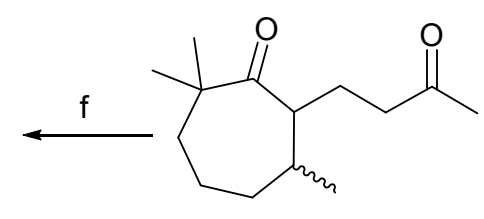

134

a) Mel, $t$-BuOK, $t-\mathrm{BuOH}$, r.t. b) $\mathrm{Br}_{2}$, $\mathrm{Et}_{2} \mathrm{O}$, r.t. c) $\mathrm{LiBr}, \mathrm{Li}_{2} \mathrm{CO}_{3}, \mathrm{DMF}, 130^{\circ} \mathrm{C}$. d) $\left.1: \mathrm{Me}_{2} \mathrm{CuLi}, \mathrm{Et}_{2} \mathrm{O} .2: 11, \mathrm{Et}_{2} \mathrm{O},-78^{\circ} \mathrm{C}, \mathrm{e}\right) \mathrm{KOH}(3.5 \mathrm{~N})$, $\mathrm{EtOH}$, r.t. f) $\mathrm{KOH}(3.5 \mathrm{~N}), \mathrm{EtOH}$, reflux. g) $\mathrm{MeLi}, \mathrm{Et}_{2} \mathrm{O},-78^{\circ} \mathrm{C}$. h) Dowex $50 \mathrm{~W}-\mathrm{X} 4, \mathrm{Et}_{2} \mathrm{O}$, r.t. i) chloranil, benzene, $75^{\circ} \mathrm{C}$. j) $\mathrm{Ph}_{3} \mathrm{P}=\mathrm{CH}_{2} \mathrm{Br}$, BuLi, THF, $0^{\circ} \mathrm{C}$.

Scheme 14. Synthesis of ar-himachalene from cycloheptanone 128.

Another method was reported by Mori et al. ${ }^{62}$ This provided an enantioselective synthesis of $(R)$ and $(S)$ ar-himachalene starting from $(S)$ - and $(R)$-citronellal 141 respectively. Treatment of $(S)$-citronellal (141) with pyridinium dichromate (PDC) provides $(S)$-citronellic acid (142). The latter was esterified and the resulting 
ester 143 was converted into the corresponding aldehyde 144 by ozonolysis. The mixture of $E$ and $Z$ diethyl ester 145 (87:13) was obtained from aldehyde 144 by Horner-Wadsworth-Emmons olefination. Catalytic hydrogenation of the double bond with Adams platinum oxide catalyst furnished diesters 146 . The $\beta$-oxo ester 147 was obtained by treatment of 146 with $t$-BuOK. ${ }^{63,64}$ Hydrolysis and decarboxylation by heating to reflux in the presence of sodium hydroxide in aqueous methanol furnished ketone (S)-148 which was methylated with potassium tert-butoxide and methyl iodide in tert-butyl alcohol to give trimethyl ketone (S)-149. The bicyclic ketone (1R,2S)-150 was obtained by Robinson annulation of (S)-151 with 3-(trimethylsilyl)-3-buten-2-one under Stork's conditions. ${ }^{65,66}$ Finally, a Wittig reaction followed by aromatization with chloranil T provided $(S)$ ar-himachalene 12. The same procedure was followed to prepare the other enantiomer $(R)$ starting from $(R)$ citronellal (Scheme 15).
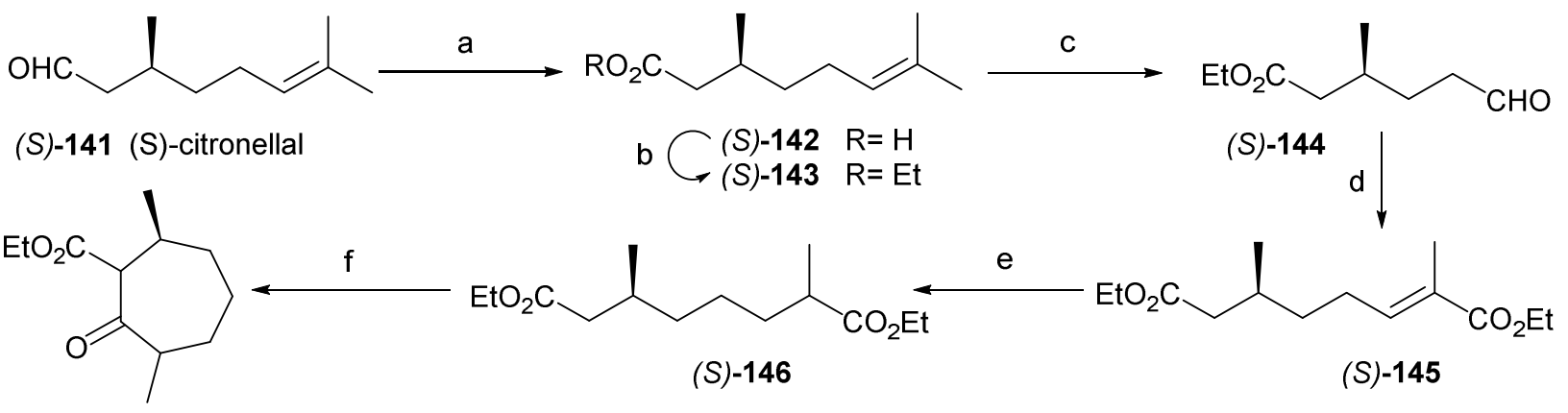

(S)-146

(S)-145

(2RS, 3S, 7RS)-147

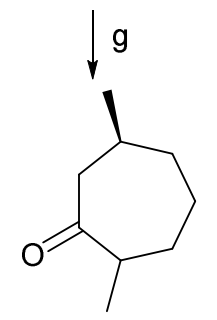

(S)-148

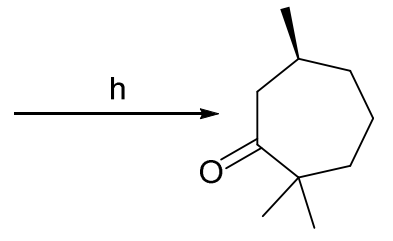

(S)-149

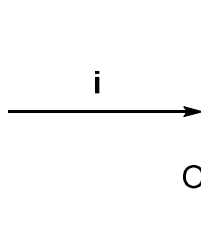

a) PDC, DMF, $0 \mathrm{C}$ to room temp.; b) $\mathrm{K}_{2} \mathrm{CO}_{3}$, Etl, DMF, $0 \mathrm{C}$ to room temp. $(74 \%, 2$ steps); c) $\mathrm{O}_{3}, \mathrm{MeOH}, 78 \mathrm{C}$; then $\mathrm{Me}_{2} \mathrm{~S}(72 \%)$; d) (EtO) ${ }_{2}-\mathrm{P}(\mathrm{O}) \mathrm{CHMeCO}_{2} \mathrm{Et}, \mathrm{NaH}, \mathrm{THF}$, $30 \mathrm{C}(96 \%)$; e) $\mathrm{H}_{2}, \mathrm{PtO}_{2}$, EtOAc, room temp. (quant.); f) 1) tBuOK, m-xylene, $150 \mathrm{C}$; 2) diluted $\mathrm{HCl}(79 \%)$; g) 1) $\mathrm{NaOH}, \mathrm{MeOH}, \mathrm{H}_{2} \mathrm{O}$, reflux; 2) diluted $\mathrm{HCl}(85 \%)$; h) tBuOK, $\mathrm{tBuOH}$, Mel, $0 \mathrm{C}$ to room temp. (88\% based on consumed 142); i) 1) LDA, TMSCI, THF, $78 \mathrm{C}$; 2) MeLi, $\mathrm{CH}_{2} \mathrm{C}(\mathrm{TMS}) \mathrm{COMe}$, THF; 3) $\mathrm{NaOMe}, \mathrm{MeOH}$, room temp. (44\% based on consumed 143), i)Wittig reaction; k) chloranil T

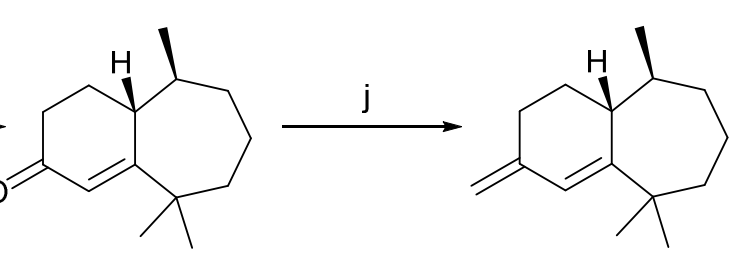

$(1 R, 2 S)-150$
(S)-151

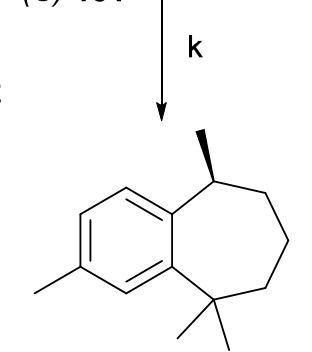

(S)-12 ar-himachalene

Scheme 15. Total synthesis of (S) ar-himachalene starting from (S)-citronellal.

One year later, Mori studied a synthesis of $(R)$-ar-turmerone and its conversion to $(R)$-ar-himachalene. ${ }^{67}$ The first step started from (4-methylphenyl)acetic acid (152). Acyl chloride 153 was obtained using thionyl chloride, followed by Evans asymmetric alkylation via (S)-4-benzyl-3-(4-methylphenylacetyl)-2-oxazolidinone (155) as the key step to introduce the stereogenic center. ${ }^{68}$ Methylation of 154 proceeded with methyl iodide and sodium hexamethyldisilazanide (NaHMDS), followed by reduction of the resulting compound with lithium aluminum hydride furnished alcohol (S)-156 (89\% ee). Activation with tosyl chloride, then chain-elongation via the carbonitrile followed by hydrolysis with hot aqueous potassium hydroxide, gave acid $(R)-160$. The next step was conversion of acid $(R)-\mathbf{1 6 0}$ to Weinreb amide ${ }^{69}(R)-\mathbf{1 6 1}$ with $N, O$-dimethylhydroxylamine 
hydrochloride, 1-ethyl-3-(3-N,N-dimethylaminopropyl)carbodiimide hydrochloride (EDC), (N,N-dimethylamino)pyridine (DMAP) and $N$-ethyldiisopropylamine. Treatment of the resulting amide 161 with the Grignard reagent 2-methylpropenylmagnesium bromide afforded (R)-ar-turmerone 162 (Scheme 16). Finaly, (R)-arturmerone was converted into ar-himachalene in two steps: intramolecular cyclization in the presence of $\mathrm{AlCl}_{3}$ and $\mathrm{CS}_{2}$, then the bicyclic ketone $(R)-163$ formed was reduced with $\mathrm{N}_{2} \mathrm{H}_{4} \cdot \mathrm{H}_{2} \mathrm{O}$ to give the final product $(R)$-arhimachalene (12). It should be noted that the authors observed a solvent effect on the specific rotation values of the product $(R)$-163. In fact, in hexane $[\alpha]_{D}^{23}=+3.8$ while in chloroform $[\alpha]_{D}^{23}=-2.4$. A different sign of specific rotation can be explained by the fact that $(R)$-ar-himachalene is dextrorotatory in hexane, while levorotatory in chloroform. Indeed, this unique chiroptical behavior was the origin of the initial misassignment of the stereochemistry of the naturally occurring $(R)$-163. A similar results of different signs of specific rotations in different solvents were observed by Mori et al. ${ }^{70}$ with $(1 S, 4 S, 5 S)$-cis-verbenol.
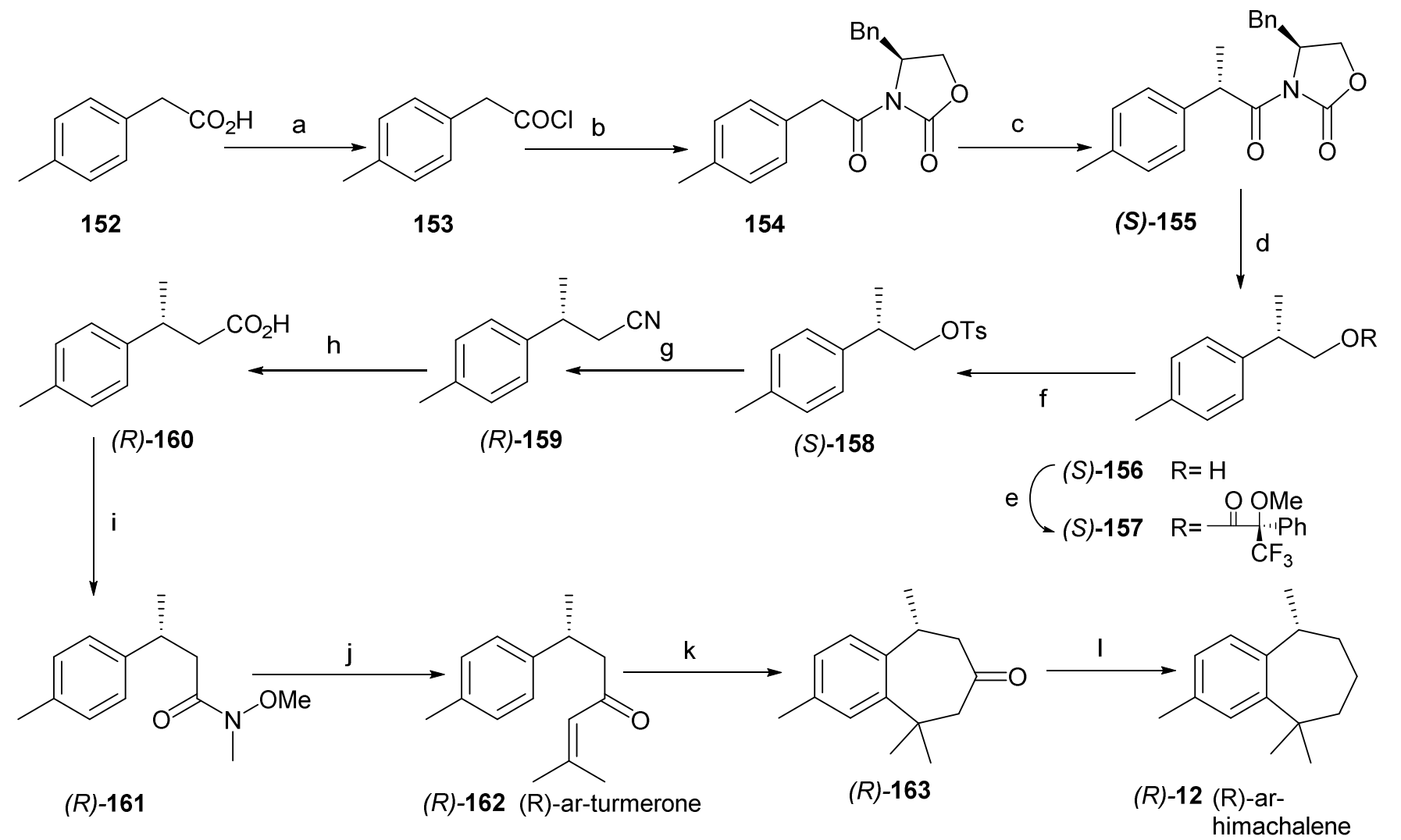

a) $\mathrm{SOCl}_{2}, \mathrm{C}_{6} \mathrm{H}_{6}$, reflux; b) (S)-4-benzyl-2-oxazolidinone, nBuLi, THF, $78{ }^{\circ} \mathrm{C}, 30 \mathrm{~min}$, then room temp, 79\%; c) NaHMDS, Mel, THF, $78 \mathrm{C}, 3 \mathrm{~h}$, then room temp, $97 \%$; d) $\mathrm{LiAlH}_{4}$, THF, $0{ }^{\circ} \mathrm{C}$ to room temp, $69 \%$; e) $\left.(R)-\mathrm{MTPACl}_{2} \mathrm{C}_{5} \mathrm{H}_{5} \mathrm{~N}, \mathrm{DMAP} ; \mathrm{f}\right) \mathrm{TsCl}, \mathrm{DMAP}, \mathrm{C}_{5} \mathrm{H}_{5} \mathrm{~N}, 0-$ $5{ }^{\circ} \mathrm{C}, 2 \mathrm{~h}, 95 \%$; g) NaCN, Nal, DMSO, $110{ }^{\circ} \mathrm{C}, 30 \mathrm{~min}, 78 \%$; h) $\mathrm{KOH}, \mathrm{HO}\left(\mathrm{CH}_{2}\right)_{2} \mathrm{OH}, \mathrm{H}_{2} \mathrm{O}, 100{ }^{\circ} \mathrm{C}, 3 \mathrm{~h}, 91 \%$; i) MeNHOMe. HCl, EDC, DMAP, (i-Pr) ${ }_{2} \mathrm{NEt}, \mathrm{CH}_{2} \mathrm{Cl}_{2}, 0^{\circ} \mathrm{C}, 4 \mathrm{~d}, 84 \%$; j) $\mathrm{Me}_{2} \mathrm{C}=\mathrm{CHMgBr}, \mathrm{THF}, 20{ }^{\circ} \mathrm{C}$ to room temp, $\left.2 \mathrm{~h}, 88 \% . \mathrm{k}\right) \mathrm{AlCl}_{3}, \mathrm{CS}_{2}, 40$ to $20{ }^{\circ} \mathrm{C}, 1 \mathrm{~h}$, then reflux $\left(46^{\circ} \mathrm{C}\right), 4 \mathrm{~h}, 40 \%$; I) $\mathrm{N}_{2} \mathrm{H}_{4} \cdot \mathrm{H}_{2} \mathrm{O}, \mathrm{KOH}$, diethylene glycol, $200-210^{\circ} \mathrm{C}, 3 \mathrm{~h}, 42 \%$.

Scheme 16. Synthesis of $(R)$-ar-turmerone and its conversion into $(R)$-ar-himachalene.

$\mathrm{Zi}$ et $a{ }^{71}{ }^{71}$ have reported a new strategy for synthesis of ar-turmerone and its conversion into (S)-arhimachalene and (+)-bisacumol 168. The key reaction of this synthesis is an enantioselective hydrogenation of $\alpha, \beta$-unsaturated nitriles catalyzed by a chiral phosphine-rhodium complex (Scheme 17). Hydrogenation of compound 164 under $\mathrm{H}_{2}$ using the Rh- $(R, R)$-spiroPhos complex provided a product $(S)$-165 with high yield and high enantioselectivity (99\%). Then 165 was hydrolyzed to the corresponding acid 166 followed by amidation with MeNHOMe. $\mathrm{HCl}$ to obtain amide 167. (S)-ar-turmerone 162 was obtained by treatment of compound 167 
with Grignard reagent $\mathrm{Me}_{2} \mathrm{C}=\mathrm{CHMgBr}$. The latter was converted into (+)-bisacumol 168 by hydrogenation of the carbonyl function, or ar-himachalene $\mathbf{1 2}$ by Friedel-Crafts cyclization.

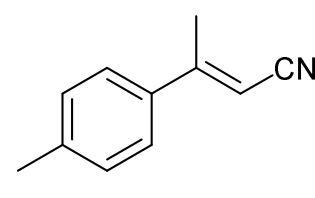

164

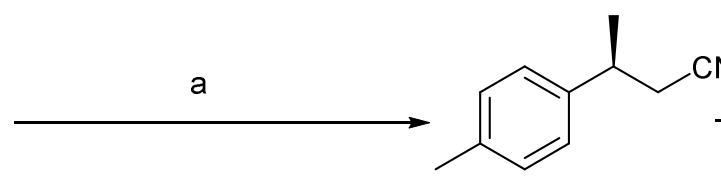

165
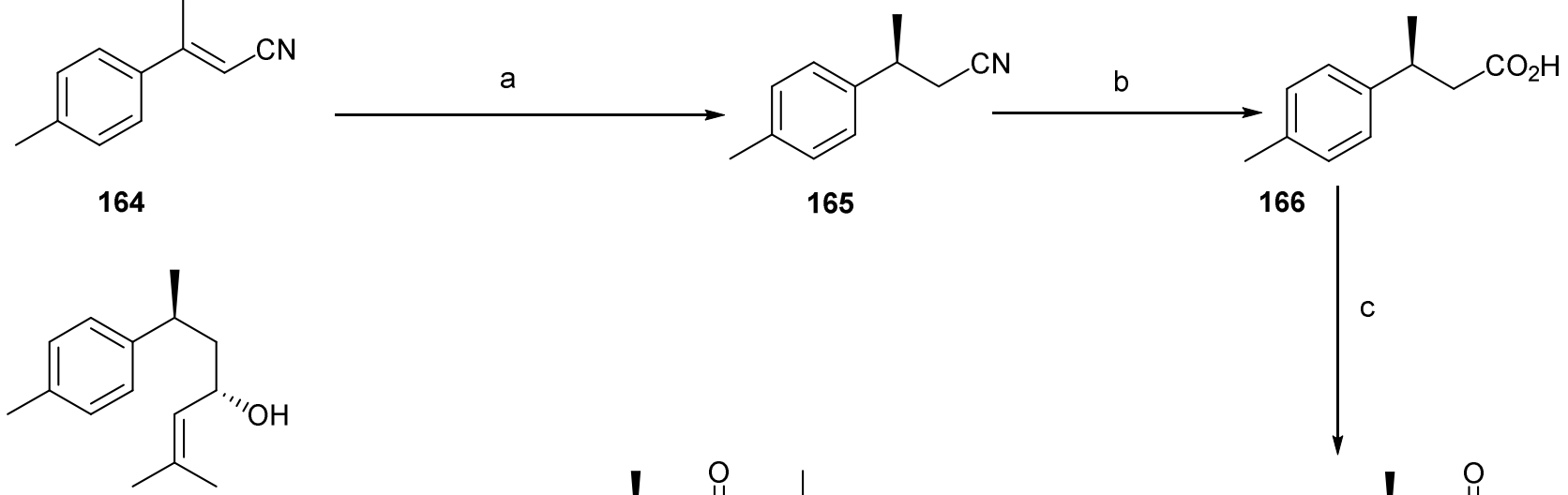

(+)-bisacumol 168

or

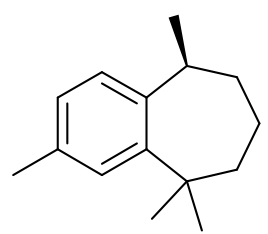

12

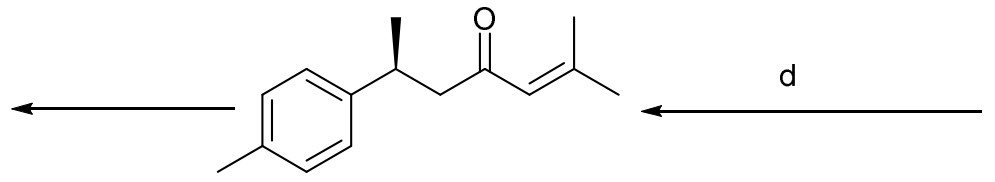

(S)-162 (S)-ar-turmerone
166

C

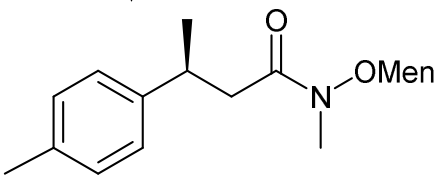

167

a) $\mathrm{H}_{2}$ (50 atm), 1 mol\% Rh-(R,R)-f-spiroPhos, $\mathrm{CH}_{2} \mathrm{Cl}_{2}$, rt, 40 min. b) $\mathrm{KOH}, \mathrm{HO}\left(\mathrm{CH}_{2}\right)_{2} \mathrm{OH}$. c) MeNHOMe, $\mathrm{HCl}$, EDC, DMAP, i- $\mathrm{Pr}_{2} \mathrm{NEt}, \mathrm{DCM}$. d) $\mathrm{Me}_{2} \mathrm{C}=\mathrm{CHMgBr}, \mathrm{THF},-20^{\circ} \mathrm{C}$, to rt, $24 \mathrm{~h}$.

Scheme 17. Synthesis of (S)-ar-turmerone and its conversion into (S)-ar-himachalene and (+)-bisacumol.

Recently, an enantioselective synthesis of both isomers of ar-himachalene was carried out by Chavan et al. ${ }^{72}$ starting from $\alpha$,4-dimethylstyrene. The key reactions include Sharpless asymmetric dihydroxylation to introduce the stereogenic center and ring expansion by hypervalent iodine reagent or trimethylsilyldiazomethane $\left(\mathrm{TMSCHN}_{2}\right)$ (Scheme 18). Indeed, Sharpless asymmetric dihydroxylation of the dimethylstyrene 169 using AD-mix- $\beta$, furnished diol (R)-170. The latter was converted into primary alcohol $(R)$ 171 by hydrogenolysis. This step was studied with various reagents under different condition to remove the tertiary hydroxyl group and to introduce the chirality at the benzylic position. The best result was obtained with $\mathrm{Pd} / \mathrm{C}$ in ethanol under pressure of $\mathrm{H}_{2}(60 \mathrm{psi})$ at room temperature. The iodo derivative $(R)-\mathbf{1 7 2}$ was obtained by treatment of the alcohol with iodine in the presence of $\mathrm{PPh}_{3}$ and imidazole. The latter was treated with diethyl malonate in presence of sodium hydride, with tetrabutylammonium iodide (TBAI) as a phase transfer catalyst, to obtain the diester (S)-173, which was decarboxylated to furnish acid (S)-174. Intramolecular acylation ${ }^{73}$ of (S)-174 using trifluoroacetic acid and trifluoroacetic anhydride gave (S)-175. Ketone (S)-126 with seven membered ring can be prepared by two routes: directly from (S)-175 with $\mathrm{TMSCHN}_{2}$ and $\mathrm{BF}_{3} \mathrm{OEt}_{2}$. However, this reaction gave a low yield. To improve the yield, the authors have chosen to obtain it in two steps: Wittig reaction of ketone (S)-175 followed by ring expansion of the six- to a seven-membered ring using Koser's reagent [hydroxy(tosyloxy)iodo]benzene (HTIB). ${ }^{74,75}$ Finally, dimethylation of (S)-126 with excess of methyl iodide and potassium $t$-butoxide furnished compound (S)-127 which after Wolff-Kishner reduction of the carbonyl group gave the (S)-ar-himachalene $12 .{ }^{76}$ 


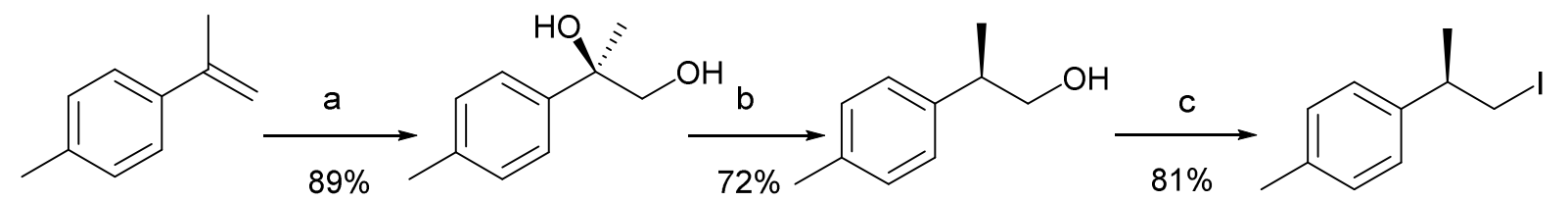

$169 \quad(R)-170(99 \%$ ee $) \quad(R)-171(97.5 \%$ ee $)$
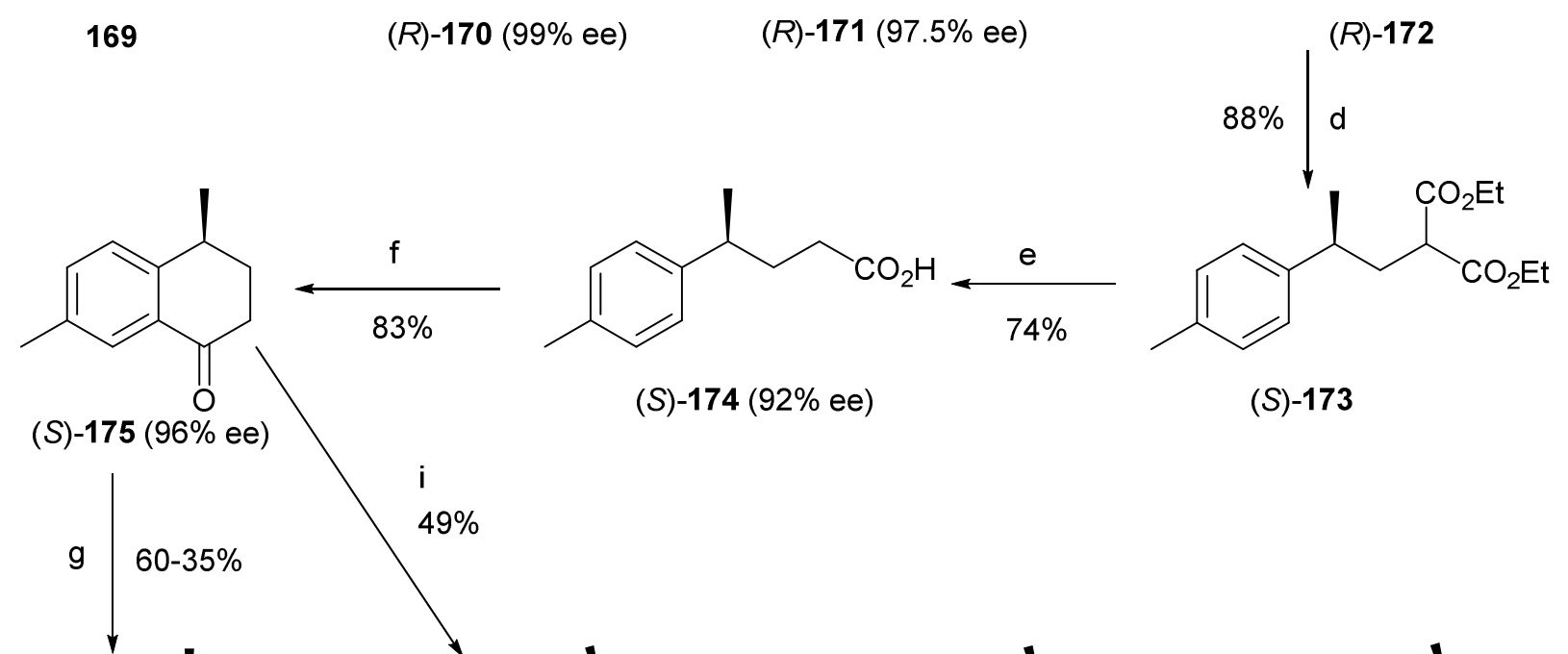

(S)-174 (92\% ee)

$(S)-173$

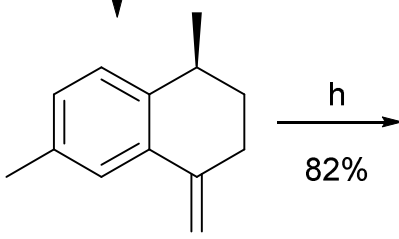

(S)-176 (96\% ee)

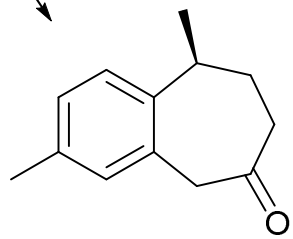

(S)-126 (93\% ee)

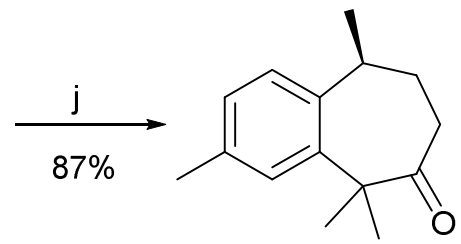

(S)-127 (93\% ee)

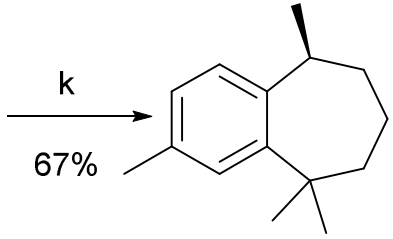

(S)-12 (S)-ar-himachalene(94\% ee)

a) AD-mix- $\beta$. b) $\mathrm{H}_{2}, \mathrm{Pd} / \mathrm{C}, \mathrm{EtOH}, 25^{\circ} \mathrm{C}$, 8h. c) $\mathrm{PPh}_{3}, \mathrm{I}_{2}, \mathrm{Im}, \mathrm{CHCl}_{3}, 0-25^{\circ} \mathrm{C}, 4 \mathrm{~h}$. d) $\mathrm{NaH}, \mathrm{CH}_{2}\left(\mathrm{CO}_{2} \mathrm{Et}\right)_{2}$, TBAl (10 mol\%), DMF, $120^{\circ} \mathrm{C}$, 10h. e) $1: \mathrm{KOH}, \mathrm{EtOH}-\mathrm{H}_{2} \mathrm{O}, 2: 140^{\circ} \mathrm{C}$, 4h. f) TFA-TFAA 0-25 $\mathrm{C}, 3 \mathrm{~h}$. g) $\mathrm{Ph}_{3} \mathrm{P}=\mathrm{CH}_{3}, \mathrm{BuLi}$, THF, 5h. h) $\mathrm{HTIB}, \mathrm{MeOH}$, $0-25^{\circ} \mathrm{C}, 45 \mathrm{~min}$. i) $\mathrm{TMSCHN}_{2}, \mathrm{BF}_{3} \mathrm{O}(\mathrm{Et})_{2}, 0^{\circ} \mathrm{C}, 45 \mathrm{~min}$. j) t-BuOK, Mel, THF, $\left.0-25^{\circ} \mathrm{C}, 4 \mathrm{~h} . \mathrm{k}\right) \mathrm{N}_{2} \mathrm{H}_{4}, 2 \mathrm{H}_{2} \mathrm{O}, \mathrm{NaOH}$, diethylene glycol, $180^{\circ} \mathrm{C}, 8 \mathrm{~h}$,

Scheme 18. Enantioselective synthesis of ar-himachalene starting from $\alpha, 4$-dimethylstyrene.

Campagne et al. $^{77}$ have reported a straightforward strategy for the syntheses $(R)$ ar-himachalene. Synthesis includes a catalytic and asymmetric vinylogous Mukaiyama reaction and a stereospecific hydrogenolysis of a tertiary benzylic center using $\mathrm{Pd} / \mathrm{C}$ or $\mathrm{Ni} /$ Raney catalysts (Scheme 19). The first step was the synthesis of the lactone starting from silyldienolate $\mathbf{1 7 8}$ and methylacetophenone $\mathbf{1 7 9}$.The reaction was carried out with a copper base catalyst associated with a various chiral ligands in the presence of $20 \%$ of TBAT (Tetrabutylammonium difluorotriphenylsilicate).The best results (93\% yield and $87 \%$ ee) were observed with (S)-(-)-MeOBIPHEP ((S)-(-)-(6,6'-Dimethoxybiphenyl-2,2'-diyl)bis(diphenylphosphine)] as a ligand.

The hydrogenolysis of unsaturated lactone 180 with $\mathrm{Pd} / \mathrm{C}$ or Ni/Raney under $1 \mathrm{~atm}$ of $\mathrm{H}_{2}$ in ethanol at room temperature gave a corresponding acide 181. Quantitative yield and good enantioselectivity (91 ee) were obtained with $\mathrm{Pd} / \mathrm{C}$ however, $\mathrm{Ni} /$ Raney gave low results (16\%, 42\% ee). It should be noted that ee of acid 181 was determined by chiral HPLC after derivatization into the corresponding methyl ester with sulfuric acid in methanol. Authors showed that $\mathrm{Ni} /$ Raney mediated hydrogenolysis of $\mathbf{1 8 0}$ has highlighted a strong dependence of the benzylic $\mathrm{OH}$ group protection on the stereochemical outcome (inversion vs retention of configuration) whereas $\mathrm{Pd} / \mathrm{C}$, under different conditions, afforded 'inversion' products. With enantiomerically enriched 181, the (R)-ar-himachalene can be obtained in two steps. First, in the presence of the Eaton's reagent $\left(\mathrm{P}_{2} \mathrm{O}_{5}\right.$ in $\left.\mathrm{MeSO}_{3} \mathrm{H}\right)$, the corresponding Friedel-Crafts seven-membered acylated product 13 was 
obtained in $86 \%$ yield. The ketone was transformed to the corresponding gem-dimethyl product using the $\mathrm{Me}_{2} \mathrm{TiCl}_{2}$ Reetz reagent ${ }^{78}$ to give $(R)$-ar-himachalene 12 in 62\%. This strategy yielded $(R)$-ar-himachalene in only four steps (35\% overall yield) from $p$-methylacetophenone 179 (Scheme 18).

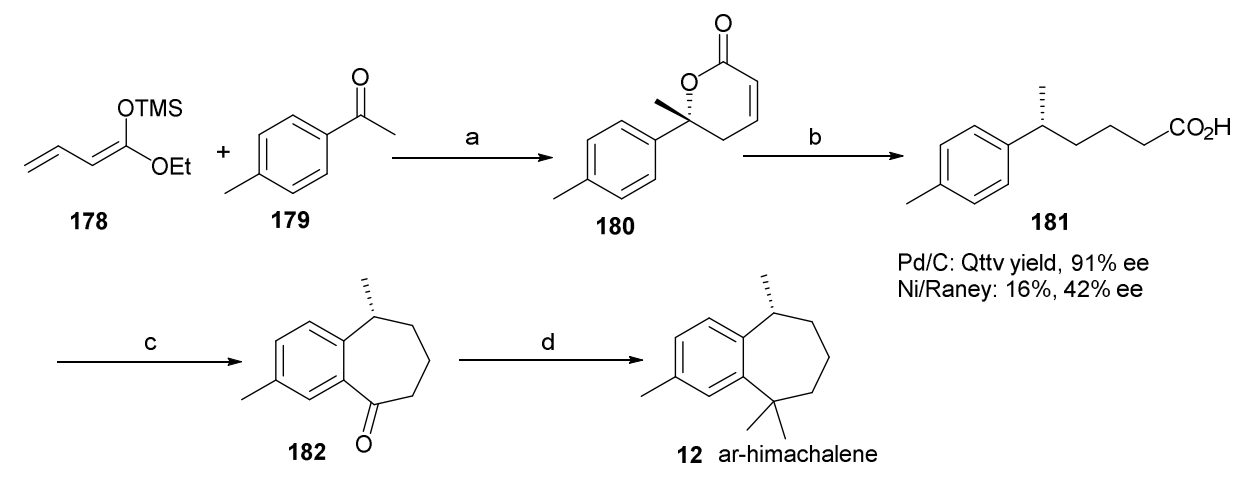

a) $\mathrm{Cu}(\mathrm{OTf})_{2} 10 \mathrm{~mol} \%$, L* $11 \mathrm{~mol} \%$, TBAT $20 \mathrm{~mol} \%$, THF, rt; b) Pd/C or Ni/Raney, $\mathrm{H}_{2}$ (1atm),

$\mathrm{EtOH}, \mathrm{rt} ; \mathrm{c}$ ) Eaton's reagent ( $86 \%$ ); d) $1 ; \mathrm{Me}_{2} \mathrm{TiCl}_{2}, \mathrm{DCM}-78^{\circ} \mathrm{C}$ to rt; 2 : m-CPBA, DCM, rt (62\%)

Scheme 19. Enantioselective synthesis of $a r$-himachalene starting from silyldienolate $\mathbf{1 7 8}$ and $p$ methylacetophenone 179.

Several studies have shown that ar-himachalene can also be obtained directly from $\alpha$-, $\beta$ - and $\gamma$-cis himachalene. The reaction can be performed either on the mixture of three himachalenes or each taken separately (Scheme 18). Various dehydrogenating agents were used: selenium, ${ }^{79,80}$ chloranil, $^{54}$ palladium, ${ }^{81}$ Raney nickel, ${ }^{82}$ bromine, ${ }^{83}$ DDQ (2,3-dichloro-5,6-dicyano-1,4-benzoquinone). ${ }^{84}$ The selectivity and yield of this transformation is dependent on the reagent employed and the operating conditions. ${ }^{85,86}$

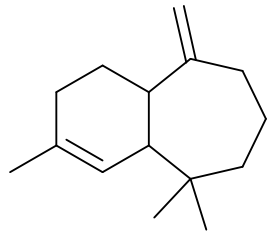

9 $\alpha$-himachalene

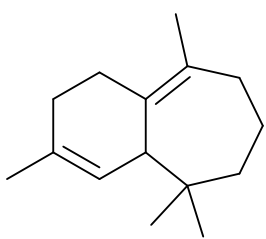

10

$\beta$-imachalene

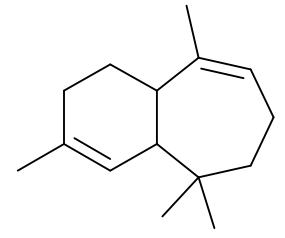

11

$\gamma$-imachalene

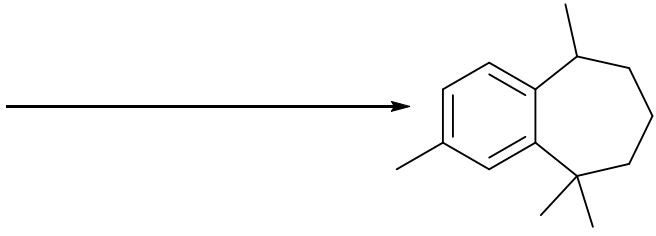

12 ar-imachalene

Scheme 20. Synthesis of ar-himachalene from $\alpha$-, $\beta$ - and $\gamma$-himachalenes.

\subsection{Synthesis of $\alpha$-atlantones}

Atlantones represent the major ketonic fraction of the essential oil of cedar. Very few studies have been concerned with their total synthesis. The synthesis of $\alpha$-atlantone 20 and dihydro- $\alpha$-atlantones 189 was performed from (+)-(4R)-limonene 182 (Scheme 21).$^{86}$ Indeed, the exocyclic double bond C8=C9 specifically reacted with diisobutyl aluminum hydride (DIBAL) to provide the diisobutyl $p$-menthenyl aluminum 183 . The latter provided, after oxidation, a mixture of two diastereoisomers $(4 R, 8 R)$ and $(4 R, 8 S) p$-menth-1-en-9-ol 184. The mixture is dehydrogenated by Raney nickel to give two diastereoisomers $(4 R, 8 R)$ and $(4 R, 8 S) p$-menth-1en-9-al 185, which transformed into cyanohydrins derivatives 186 using potassium cyanide and acetic acid. Dehydration of cyanohydrins with phosphorus oxychloride in hexamethylphosphoramide (HMPT) provided a mixture of cis- and trans-cyanolimonene 187a-b which were intermediates to obtain atlantones and dihydroatlantones 189. In addition, the action of allylmagnesium chloride on cyanolimonenes 187a-b in THF 
yielded the mixture of trans-isoatlantone $188 \mathrm{a}$ and cis-isoatlantone $188 \mathrm{~b}$, which were isomerized into $Z$ - and $E$ - $\alpha$-atlantone $\mathbf{2}$ and $\mathbf{2 0}$ under the action of $\mathrm{KOH} / \mathrm{MeOH}$. Treatment of these cyanolimonenes by isobutyllithium gave a mixture of trans- and cis-12,13-dihydroatlantone 189a and 189b (Scheme 21).

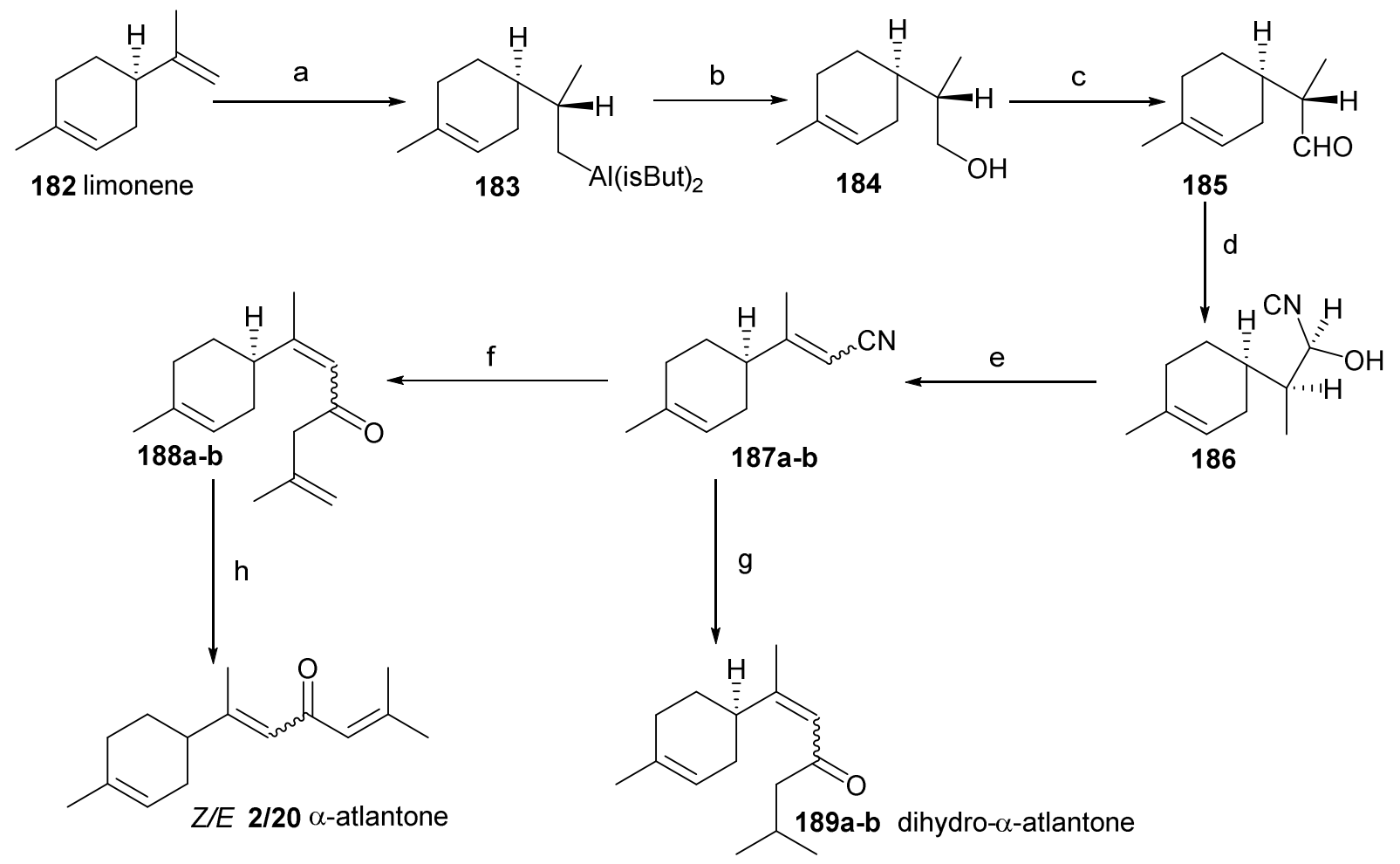

a) $\mathrm{HAl}\left(\right.$ isBut) 2 - b) 1: $\left[\mathrm{O}_{3}\right], 2: \mathrm{H}_{2} \mathrm{O}$. c) $\mathrm{Ni}$ (Raney). d) $\mathrm{HCN}$. e) $\left.\mathrm{POCl}_{3},\left[\mathrm{CH}_{3}\right)_{2} \mathrm{~N}_{3} \mathrm{P}\right]$. f) $\mathrm{MeAllylMgCl}, \mathrm{THF}$. g) 1: $\mathrm{LiCH}_{2} \mathrm{CH}(\mathrm{Me})_{2}, 2: \mathrm{H}_{2} \mathrm{O}$. h) $\mathrm{KOH} / \mathrm{MeOH}$

Scheme 21. Synthesis of $\alpha$-atlantone and dihydro- $\alpha$-atlantone from limonene.

Still from (+)-(4R)-limonene 182, Malanco et $a l^{87}$ have reported a short synthesis of $\alpha$-atlantone and $\alpha$ bisablolone 194. Epoxidation of limonene followed by monitoring their opening with protected cyanohydrins 191 gave hydroxy-lactone 192 (63\%). The latter was then reduced with excess of lithium aluminum hydride in refluxing THF to provide triol 193 (91\%). Oxidative cleavage by periodic acid furnished $\alpha$-bisablolone 194 (55\%) followed by dehydration with aqueous acetic acid (90\%) at $60-70{ }^{\circ} \mathrm{C}$ for $14 \mathrm{~h}$ to give trans- $\alpha$-atlantone 20 in $50 \%$ yield (Scheme 22 ). 


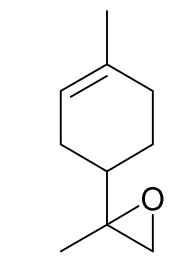

190

limonene epoxide

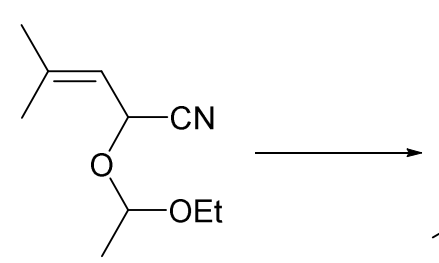

191<smiles>CC(C)=CC1(O)CC(C)(C2CC=C(C)CC2)OC1=O</smiles>

192<smiles>CC(C)=CC(O)(CO)CC(C)(O)C1CC=C(C)CC1</smiles>

193
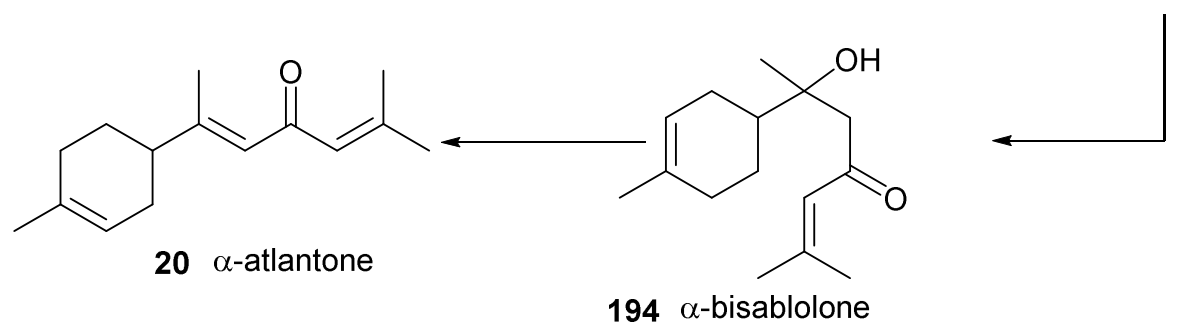

Scheme 22. Synthesis of $\alpha$-atlantone from limonene epoxide.

Delmond et $a .^{88,89}$ have also reported the synthesis of (Z)- and (E)- $\alpha$-atlantone starting from limonene. The key step of this method was to synthesize 10-(trimethylstannyl)limonene 195, which was prepared by metallation with $n$-butyllithium-tetramethylethylenediamine complex ${ }^{90,91}$ followed by trapping with trimethyltin chloride. Acylation of the stannane 195 with senecoyl chloride introduces the required additional isoprene unit and formed the sesquiterpene ketones 196 and 20 (Scheme 23).

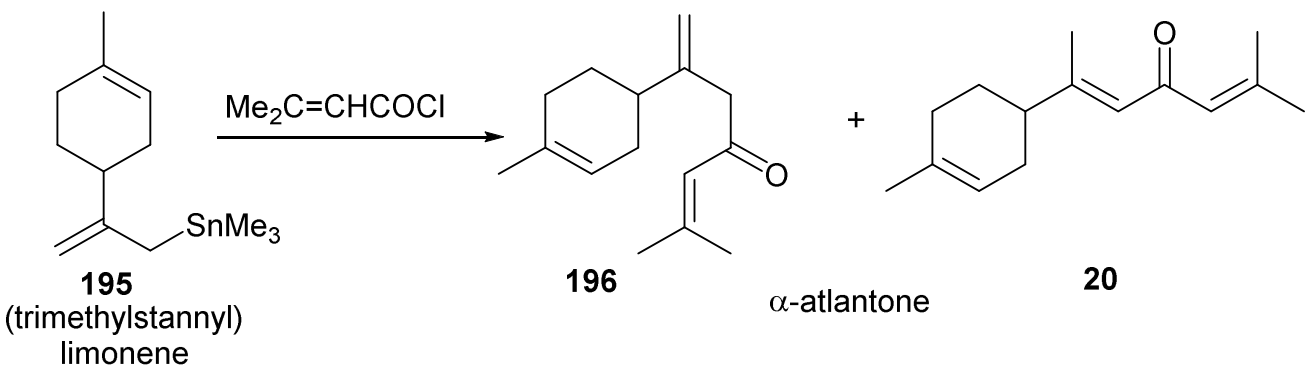

Scheme 23. Synthesis of (Z)- and (E)- $\alpha$-atlantone from (trimethylstannyl)limonene.

Another method, developed by Cookson and Parsons, ${ }^{92}$ involves a synthesis of allenyl sulfoxide made from propynyl alcohol 197 and benzenesulfenyl chloride. ${ }^{93}$ Metalation of allenyl sulfoxide 198 with $n$-BuLi, followed by alkylation with a variety of electrophiles, gave compound 200 (Scheme 24). The oxygen atom of the sulfoxide 199 was removed using $\mathrm{P}_{2} \mathrm{~S}_{5}$ and pyridine. The opening of isobutylene oxide by the lithiated allenyl sulfide 201 gave the alcohol (202; Ar = Ph). The new allenyl sulfide 202 underwent an intramolecular cyclization by action of $p$-toluenesulfonic acid (PTSA) in THF to give compound 203, which was converted into $(Z)$ - and $(E)$ - $\alpha$-atlantone ${ }^{94} 20(E / Z=10: 1)$ with other side products 204 and 205. 


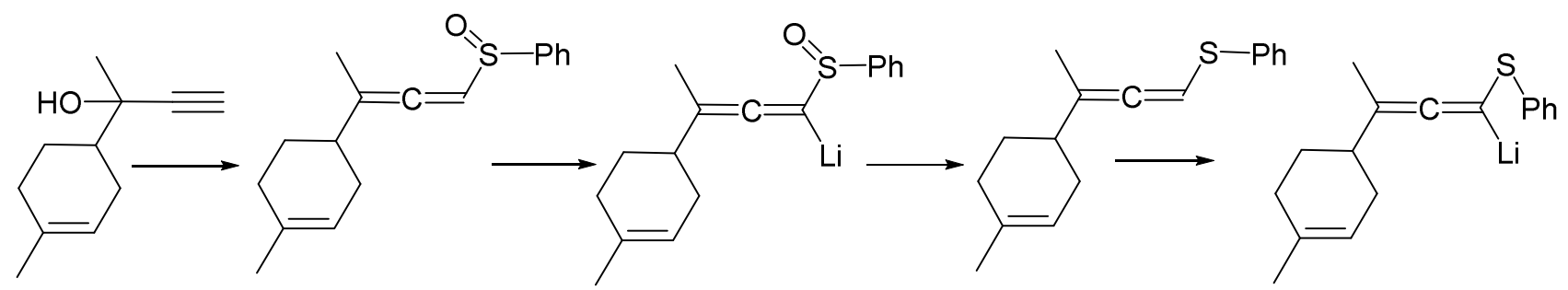

197 198

199

200

201<smiles>CC(C)=CC(C)=CC1CC=C(C)CC1</smiles>

205

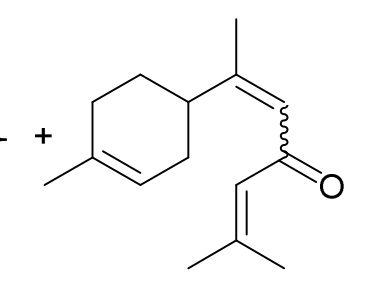

(E/Z) $\alpha$-atlantone
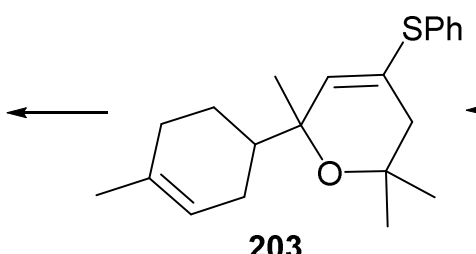

203

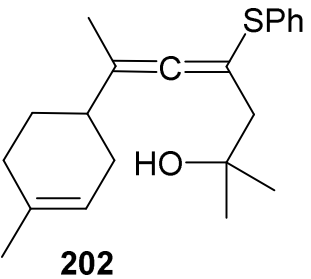

202

Scheme 24. Synthesis of $Z$ and $E \alpha$-atlantone from the acetylenic alcohol 197.

Torssell et al. ${ }^{95}$ have successfully used $\alpha, \beta$-unsaturated nitrile oxides as a precursor in the synthesis of deodarone 209 and atlantones. Nitrile oxide prepared from senecialdehyde oxime 206 reacted with (+)limonene 182 to furnish 207, which was methylated with $(\mathrm{MeO})_{2} \mathrm{SO}_{4}$ to give 208. Electrolytic reduction provided access to deodarone $\mathbf{2 0 9}$ as a mixture of two diasterroisomers (1:1). In acidic medium deodarone 209 undergoes an opening of the tetrahydro- $\gamma$-pyrone ring to give a mixture of two isomers $(Z)$ - and $(E)-\alpha$ atlantone (Scheme 25).
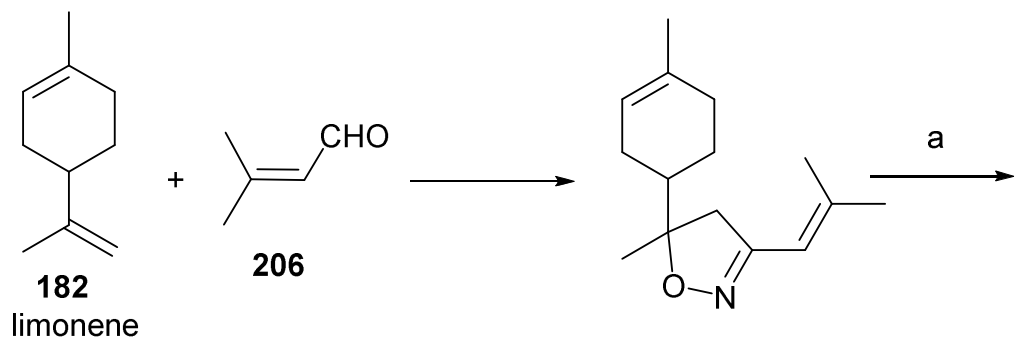

207

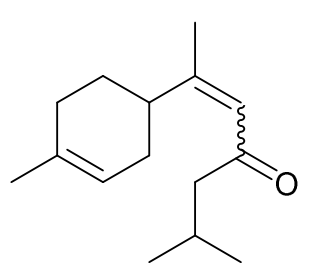

Z/E atlantone

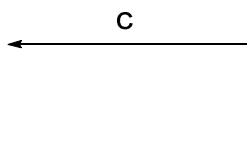

a) $(\mathrm{MeO}) \mathrm{SO}_{4}$

Scheme 25. Synthesis of deodarone and atlantones. 
Kakurai et al. $^{96}$ described a new brief synthesis of $( \pm)$ - $\alpha$-atlantone and $( \pm)$-ar-turmerone using dimethyl (2oxo-4-methyl-3-pentenyl)phosphonate $\mathbf{2 1 2}$ as a precursor. The phosphonate derivative $\mathbf{2 1 2}$ was prepared from 3,3-dimethylacrylic acid derivative $\mathbf{2 1 0}$ with (dimethylphosphono)methanide 211. Its carbanion was generated by sodium hydride in 1,2-dimethoxyethane (DME) or sodium ethoxide in ethanol and reacted with carbonyl compounds $\mathbf{2 1 3}$ or $\mathbf{2 1 4}$ to give $( \pm)$ - $\alpha$-atlantone or ( \pm )-ar-turmerone $\mathbf{1 6 2}$ according to the ketone used.

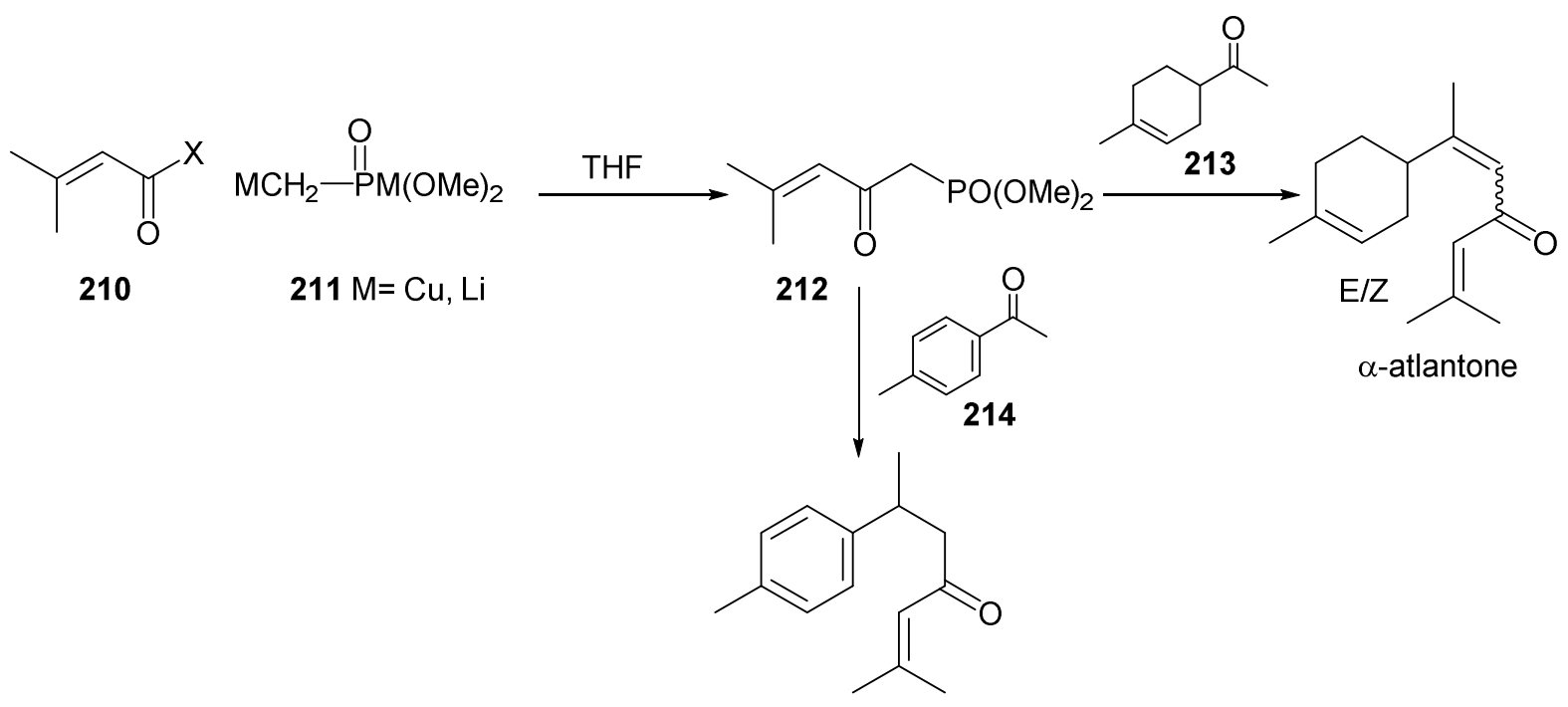

162 ar-turmerone

Scheme 26. Synthesis of $( \pm)$ - $\alpha$-atlantone and $( \pm)$-ar-turmerone.

The same intermediate dimethyl (2-oxo-4-methy1-3-pentenyl)phosphonate $\mathbf{2 1 2}$ was synthesized by Blouin and Friesen from a tertiary $\alpha$-allenic alcohol in four steps. This was used in the synthesis of $(Z)-$ and $(E)-\alpha$ atlantone by condensation with acetone in presence of $\mathrm{NaN}(\mathrm{TMS})_{2}$ in $\mathrm{THF}^{.}{ }^{97}$

Recently, a new strategy for synthesizing of ar-atlantone and $\alpha$-atlantone was developed by Nakajima et al. ${ }^{98}$ This method is based on a sequential $\mathrm{TiCl}_{4}$-promoted aldol reaction to simple ketones and base-promoted elimination to obtain $\beta, \beta$-substituted and $\alpha, \beta$-unsaturated carbonyl compounds. Treatement of 4-methylpent3-en-2-one with $\mathrm{TiCl}_{4}$ and $\mathrm{Bu}_{3} \mathrm{~N}$ at $-78{ }^{\circ} \mathrm{C}$, in presence of $p$-methylacetophenone 214 or 1-(4-methylcyclohex-3en-1-yl)ethan-1-one 213, the reaction gave ar-atlantone $\mathbf{1 6 2}$ or $\alpha$-atlantone according to the ketone used. Both products were obtained in $78 \%$ and $71 \%$ yield respectively as a mixture of two isomers $Z$ and $E$ with $90 \%$ for $E$.

\section{Chemical Modifications of Major Compounds of the Essential Oil of Cedar}

\subsection{Hydrochlorination of himachalenes}

Hydrochlorination is a well studied reaction of himachalenes since it provides a pathway to synthesize transhimachalenes. $^{39}$ In fact, treatment of the mixture of himachalenes with hydrochloric acid gave 3,7dichlorohimachalane 37; then its crystallization from methanol led to the formation of 3-chloro-7-methylene himachalane $\mathbf{2 1 5}$ by loss of an $\mathrm{HCl}$ molecule. The authors showed that the ring junction changes configuration during formation of the product $\mathbf{3 7}$, becoming trans (Scheme 27$).^{50,51}$ 


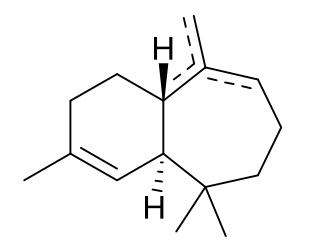

$\alpha-, \beta$ - and $\gamma$-himachalene

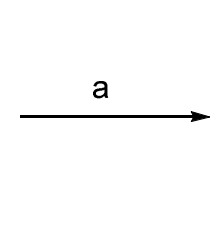

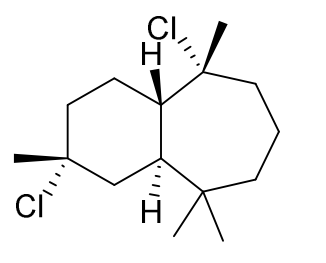

37 3,7-dichlorohimachalane

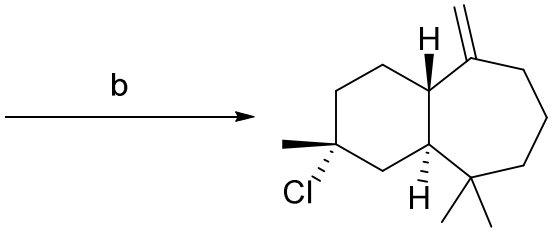

215

a) $\mathrm{HCl}$ (gas), $\mathrm{AcOH} 0^{\circ} \mathrm{C}$. b) Recrystallization from methanol

Scheme 27. Hydrochlorination and dehydrochlorination of himachalene.

\section{2 dehydrohalogenation}

Benharref et al..$^{51}$ carried out the dehydrohalogenation of 3,7-dichlorohimachalane 37 by various methods. Indeed, by refluxing in pyridine or by filtration through basic alumina, they have obtained five new isomeric hydrocarbons, 216, 217, 218, 219 and 38: their results showed that the ring junction in each case was trans. (Scheme 28).

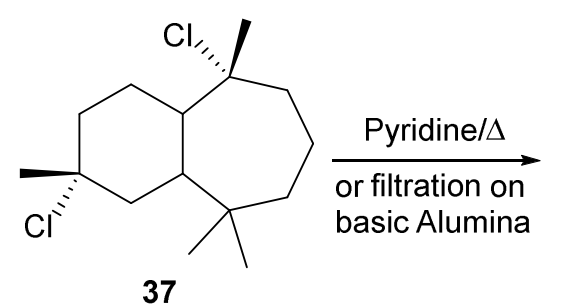

3,7-dichlorohimachalane

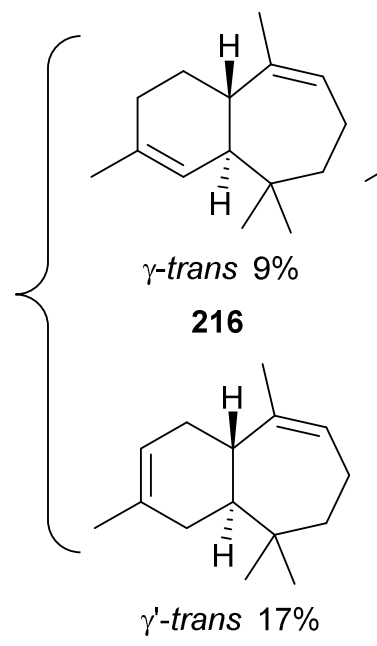

219

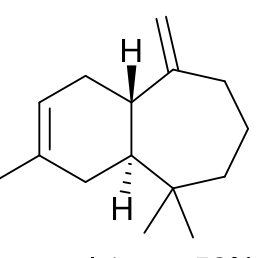

$\alpha^{\prime}$-trans $50 \%$

217<smiles>C=C1CCCC(C)(C)[C@H]2C=C(C)CC[C@@H]12</smiles>

$\alpha$-trans $14 \%$

38

Scheme 28. Dehydrochlorination of compound 37.

\subsection{Oxidation of himachalenes}

4.3.1 Oxidation with $\mathrm{KMnO}_{4}$. Oxidation of $\beta$-himachalene 10 was carried out by Benharref et al. ${ }^{99,100}$ using $\mathrm{KMnO}_{4}$. The authors showed that the tetrasubstituted double bond reacted easily with $\mathrm{KMnO}_{4}$. Indeed, treatment of $\beta$-himachalene with a stoichiometric quantity of $\mathrm{KMnO}_{4}$ quantitatively produced a diol, $\mathbf{2 2 0}$. However, with an excess of $\mathrm{KMnO}_{4}(3 \mathrm{eq})$ in a mixture of acetone/water (9/1) the product 221 was regioselectively formed in $30 \%$ yield (Scheme 29 ). 


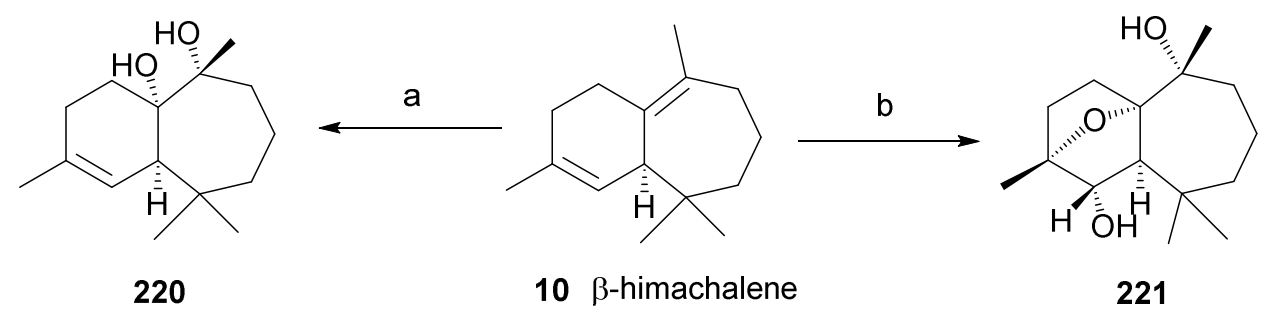

a) stoichiometric quantity of $\mathrm{KMnO}_{4},-10{ }^{\circ} \mathrm{C}$. b) excess of $\mathrm{KMnO}_{4}(3 \mathrm{eq}),-10^{\circ} \mathrm{C}$

Scheme 29. Oxidation of $\beta$-himachalene with $\mathrm{KMnO}_{4}$.

4.3.2 Epoxidation of himachalenes. Epoxidation of himachalenes is one of the most studied reactions since it provides new enantiomerically pure oxygenated compounds that could be used for perfumery or agrochemicals, or in pharmacology. The reactivity of two double bonds present in himachalenes with different systems has a particular interest. Thus, Dev et al. prepared the product $6 \alpha, 7 \alpha$-epoxyhimachalene 5 by action of $m$-chloroperbenzoic acid on $\beta$-himachalene (10) (Scheme 30). ${ }^{101}$ The same epoxide 5 was prepared chemoand stereo-selectively by Benharref et al. ${ }^{102,103}$ The stereochemistry of the $\alpha$-oxiran bridge in 6,7-position has been confirmed by X-ray diffraction carried out on the product $222 .{ }^{104,105}$ Both diepoxides 222 and 223 was obtained by treating the monoepoxide $\mathbf{5}$ with a stoichiometric amount of $m$-CPBA, as well starting from compound 10 using an excess of peracid ( $m$-CPBA).

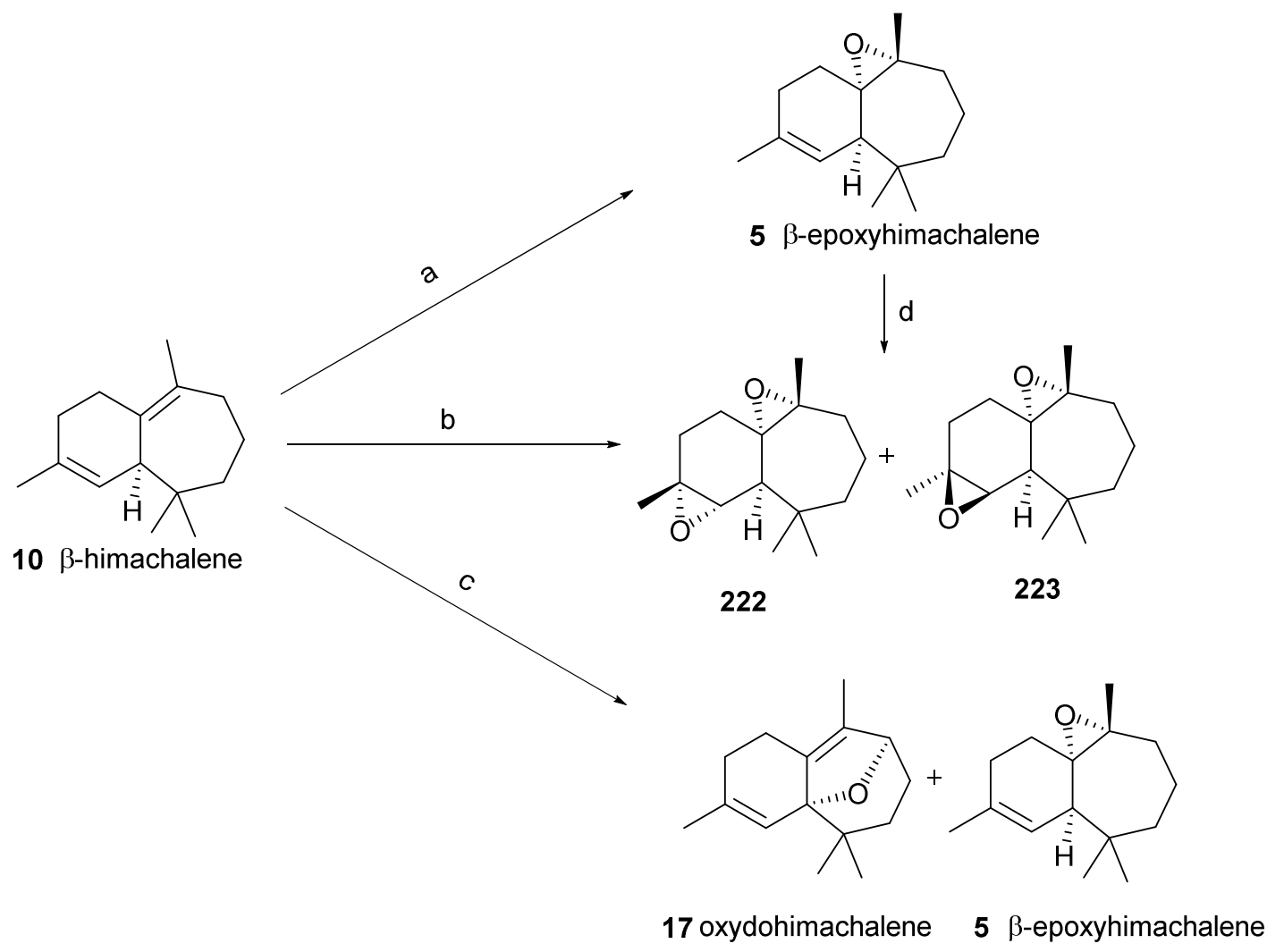

a) m-CPBA (1 eq). b) m-CPBA (2 eq). c) CuBr, t-butyl perbenzoate or $\mathrm{H}_{2} \mathrm{O}_{2}$, EtOAc or $\mathrm{CuO}_{2}, \mathrm{Cu}\left(\mathrm{NO}_{3}\right)_{2}$,

$\mathrm{H}_{2} \mathrm{O}_{2} \cdot$ d) m-CPBA (1 eq)

Scheme 30. Epoxidation of $\beta$-himachalene. 
Metal-ion-catalyzed epoxidation of olefinic substrates has been exploited with $\beta$-himachalene (Scheme 30). ${ }^{15,106}$ When $\beta$-himachalene isolated from Cedrus deodara was reacted with $t$-butyl perbenzoate in presence of cuprous bromide, the reaction led to the oxydohimachalene $\mathbf{1 7}$ in low yield.

However, heating $\beta$-himachalene with copper peroxide yielded besides unchanged $\beta$-himachalene $(70 \%)$, oxygenated product (30\%), which was shown by GC to contain $8 \%$ of oxydohimachalene 17 and $16 \%$ of the mono-epoxide 5. The same group showed that the action of $\mathrm{Ag}_{2} \mathrm{CO}_{3}$-celite led to $5 \%$ of oxygenated product containing $21 \%$ of $\mathbf{1 7}$ and $19 \%$ of $\mathbf{5}$. A similar conversion was obtained using $\mathrm{H}_{2} \mathrm{O}_{2}$ under UV light. When $\beta$ himachalene in EtOAc containing $\mathrm{H}_{2} \mathrm{O}_{2}(90 \%)$ was irradiated, $12 \%$ of oxygenated products were formed with $13 \%$ of oxydohimachalene $17 .^{15}$

Catalytic epoxidation using organometallic catalysis was also studied. Indeed, the same reaction was carried out with 1,2,4-triazepine complexes [RuCl(TAZO)(p-cymene)] $\mathbf{C} 1$ and [Ru(TAZS)( $p$-cymene) $]_{2} \quad \mathbf{C 2}$ prepared from $\left[\mathrm{RuCl}_{2}(p \text {-cymene })\right]_{2}$ in the presence of 2-methyl-5-oxo-7-phenyl-3-thioxo-3,4,5,6-tetrahydro$2 \mathrm{H}$-1,2,4-triazepine (HTAZO) and 2-methyl-7-phenyl-3,5-dithioxo-3,4,5,6-tetrahydro-2H-1,2,4-triazepine $\left(\mathrm{H}_{2}\right.$ TAZS) respectively. Good stereoselectivity was observed using complexes $\mathbf{C 1}$ which allowed isolation of the $6 \alpha, 7 \alpha$-epoxyhimachal-2-ene 5 with a chemoselectivity greater than $96 \%$ after $7 \mathrm{~h}$ of reaction. ${ }^{106}$

Analogously, the epoxidation of cis- $\alpha$-himachalene 9 led to mono- 224 or di-epoxides 225 and 226 according to the amount of peracid used (Scheme 29). The reaction also showed that the epoxidation of cis $\alpha$ himachalene was stereoselective since only the $\alpha$-side of the double bond $\mathrm{C} 2=\mathrm{C} 3$ was attacked. The stereochemistry of the oxirane bridge was established by X-ray crystallographic data of the major product 225. $^{107,108}$

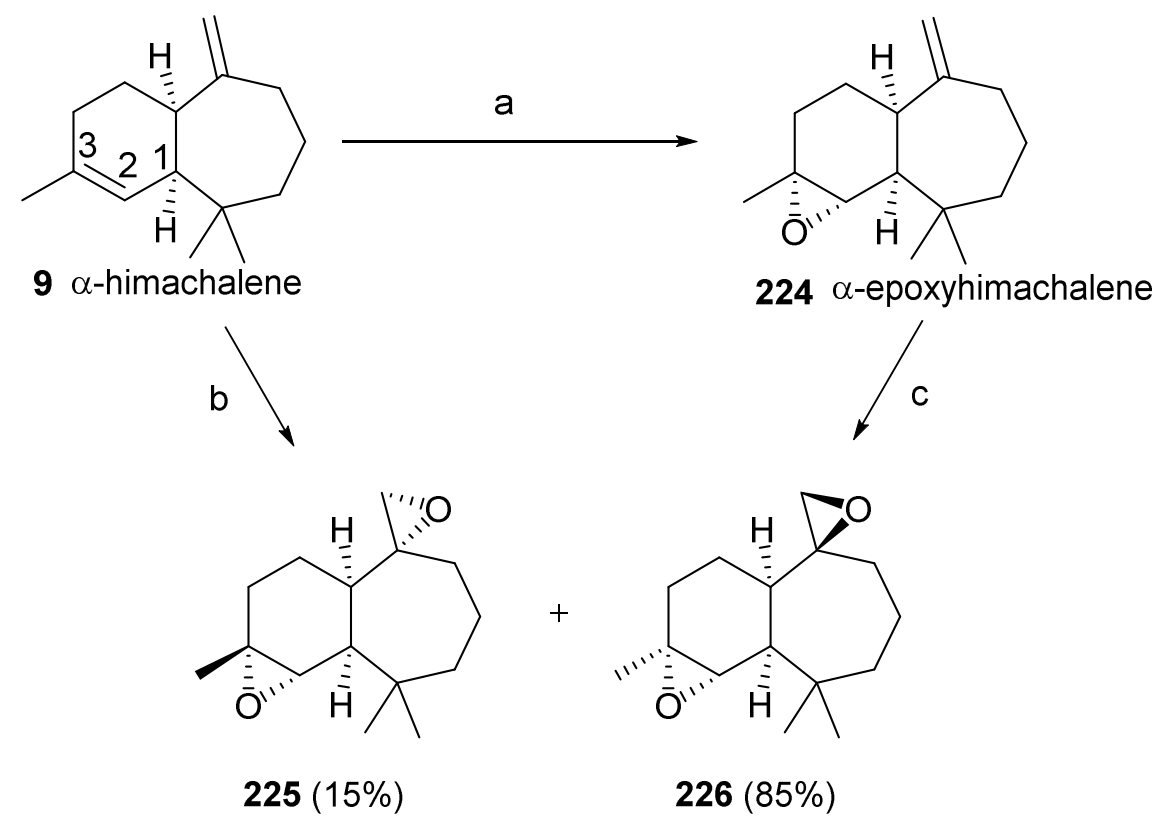

a) m-CPBA (1 eq). b) m-CPBA (2 eq). c) m-CPBA (1 eq)

Scheme 31. Epoxidation of $\alpha$-himachalene.

In contrast, oxidation of cis- $\gamma$-himachalene 11 provided two diepoxides 227 and 228 regardless of the amount of the peracid used (Scheme 32). This was explained by the equivalence of the two double bonds of the structure. ${ }^{108,109}$ 


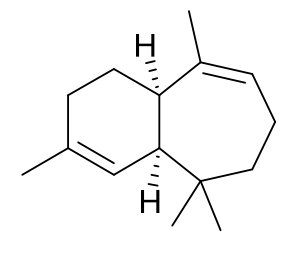

$11 \gamma$-himachalene

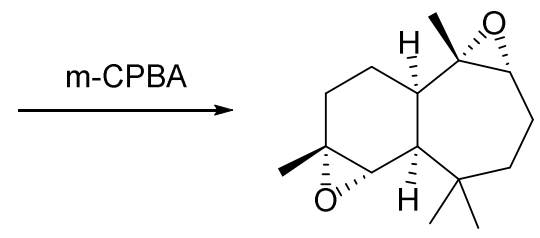

227

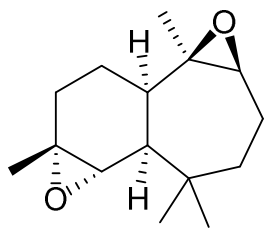

228

Scheme 32. Epoxidation of $\gamma$-himachalene.

Recent studies have shown that the epoxides $\mathbf{2 2 4}$ and $\mathbf{5}$ described previously can be obtained from a mixture of two isomeric $\alpha$ - and $\beta$-himachalenes. Indeed, the mixture of $\alpha$ - and $\beta$-himachalene on reaction with stochiometric amount of peracid gave two monoepoxides 224 and 5 in 28/72 ratio. ${ }^{110}$

A catalytic oxidation of the himachalene mixture was carried out at $80{ }^{\circ} \mathrm{C}$ using the complex $\left[\mathrm{MoO}_{2}(\mathrm{SAP})\right]_{2}$ shown in Scheme 31. Using a catalytic amount (1\%) of the catalyst in the presence of TBHP as the oxygen source, both products 224 and $\mathbf{5}$ could be obtained in $80 \%$ and $90 \%$ yields after 90 min in a ratio of 33/67. and the greener conditions of the solvent-free catalyzed method claimed to be a significant improvement. ${ }^{110}$

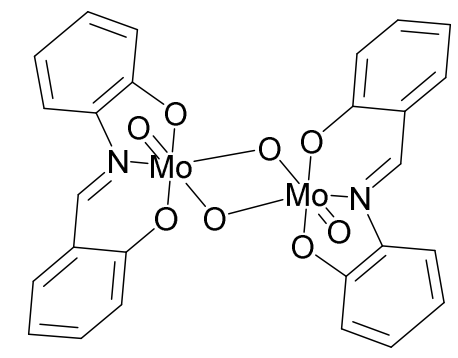

Scheme 33. $\left[\mathrm{MoO}_{2}(\mathrm{SAP})\right]_{2}$ complex.

Concerning the metal-catalyzed olefin epoxidation by TBHP, mostly realized with molybdenum- or vanadium-based catalysts. Poli et al. have proposed relevant mechanisms in organic solvents that involve the addition of TBHP to the catalyst in the activation phase. They have recently shown that the olefin epoxidation with the $\left[\mathrm{MoO}_{2}(\mathrm{SAP})\right]$ fragment as a catalyst and TBHP as an oxidant follows a mechanism relatively similar to that operating in the presence of peracids. On this basis, the slight difference in selectivity observed between $m$-CPBA and $\left[\mathrm{MoO}_{2}(\mathrm{SAP})\right] /$ TBHP system can be attributed to the slight differences in steric interaction between the oxygen atom delivering species and the substrate in the transition state. ${ }^{111}$

The reaction of the exocyclic double bond of 7-chlorohimachal-7,13-ene 215, which is obtained from $\alpha$-, $\beta$ and $\gamma$-himachalene by hydrochlorination, with one equivalent of $m$-chloroperbenzoic acid under the same conditions as above, provided two diastereoisomers 229 and 230 in 85/15 ratio (Scheme 34). ${ }^{110}$

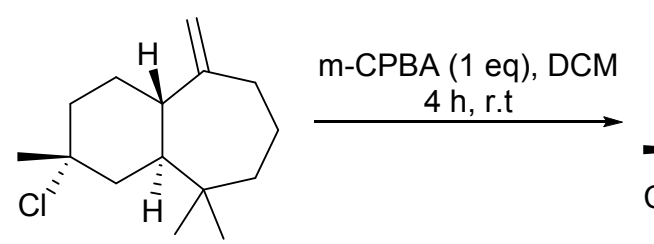

215 7-chlorohimachal-7,13-ene

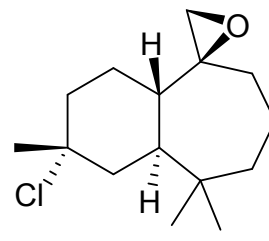

229

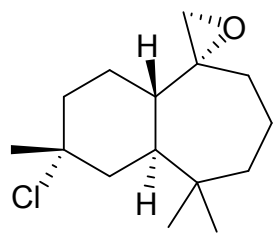

230

Scheme 34. Epoxidation of chlorohimachalene 215. 
Treatment of (1S,3R,8R)-2,2-dichloro-3,7,7,10-tetramethyltricyclo[6,4,0,0 $\left.0^{1,3}\right]$ dodec-9-ene 231 with a stoichiometric amount of $m$-CPBA gave two products 232 and $\mathbf{2 3 3}$ in a 70:30 ratio with $80 \%$ yield (Scheme 33). ${ }^{110}$ Epoxidation of $\mathbf{2 3 1}$ has been also monitored under the conditions previously described for the Mo-catalyzed epoxidation of 7-chlorohimachal-7,13-ene 215. The epoxides were isolated as a mixture of two diastereoisomers in 50:50 ratio with $80 \%$ conversion after 5 h. ${ }^{110}$<smiles>CC1=C[C@H]2C(C)(C)CC[C@H](C)[C@]2(C(Cl)Cl)CC1</smiles>

231
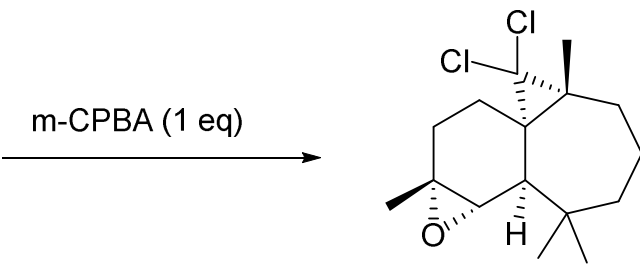

232

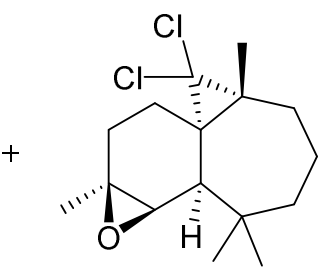

233

Scheme 35. Epoxidation of compound 231.

\subsection{Gem-dihalogenocyclopropanation of $\beta$-himachalene}

Several products containing a cyclopropane ring were prepared from $\beta$-himachalene. Treatment of $\beta$ himachalene 10 with a stoichiometric amount of dichlorocarbene, generated in situ from chloroform using $\mathrm{NaOH}$ as a base at $0{ }^{\circ} \mathrm{C}$ in the presence of tetrabutylammonium chloride (TBA-Cl) as a catalyst, gave the dihalogenated products $\mathbf{2 3 1}$ and 234. Similar products were obtained using bromoform (Scheme 36). ${ }^{112}$

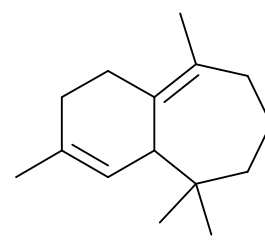

$10 \beta$-himachalene

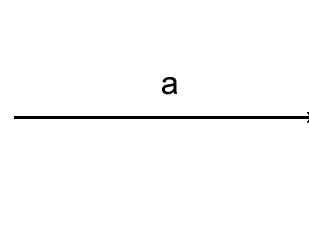

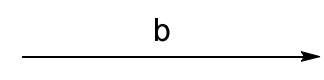

a) $\mathrm{CHX}_{3} / \mathrm{t}-\mathrm{BuOK} 1$ eq, TBA-Cl. b) $\mathrm{CHX}_{3} / \mathrm{t}-\mathrm{BuOK} 1$ eq, Cyclohexane
231

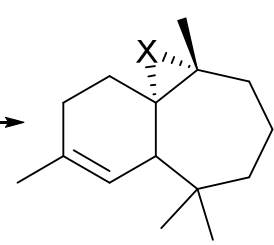

$231 \mathrm{X}=\mathrm{CCl}_{2}$ $234 \mathrm{X}=\mathrm{CBr}_{2}$

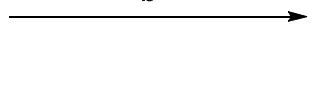

236

237

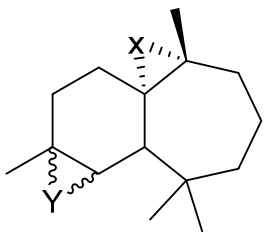

$$
\begin{array}{ll}
\mathrm{X}=\mathrm{CCl}_{2} & \mathrm{Y}=\mathrm{CCl}_{2} \\
\mathrm{X}=\mathrm{CCl}_{2} & \mathrm{Y}=\mathrm{CBr}_{2} \\
\mathrm{X}=\mathrm{CBr}_{2} & \mathrm{Y}=\mathrm{CCl}_{2}
\end{array}
$$

Scheme 36. Synthesis of di-and tetra-halo-cyclopropahimachalenes.

Ourhriss et al. ${ }^{113,114}$ founded that the tetrachloro-dicyclopropa-himachalenes 235 was obtained in $60 \%$ yield as two diastereoisomers in 85/15 ratio. However when they used an excess of bromoform, only the dibromated product 234 was obtained (Scheme 36). The mixed tetrahalogenated products were prepared by treatment of the dichlorocyclopropa-himachalene $\mathbf{2 3 1}$ with 1.5 equivalents of bromoform, or treatment of dibromocyclopropa-himachalene 234 under the same conditions with 1.5 equivalents of chloroform. ${ }^{115,116}$ In order to prepare other cyclopropahimachalene derivatives they reduced the product $\mathbf{2 3 1}$ with metallic sodium in a mixture of $\mathrm{MeOH} / \mathrm{H}_{2} \mathrm{O}$ which gave 237 with a cyclopropane motif. ${ }^{117}$ The gem-dihalocyclopropanation reaction of compound $\mathbf{2 3 8}$ was performed in the same condition described above and gave the products $\mathbf{2 3 9}$ and $\mathbf{2 4 0}$ with $\mathbf{4 0 \%}$ and $25 \%$ yield respectively as two diastereoisomers in each case (Scheme 37 ). 

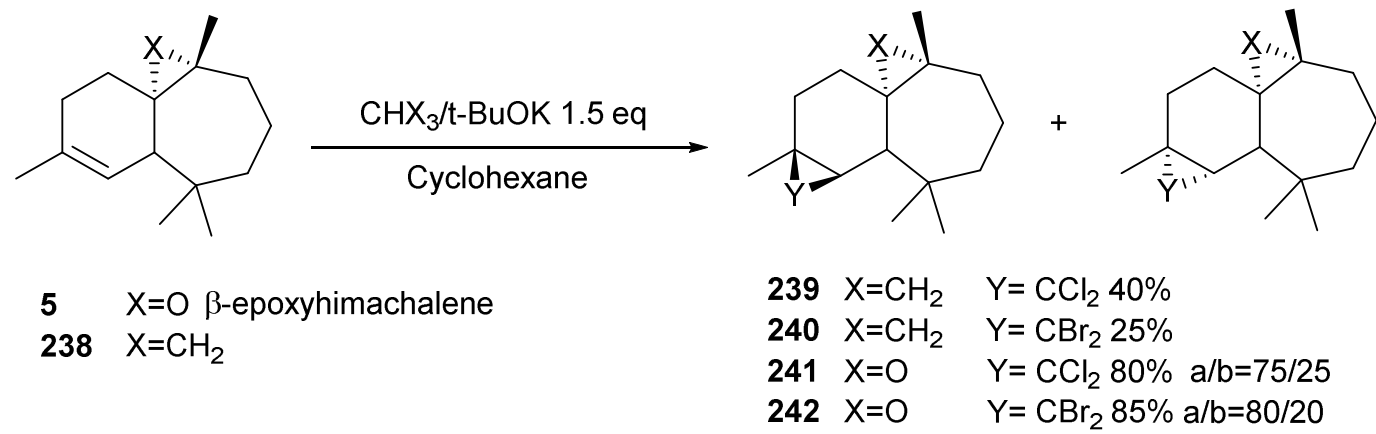

Scheme 37. Dihalogenocyclopropanation of 5 and 238.

$\beta$-Epoxyhimachalene was transformed into the corresponding epoxy-dihalocyclopropa-himachalene by treatment with 1.5 equivalents of chloroform (bromoform) in hexane in the presence of $t$-BuOK at $0{ }^{\circ} \mathrm{C} .{ }^{118-120}$ The reaction led to the tetracyclic products 241 and 242 in $80 \%$ and $85 \%$ yields respectively. The products were obtained in the form of two diastereoisomers in 75/25 and 80/20 ratios respectively (Scheme 35).

\subsection{Rearrangements of epoxy-himachalenes}

Epoxides constitute a class of compound with high interest. They are known as important synthons in organic synthesis. These have the advantage of generating a wide variety of functions including several different polyfunctional compounds. The ring-opening of $\beta$-diepoxy-himachalene 223 was performed by bubbling $\mathrm{HCl}$ gas for one minute in chloroform (Scheme 38). ${ }^{121}$ The formation of the tricyclic derivative 245 can be explained by double $S_{N} 2$ type reactions. After the protonation of epoxide at position 6-7, anti nucleophilic attack of $\mathrm{Cl}^{-}$at position $\mathrm{C} 3$ opened the 2,3-epoxide and then the oxygen at $\mathrm{C} 2$ in an intramolecular nucleophilic attack on the carbon $\mathrm{C} 7$ forms the bridging tetrahydrofuran ring.

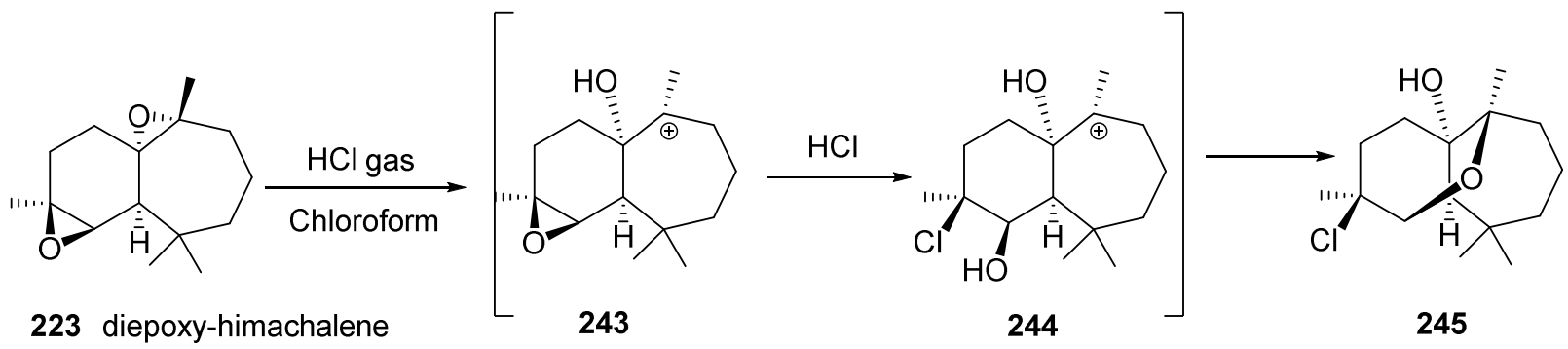

Scheme 38. Rearrangement of diepoxy-himachalene by $\mathrm{HCl}$ gas.

Rearrangement of $\alpha$-epoxyhimachalene 224 was studied by El Haib et al. ${ }^{122}$ The rearrangement of epoxide 224 in presence of a catalytic amount of Lewis acid in dichloromethane led mainly to the formation of two tricyclic products, ketone 246 and alcohol 247 (Scheme 39).

The ketone was the product formed predominantly, using $\left(\mathrm{BF}_{3} \mathrm{Et}_{2} \mathrm{O}, \mathrm{BF}_{3} \mathrm{MeOH}, \mathrm{InCl}_{3}, \mathrm{FeCl}_{3}\right)$ except in the case of $\mathrm{Bi}(\mathrm{OTf})_{3}$ since the alcohol was the main product produced. The comparisons of the various results obtained showed the effect of the Lewis acid on the kinetic and the selectivity of the reaction. With $\mathrm{BF}_{3} \mathrm{Et}_{2} \mathrm{O}$ and $\mathrm{BF}_{3} \mathrm{MeOH}$, a rapid and complete conversion of the epoxide was observed while the reaction time must be increased to 6 hours or $9 \mathrm{~h} 30 \mathrm{~min}$ to achieve complete conversion of substrate with $\mathrm{FeCl}_{3}$ and $\mathrm{InCl}_{3}$ respectively. Rearrangement of $\beta$-epoxyhimachalene 5 in the presence of $\mathrm{BF}_{3} \mathrm{Et}_{2} \mathrm{O}$ in dichloromethane, gave ketone 248 and ar-himachalene 12, the two products can be isolated in 62\% and 16\% yield respectively 
(Scheme 39). However, the compound 249 with cyclobutane motif could be isolated using $\mathrm{BF}_{3} \mathrm{MeOH}$ as catalyst. $^{123}$

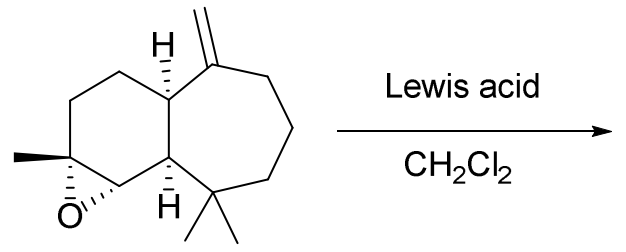

$224 \alpha$-epoxyhimachalene<smiles>CC1=C[C@@H]2[C@H](CC1)[C@@](C)(O)CCCC2(C)C</smiles>

5 -epoxyhimachalene

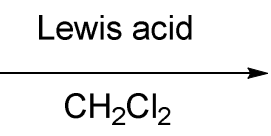

Bronsted acid

Solvent

$224 \alpha$-epoxyhimachalene<smiles>CC1=C[C@H]2C(C)(C)CCC[C@](C)(O)[C@@]2(C)CC1</smiles>

$5 \beta$-epoxyhimachalene

\section{Bronsted acid}

Solvent<smiles>CC1=C[C@H]2C(C)(C)CCC[C@]2(C)C(=O)CC1</smiles>

248

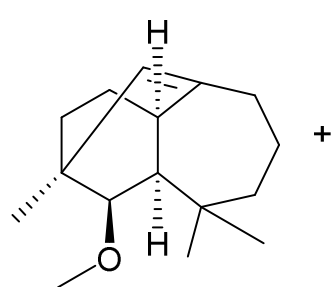

250

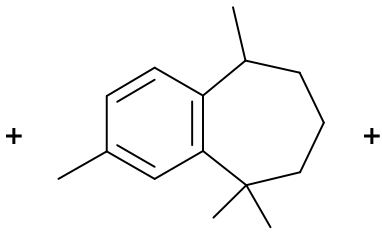

12

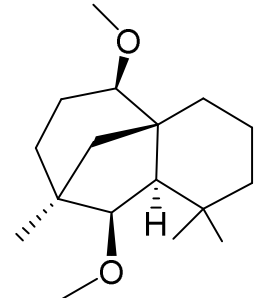

251

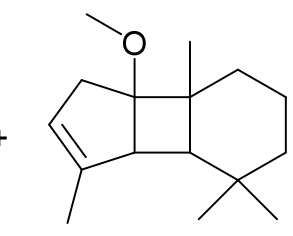

252

Scheme 40. Rearrangement of epoxy-himachalene by Brønsted acid.

Several experiments were conducted using different solvents and temperatures. The results showed that the total conversion of epoxide requires larger amount of Brønsted acids (1\%) and longer reaction times. Unidentifiable by-products in small quantities were observed by gas chromatography as with Lewis acids. The 
chemoselectivity of the reaction depends on the solvent, temperature, and catalyst used. In methanol, MSA and PTSA catalysts promoted the rearrangement of $\alpha$-epoxyhimachalene 224 into alcohol 247 and methoxy derivative $\mathbf{2 5 0}$ as a new product. However, in the case of epoxyhimachalene 5, a compound $\mathbf{2 5 2}$ was isolated besides the ketone $\mathbf{2 4 8}$ and ar-himachalene 12. In addition, the selectivity in favor of alcohol 247 at room temperature was switched and in favor of methoxy compound 250 by heating at $60^{\circ} \mathrm{C}$. With PTSA, compound 250 could be obtained in 63\% yield. However, using MSA, the epoxide rearrangement afforded a mixture of three products, 247, 250 and $\mathbf{2 5 1}$ in 35\%, 44\%, and 10\% respectively.

\subsection{Amination of himachalenes}

Benzocycloheptene and their derivatives are a biologically potent class of bicyclic frameworks and are attractive synthetic targets for organic and medicinal chemistry. A new series of benzocycloheptene amino vinyl bromide derivatives were synthesized from the mixture of $\alpha, \beta$ and $\gamma$-himachalenes through two steps: The mixture of three isomers $\alpha, \beta$ and $\gamma$-himachalenes was treated with DDQ in dry benzene under nitrogen at reflux. In these conditions, the reaction gave $\alpha$-dehydro-ar-himachalene $\mathbf{2 5 3}$ as major product (Scheme 41). Optimization of the bromination of $\alpha$-dehydro-ar-himachalene 253 with $\mathrm{Br}_{2} / \mathrm{DCM}, \mathrm{Br}_{2} / \mathrm{AcOH}$ and NBS all led to the formation of mixture of dibrominated products. Finally, bromination using $\mathrm{KBr}(4$ equiv) and ceric ammonium nitrate (CAN, 3 equiv) in $\mathrm{DCM} / \mathrm{H}_{2} \mathrm{O}(1: 1, \mathrm{v} / \mathrm{v})$ for $5 \mathrm{~h}$ at room temperature provided a compound 254 as a major product, which was founded to be unstable during its purification by column chromatography.

Mechanistically, the alkene reacted with bromide radicals to form a dibromo intermediate 254 which rearranged to product 255. The intermediate $\mathbf{2 5 5}$ was further treated with 1.5 equiv of amine in the presence of 2 equiv of $\mathrm{K}_{2} \mathrm{CO}_{3}$ in DMF at $90{ }^{\circ} \mathrm{C}$ for $15 \mathrm{~h}$ to produce benzocycloheptenamino derivative 256 as major product. This reaction was investigated using different aromatic and aliphatic amines. Several secondary amines such as morpholine, piperidine, piperazine, pyrrolidine, and diethylamine were used giving satisfactory yields ranging from $62 \%$ to $76 \%$. Different primary amines such as cyclohexyl-, benzyl-, iso-butyl-, $t$-butylamine, and phenylethyl-amines were also tested in the same reaction. Good yields were founded, ranging from 50 to $72 \%$ according to the amine used. The structures of the various products were confirmed by NMR and X-ray crystallographic analyses. The new products were further evaluated for their antidepressant activities and it was observed that the piperazine substituted derivative showed good activity. Thus, the piperazine derivative was considered as a lead entity selected for further modifications to obtain more efficacious and potent antidepressant drugs. ${ }^{124}$

Recently, five new 2,9,9-trimethyl-6,7,8,9-tetrahydro-benzocyclohepten-5-ylidene imine derivatives were synthesized by Chaudhary et al. ${ }^{84}$ Starting from the same substrate $\alpha$-dehydro-ar-himachalene 253. Oxidation of the exocyclic double bond with $\mathrm{NalO}_{4}$ and $\mathrm{OsO}_{4}$ in a mixture of water/THF $(1: 1, \mathrm{v} / \mathrm{v})$ for $20 \mathrm{~h}$ at room temperature produced a corresponding benzocycloheptenone $\mathbf{1 1 8}$ in $\mathbf{7 3} \%$ yield. Finally, using dry silica gel $(\mathrm{H})$ as a Lewis acid and an appropriate amine gave good conversions to the corresponding imines. Different imines 257 were obtained with good yields up to $79 \%$ according to the amine used (Scheme 41). The prepared compounds were tested against a group of sixteen organisms including gram positive and gram negative bacterial and fungal strains. The imine containing an isobutyl group showed the highest activity amongst tested compounds. 


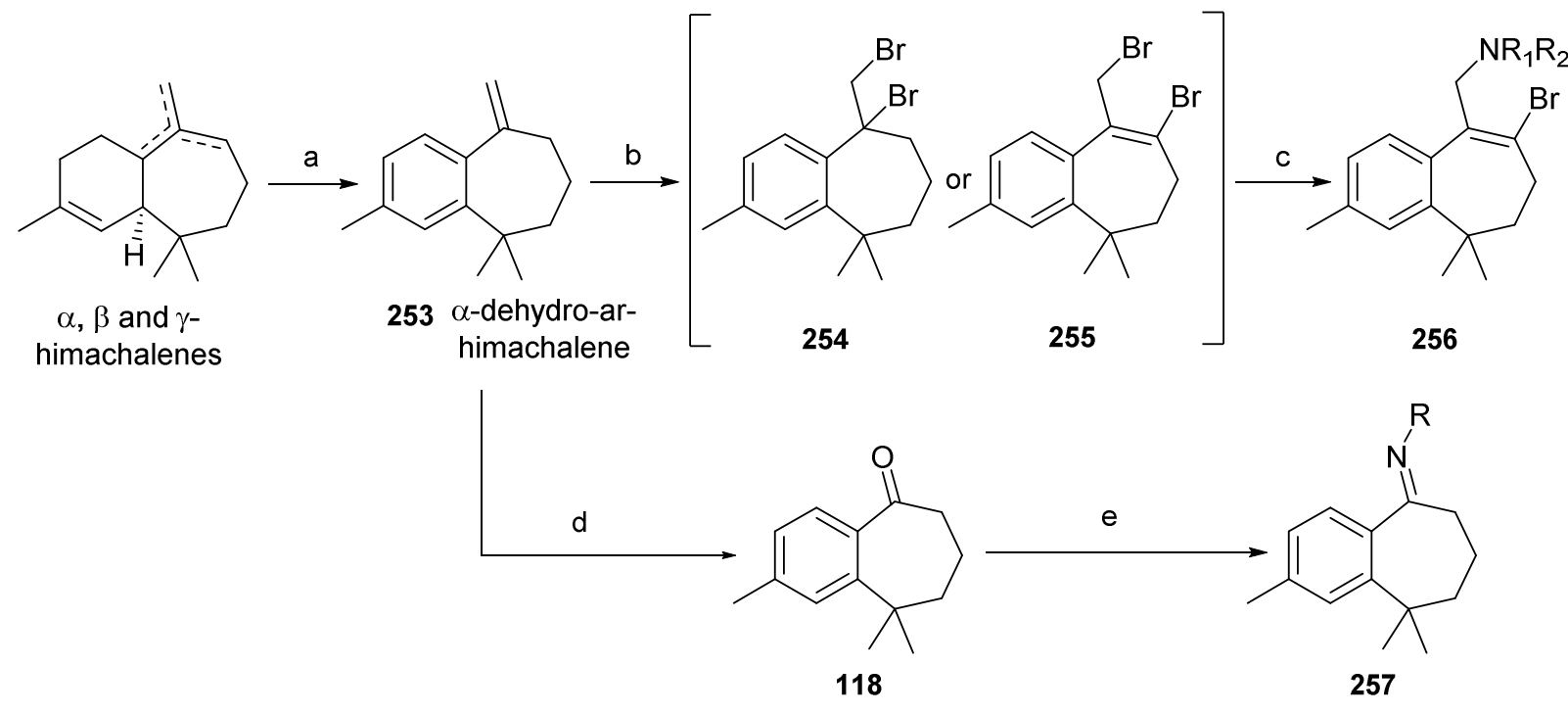

a) $\mathrm{DDQ}$, dry benzene, reflux, $24 \mathrm{~h}, \mathrm{~N}_{2}$; b) $\mathrm{CAN}, \mathrm{KBr}, \mathrm{DCM} / \mathrm{H}_{2} \mathrm{O}$, r.t, $5 \mathrm{~h}$; c) Amine, $\mathrm{K}_{2} \mathrm{CO}_{3}$, DMF, 80-90 ${ }^{\circ} \mathrm{C}$. d) $\mathrm{OsO}_{4}$, $\mathrm{NalO}_{4}, \mathrm{H}_{2} \mathrm{O}: \mathrm{THF}(1: 1), 20 \mathrm{~h}$, r.t. e) Amine, silica gel, $\mathrm{H}, 4-7 \mathrm{~h}$

Scheme 41. Synthesis of amino-dehydro-ar-himachalenes.

Other amino-himachalene derivatives was reported by Auhmani et al. ${ }^{125}$ Firstly, $(1 S, 3 R, 8 R)$-2,2-dichloro3,7,7,10-tetramethyltricyclo[6,4,0,0 $\left.{ }^{1,3}\right]$-dodec-9-en-11-one 258 was prepared in good yield from 231 by allylic oxidation with $\mathrm{N}$-bromosuccinimide (NBS). When a compound $\mathbf{2 5 8}$ treated with sodium azide in trifluoroacetic acid medium, the enone $\mathbf{2 5 8}$ was easily transformed into enaminone $\mathbf{2 6 1}$ and iminol 262. Formation of enaminone 248 and iminol 249 proceeded by a [3+2] cycloaddition with $\mathrm{HN}_{3}$, generated in situ from sodium azide and trifluoroacetic acid. The $N$-substituted pyrazole 263 was formed regiospecifically by treatment of $\beta$ enaminone $\mathbf{2 6 1}$ with 2-hydrazinopyridine (Scheme 42).
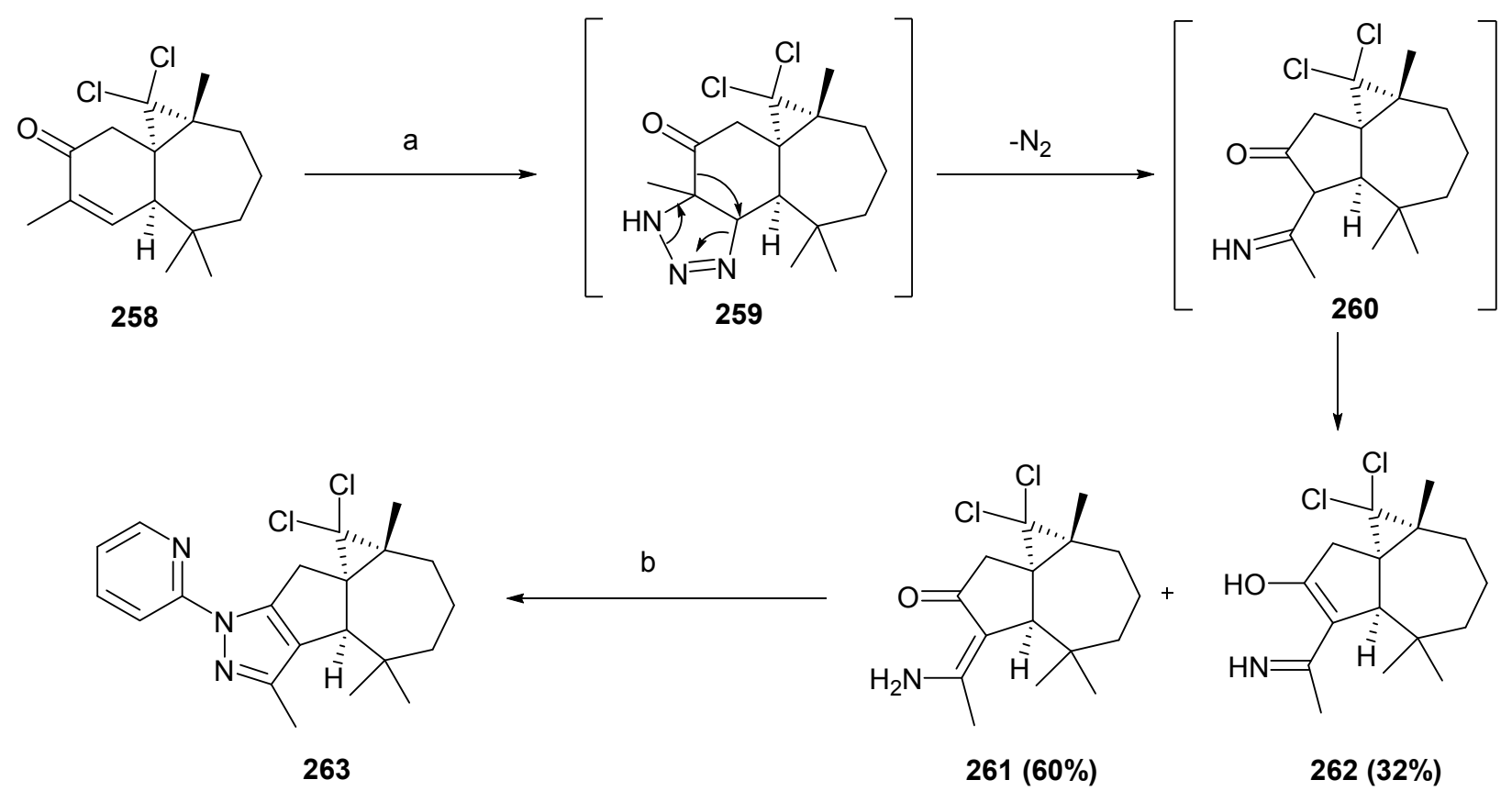

a) $\mathrm{HN}_{3}$, b) Py-NH-NH, $\mathrm{AcOH}$, reflux

Scheme 42. Synthesis of enaminones and fused pyrazoles. 
Aziridines 264 were formed by treatment of epoxide 242 with an excess of $\mathrm{NaN}_{3}$ and $\mathrm{NH}_{4} \mathrm{Cl}$ in a mixture of methanol/water (15/1) at reflux for 2 hours. Under these conditions the reaction led to a mixture of azidoalcohol derivatives. They were purified by column chromatography and then treated with an excess of $\mathrm{PPh}_{3}$ in acetonitrile under reflux for $1.5 \mathrm{~h}$. The product 264 was obtained with $82 \%$ yield from azido alcohol after purification by column chromatography (Scheme 43). The structure was determined by X-ray diffraction analysis. $^{126}$

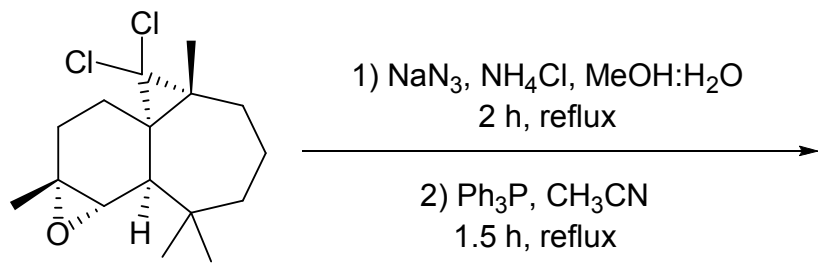

232

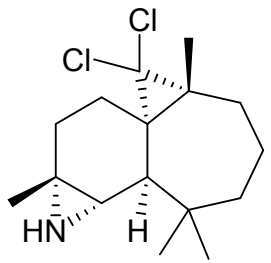

264

Scheme 43. Aziridination of 232.

Lassaba et al. reported the synthesis of $(1 S, 6 S)$-tetrazolo[1,5-g]-7-aza-trans-himachal-2-ene by ozonolysis of $\mathbf{2 1 5}$ followed by a dehydrohalogenation to give two sesquiterpenic ketones $\mathbf{2 6 5}$ and $266 .{ }^{118}$ Then, action of two equivalents of $\mathrm{NaN}_{3}$ on $\mathbf{2 6 5}$ and 266 in presence of trifluoroacetic acid provided 267 and 268 in $75 \%$ and $70 \%$ yield respectively (Scheme 44$)$.

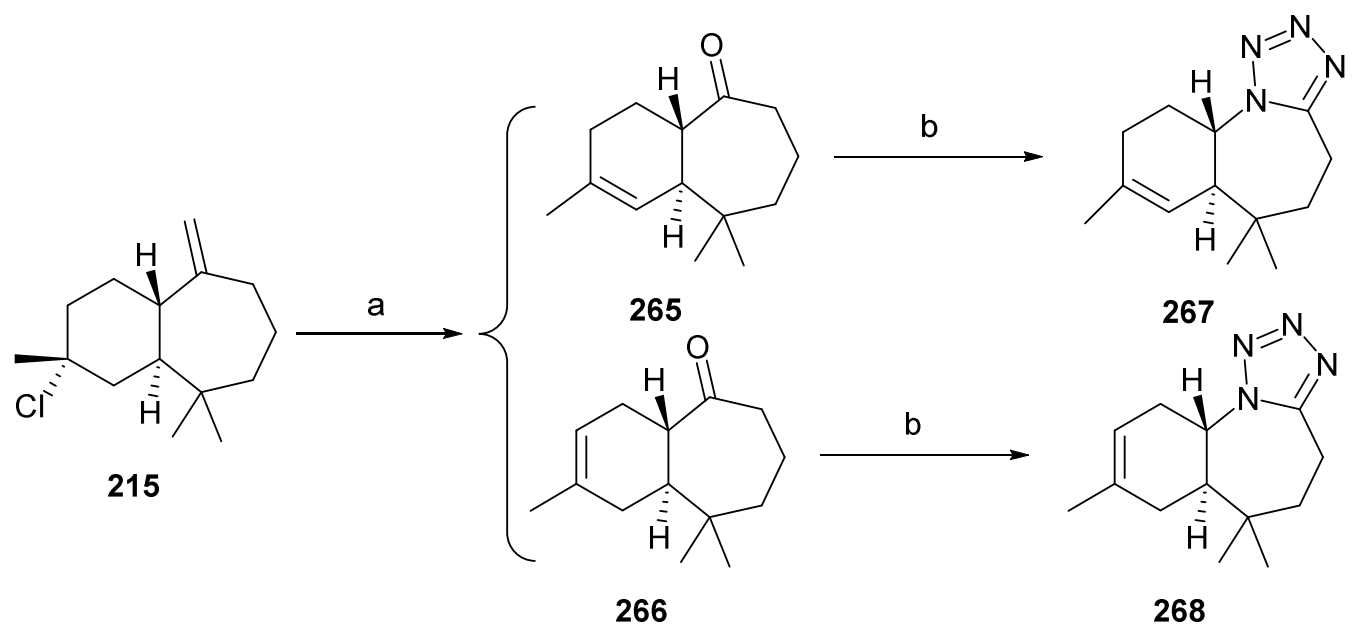

a) 1: $\mathrm{O}_{3}, 2:-\mathrm{HCl}$, b) $\mathrm{NaN}_{3}, \mathrm{CF}_{3} \mathrm{CO}_{2} \mathrm{H}$

Scheme 44. Synthesis of tetrazolo-himachalenes 267 and 266.

Ourhriss et al. ${ }^{127}$ have described the synthesis of tricyclic thiosemicarbazone derivative of $\beta$-himachalene. Dichlorocyclopropanation of $\beta$-himachalene, from essential oil of Atlas cedar, followed by allylic oxidation using $N$-bromosuccinimide and condensation with thiosemicarbazide, gave a compound 269 (Scheme 43). The structure was elucidated by ${ }^{1} \mathrm{H}$ and ${ }^{13} \mathrm{C}$ NMR spectroscopy and its absolute configuration established by singlecrystal $\mathrm{X}$ ray diffraction analysis. 


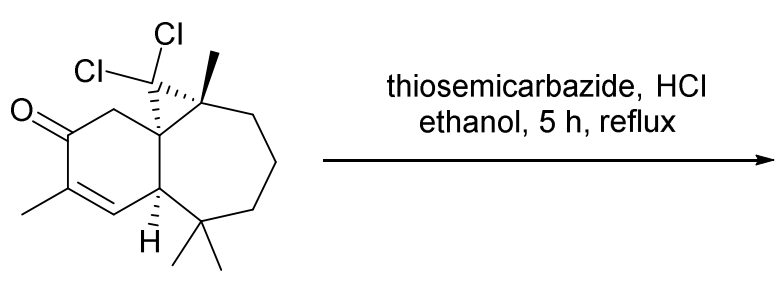

258

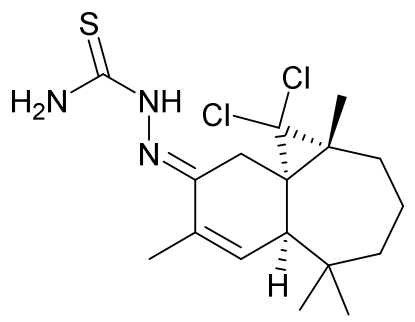

269

Scheme 45. Condensation of enone $\mathbf{2 5 8}$ with thiosemicarbazide.

\section{Synthesis of ar-Himachalene Derivatives}

The Friedel Craft acylation of ar-himachalene obtained by dehydrogenation of a mixture of the three isomers $\alpha$-, $\beta$ - and $\gamma$-himachalene was carried out with acetyl chloride and $\mathrm{AlCl}_{3}$ at room temperature. ${ }^{128}$ Under these conditions the reaction produced one product: 1-(3,5,5,9-tetramethyl-6,7,8,9-tetrahydro-5H-benzocyclohepten-2-yl)ethanone $\mathbf{2 7 0}$. The study also showed that with increasing the temperature from 25 to $100{ }^{\circ} \mathrm{C}$ the reaction gave a mixture of the acylated compound $\mathbf{2 7 0}$ as major product (69\%) and 1-(8-ethyl-8-hydroperoxy3,5,5-trimethyl-5,6,7,8-tetrahydronaphthalen-2-yl)ethanone 271 (21\%) (Scheme 46). The formation of the acyl hydroperoxide 271 could be explained by oxyfunctionalization of the acyl-ar-himachalene with molecular oxygen when exposed to air. Its structure was confirmed by X-ray diffraction.

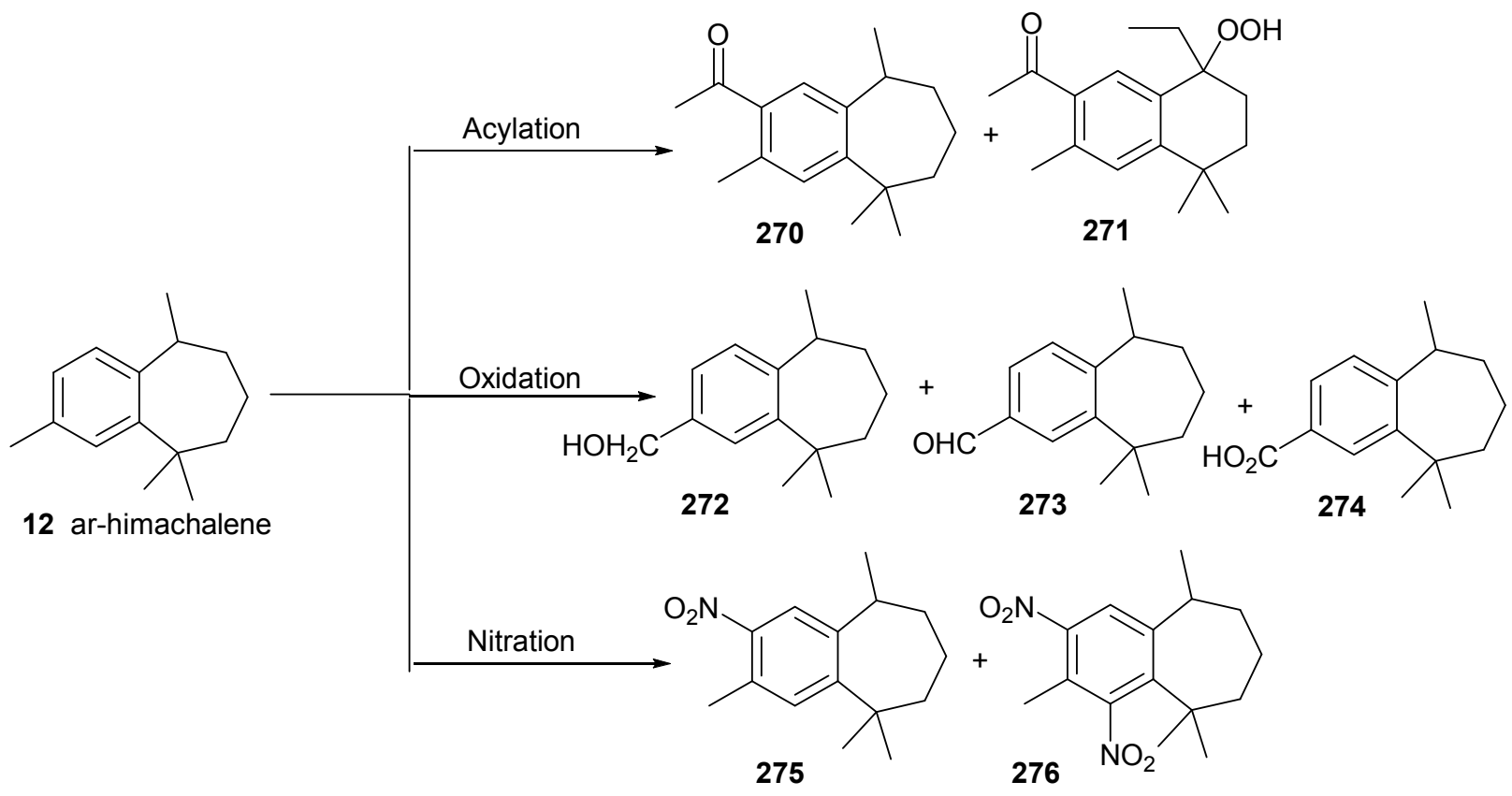

Scheme 46. Synthesis of ar-himachalene derivatives.

Nitration of ar-himachalene with nitric acid in a mixture of acetic anhydride and acetic acid produced two products, $\mathbf{2 7 5}$ and $\mathbf{2 7 6}$. When the reaction was performed in sulfuric acid medium, only the dinitrate compound was obtained. ${ }^{129}$

Recently, similar results were obtained by a catalytic route. Catalytic nitration of ar-himachalene was studied with complexes based on transition metals. ${ }^{130}$ In fact, a practical system of metal (2,4-pentanedionate) 
$\left(\mathrm{M}(\mathrm{acac})_{\mathrm{n}}(\mathrm{M}=\mathrm{Fe}, \mathrm{Zn}\right.$, Co and $\left.\mathrm{V})\right)$ with phosphorus pentoxide $\left(\mathrm{P}_{2} \mathrm{O}_{5}\right)$ in the presence of nitric acid, catalyzed regioselective nitration of ar-himachalene to the mononitro-ar-himachalene in moderate to good yields under mild conditions. It was founded that the reaction selectivity was excellent if the mononitrate was required, compared with the classical method using $\mathrm{HNO}_{3} / \mathrm{H}_{2} \mathrm{SO}_{4}$.

\section{Reactivity of $\alpha$-Atlantones}

\subsection{Aromatization/condensation with thiosemicarbazone}

Both isomeric $(Z)$ - and $(E)$ - $\alpha$-atlantones $\mathbf{2 0}$ and $\mathbf{2 1}$ were quantitatively converted into $N$-[4-acetyl-5-isobutyl-5(2-p-tolylpropyl)-4,5-dihydro-1,3,4-thiadiazol-2-yl]acetamide ${ }^{131} \mathbf{2 7 8}$ or to $\mathrm{N}$-[4-acetyl-5-(2-methylprop-1-enyl)5-(2-p-tolylpropyl)-4,5-dihydro-1,3,4-thiadiazol-2-yl]acetamide 132,133279 (Scheme 47). The reaction was carried out in two steps: firstly a treatment with $\mathrm{Pd} / \mathrm{C}$ and by adjusting the temperature conditions, aromatic ketone intermediate $\mathbf{2 7 7}$ and $\mathbf{1 6 7}$ could be obtained selectively. Reaction with thiosemicarbazone resulted in formation of products $\mathbf{2 7 8}$ and $\mathbf{2 7 9}$ in good yields.

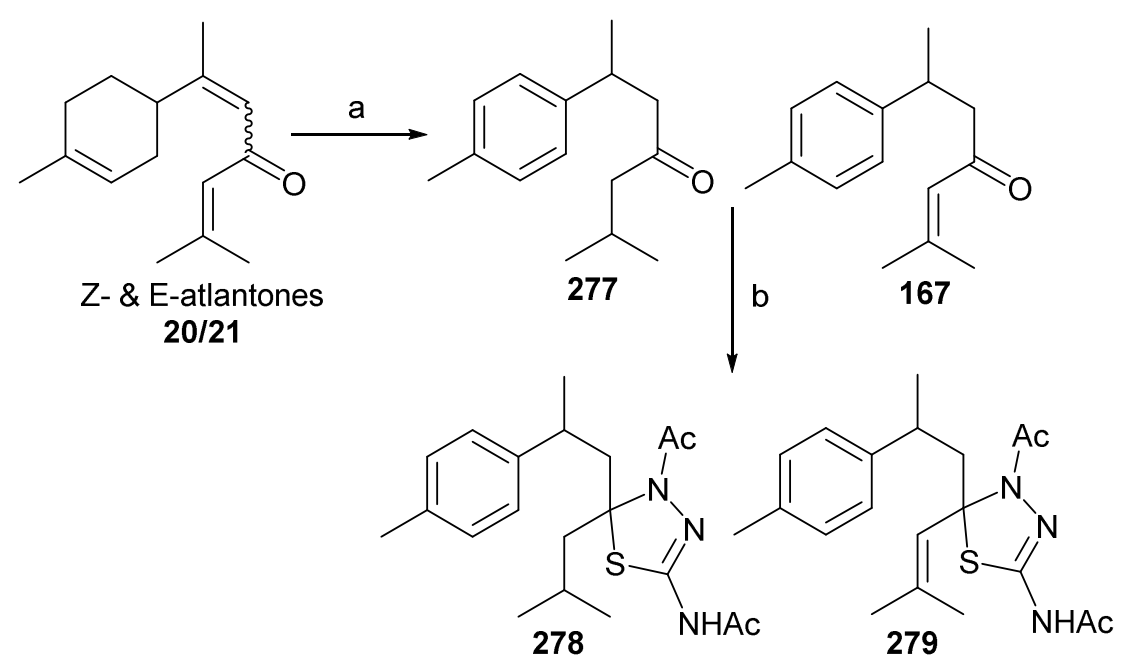

a) Pd/C, Reflux. b) thiosemicarbazone

Scheme 47. Aromatization of atlantones followed by condensation with thiosemicarbazone.

\subsection{Cyclocarbonylation of atlantone derivatives}

Cyclocarbonylation is an alkoxycarbonylation reaction of a substrate containing both olefin and - $\mathrm{ZH}$ function ( $\mathrm{Z}$ $=\mathrm{O}, \mathrm{N}$ ) which will react with the acyl intermediate formed during the catalytic cycle. Cyclocarbonylation of allylic alcohols $\mathbf{2 8 0}$ and $\mathbf{2 8 1}$ obtained from $Z$ and $E$ - $\alpha$-atlantones after aromatization with $\mathrm{Pd} / \mathrm{C}$ followed by Grignard reaction was studied in the presence of catalyst $\left[\mathrm{PdCl}_{2} \mathrm{~L}_{2} / \mathrm{SnCl}_{2} \cdot 2 \mathrm{H}_{2} \mathrm{O}\right]$ with $\mathrm{L}=$ monophosphine or diphosphine ligand (Scheme 48). ${ }^{134}$ 


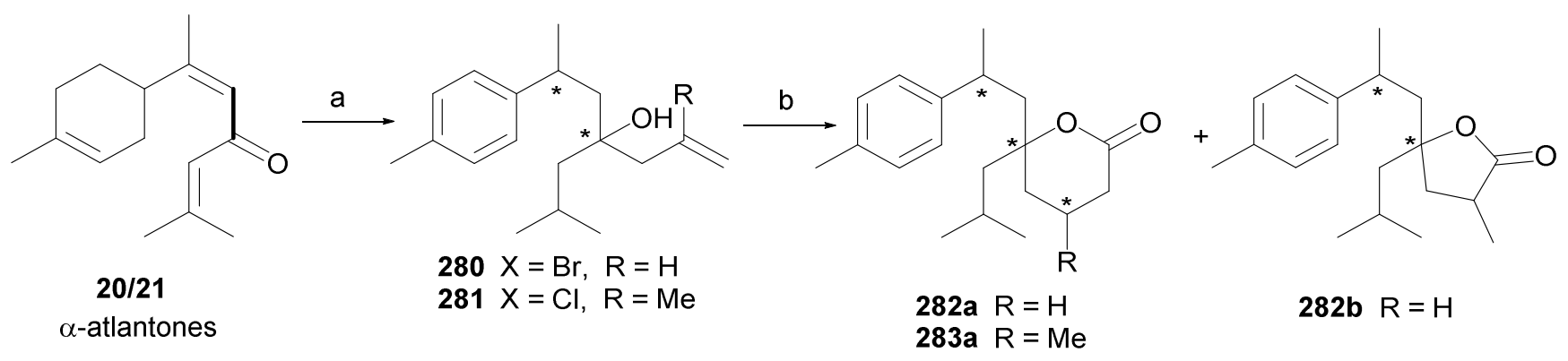

a) 1: $\mathrm{Pd} / \mathrm{C}, 160^{\circ} \mathrm{C}, 2: \mathrm{CH}_{2} \mathrm{CRCH}_{2} \mathrm{MgX}, \mathrm{THF}, 0^{\circ} \mathrm{C}$. b) $\mathrm{PdCl}_{2} \mathrm{~L}_{2} / \mathrm{SnCl}_{2} \cdot 2 \mathrm{H}_{2} \mathrm{O}, \mathrm{CO}$

Scheme 48. Cyclocarbonylation of homoallylic alcohols derived from (E)- and (Z)- $\alpha$-atlantones.

Alcohol $\mathbf{2 8 0}$ was transformed into lactones $\mathbf{2 8 2 a}$ and $\mathbf{2 8 2} \mathbf{b}$ with a selectivity ranging from 78 to $82 \%$. This study showed that the regioselectivity depends heavily on the nature of the ligand used. Indeed, using monophosphine ligand mainly promoted the formation of the lactone five-membered ring $\mathbf{2 8 2} \mathbf{b}$, whereas in the case of diphosphines, the regioselectivity was reversed in favor of the six-membered lactone 282a. Similarly, cyclocarbonylation of alcohol $\mathbf{2 8 1}$ was performed under the same catalytic and experimental conditions. Introduction of a methyl group in position $\gamma$ resulted in a lower conversion but the regioselectivity to form the six-membered lactone 283a was excellent since the latter was formed exclusively. This result showed that this reaction does not depend only on the nature of the ligand used, but also on the nature of the substrate.

\subsection{Acylation of atlantone derivatives}

The acylation of 2-methyl-6-(4-methylphenyl)hept-2-en-4-one $\mathbf{1 6 7}$ was performed in the presence of acetyl chloride and $\mathrm{AlCl}_{3}$ in dichloromethane. ${ }^{135}$ The reaction led to the formation of two acylated compounds 284 and $\mathbf{2 8 5}$ with an overall yield of $\mathbf{9 0 \%}$, in a ratio $\mathbf{2 8 4 / 2 8 5}$ of 55/35 (Scheme 47 ). Formation of product $\mathbf{2 8 5}$ can be explained by activation of the double bond in the presence of $\mathrm{AlCl}_{3}$ which generates a positive partial charge on the $\mathrm{C} 2$ carbon, leading to an intramolecular Friedel-Crafts reaction.

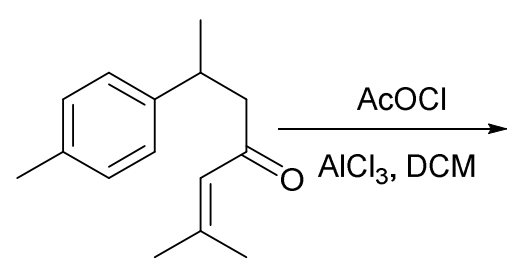

167

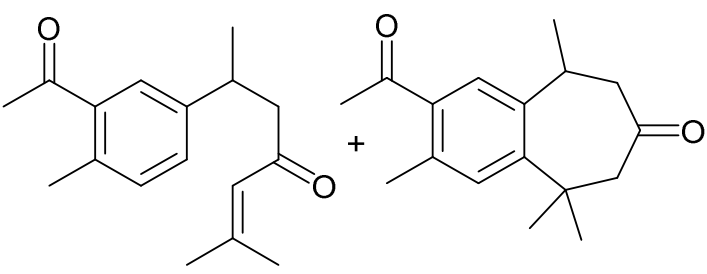

284
285

Scheme 49. Acylation of atlantone derivative 167.

\section{Conclusions}

Chemists have a compelling curiosity to discover what compounds nature provides, but to obtain this information it is necessary to isolate compounds from their natural source and to determine their structures. This is seldom an easy task, especially when the compound of interest is present at low concentrations. In this circumstance a high degree of skill and technology is required in both the isolation procedures and the subsequent investigations to establish the chemical structure. A second objective is the total synthesis of the 
compound from smaller molecules. Indeed, in the classical approach to structure determination, a structure was assigned to a natural product through chemical degradation studies to smaller, identifiable molecules. However, the assigned structure was not regarded as fully confirmed until the compound was synthesized and shown to be identical in all respects (composition, configuration, conformation) with the natural compound. This approach persists, although the enormous impact of modern methods of separation and spectroscopic analysis has made it possible to determine structure beyond a reasonable doubt in almost all cases without recourse to synthesis. Nevertheless, despite the problems of stereoselectivity and the high number of steps, the synthesis of natural products continues to be important. It provides new methodology, new reactions and techniques. It also provides alternative sources of natural compounds and offers routes to related but unnatural analogs. In the case of a useful drug, the synthetic objective is to find a related structure that is more potent at lower dosages with fewer side effects than the natural compound. This review provides an overview of research concerning the upgrading of essential oil of cedar. Firstly we showed the different work cited in the literature on the chemical constituents of these essences and the different methods that allow synthesis of the main constituents from commercial products. We have also reviewed the significant contributions of various research groups on the chemical transformation of the main sesquiterpenes in order to increase the biological activity of the molecule or to discover new activities. This inexhaustible source allows the identification of several products to achieve a range of activities of growing potential and targeted to cover a broad spectrum of diseases.

\section{References}

1. Koehn, F. E.; Carter, G. T.; The evolving role of natural products in drug discovery, Nature Review Drug Discovery 2005, 4, 206-220.

https://doi.org/10.1038/nrd1657

2. Hostettmann, K.; Marston, A. Phytochem. Revs 2002, 1, 275-285. https://doi.org/10.1023/A:1026046026057

3. Chevallier, A. Encyclopédie des plantes médicinales : identification, préparation, soins, 2ème édition Larousse, 2001.

4. Grimal, E. Compt. rend. hebd. Séances Acad. Sci. 1902, T135, 582-583.

5. Pfau A. S.; Plattner, P. Helv. Chim. Acta 1934, 17, 129-157.

https://doi.org/10.1002/hlca.19340170118

6. Plattier, M.; Teisseire, P. Recherches 1974, 19, 131-144.

7. Rao, G. S.; Krishna; Dev, S.; Guha, P. C. Indian J. Chem. Soc. 1952, 29, 721-730.

8. Ruzička, L.; Schinz, H.; Müller, P. H. Helv. Chim. Acta 1944, 27, 195-206. https://doi.org/10.1002/hlca.19440270121

9. Rao, G. S. K.; Dev, S.; Guha, P.C. J. Indian Chem. Soc. 1952, $29,721$.

10. T. C. Joseph, T.C.; Dev, S. Tetrahedron Lett. 1961, 2, 216-222.

https://doi.org/10.1016/S0040-4039(01)99234-2

11. Berdenberg, J. B. Erdtman, H. Acta Chem. Scand. 1961, 15, 685-686.

https://doi.org/10.3891/acta.chem.scand.15-0685

12. Teisseire, P.; Plattier, M. Recherches 1974, 19, 153-166.

13. Bisarya, S. C.; Dev, S. Tetrahedron 1968, 24, 3861-3867.

https://doi.org/10.1016/S0040-4020(01)92593-1

14. Bhan, P.; Dev, S.; Bass, L. S.; Tagle, B.; Clardy, J. J. Chem. Res. (S) 1982, 344-345. 
15. Shankaranarayan, R.; Bisarya, S. C. Dev, S. Tetrahedron 1977, 33, 1207-1210. https://doi.org/10.1016/0040-4020(77)80416-X

16. Shankaranarayan, R.; Krishnappa, S.; Bisarya, S. C.; Dev, S. Tetrahedron 1977, 33, 1201-1205. https://doi.org/10.1016/0040-4020(77)80415-8

17. Krishnappa, S.; Dev, S. Tetrahedron 1978, 34, 599-602. https://doi.org/10.1016/0040-4020(78)80059-3

18. Kulshreshtha, D. K.; Rastogi, R. P. Phytochemistry 1975, 14, 2237-2240. https://doi.org/10.1016/S0031-9422(00)91106-3

19. Kulshreshtha, D. K.; Rastogi, R. P. Phytochemistry 1976, 15, 557-558. https://doi.org/10.1016/S0031-9422(00)88974-8

20. Avcibasi, H.; Anil, H.; Toprak, M. Phytochemistry 1987, 26, 2852-2854. https://doi.org/10.1016/S0031-9422(00)83605-5

21. Pfau, A. S. Helv. Chim. Acta 1932, 15, 1481. https://doi.org/10.1002/hlca.193201501175

22. Agarwal, P. K.; Rastogi, R. P. Phytochemistry 1981, 20, 1319-1321. https://doi.org/10.1016/0031-9422(81)80031-3

23. Ez zoubi, Y.; El-akhal, F.; Farah, A.; Taghzouti, K.; El ouali Lalami, A. J.Appl.Pharm Sci, 2017, 7, 30-34. https://doi.org/10.7324/JAPS.2017.70704

24. Zrira, S.; Ghanmi, M. Journal of Essential Oil-Bearing Plants 2016, 19, 1267-1272. https://doi.org/10.1080/0972060X.2015.1137499

25. Boudarene, M. L.; Rahim, L.; Baaliouamer, A.; Y. Meklati, B. Journal of Essential Oil Research 2004, 16, 531-534. https://doi.org/10.1080/10412905.2004.9698790

26. Aberchane, M.; Fechtal, M.; Chaouch, A. Journal of Essential Oil Research 2004, 16, 542-547. https://doi.org/10.1080/10412905.2004.9698793

27. Paoli, M.; Nam, A-M.; Castola, V.; Casanova, J.; Bighelli, A. CHEM. BIODIVERS. 2011, 8, 344-351. https://doi.org/10.1002/cbdv.201000094

28. Challand, B. D.; Kornis, G.; Lange, G.; De Mayo, P. Chem. Comm. 1967, 704-705. https://doi.org/10.1039/C1967000704B

29. Challand, B. D.; Hikino, H.; Kornis, G.; Lange, G.; De Mayo, P. J. Org. Chem. 1969, 34, 794-806. https://doi.org/10.1021/jo01256a006

30. Wenkert, E.; Naemura, K. Synth. Comm. 1973, 3, 45-48. https://doi.org/10.1080/00397917308062002

31. Oppolzer, W.; Snowden, R. L. Helv. Chim. Acta 1981, 64, 2592-2597. https://doi.org/10.1002/hlca.19810640815

32. Evans, D. A.; Ripin, D. H. B.; Johnson, J. S.; Shaughnessy, E. A. Angew. Chem. Int. Ed. Engl. 1997, 36, 2119-2121.

https://doi.org/10.1002/anie.199721191

33. Evans, D. A.; Bartloti, J.; Shik, T. L. J. Am. Chem. Soc. 1981, 103, 2127-2129. https://doi.org/10.1021/ja00398a058

34. Parikh, J. R.; Doering, E. W. J. Am. Chem. Soc. 1967, 89, 5505-5507. https://doi.org/10.1021/ja00997a067

35. Pine, S. H.; Zahler, R.; Evans, D. A.; Grubbs, R. H. J. Am. Chem. Soc. 1980, 102, 3270-3272. https://doi.org/10.1021/ja00529a076 
36. Liu, H. J.; Brown, E. N. C. Can. J. Chem. 1981, 59, 601-608.

https://doi.org/10.1139/v81-088

37. Mehta, G.; Kapoor, S. K. J. Org. Chem. 1974, 39, 2618-2624.

https://doi.org/10.1021/jo00931a038

38. Corey, E. J.; Mitra, R. B.; Uda, H. J. Am. Chem. Soc. 1964, 86, 485-492.

https://doi.org/10.1021/ja01057a040

39. Joseph, T. C.; Dev, S. Tetrahedron 1968, 24, 3853-3859.

https://doi.org/10.1016/S0040-4020(01)92592-X

40. Shastri M. H.; Dev, S. Tetrahedron 1992, 48, 4905-4918.

https://doi.org/10.1016/S0040-4020(01)81583-0

41. Piers, E.; Ruediger. H. E. Can. J. Chem. 1983, 61, 1239-1247.

https://doi.org/10.1139/v83-220

42. Rigby, J. H.; McGuire, T. W. Tetrahedron Lett. 1993, 34, 3017-3020.

https://doi.org/10.1016/S0040-4039(00)93367-7

43. Piers, E.; Ruediger, E. H. J. Chem. Soc. Chem. Commun. 1979, 166-167. https://doi.org/10.1039/C39790000166

44. Rigby, J. H.; Sage, J-M.; Raggon, J. J. Org. Chem. 1982, 47, 4815-4816.

https://doi.org/10.1021/jo00145a054

45. Ho, T. L.; Chein, R. J. Helv. Chim. Acta 2006, 89; 231-239.

https://doi.org/10.1002/hlca.200690025

46. Corey, E. J.; Boger, D. L. Tetrahedron Lett. 1978, 19, 2461-2464.

https://doi.org/10.1016/S0040-4039(01)94800-2

47. Alonso, F.; Mico, I.; Najera, C.; Sansano, J. M.; Gracia, I. Tetrahedron 1995, 51, 10259-10265.

https://doi.org/10.1016/0040-4020(95)00586-W

48. Hudrlik, P. F.; Hudrlik, A. M.; Misra, R. N.; Peterson, D.; Withers, G. P.; Kulkarni, A. K. J. Org. Chem.

1980, 45, 4444-4448.

https://doi.org/10.1021/jo01310a035

49. Srikrishna, A.; Kumar, P. R. Indian J. Chem. 2008, 47B, 1414-1422.

50. Nambudiry, M. E. N.; Rao, G. S. K. Indian J. Chem. 1974, 12, 389-390.

51. Harref, A. B.; Bernardini, A.; Fkih-Tetouani, S.; Jacquier, R.; Viallefont, P. J. Chem. Res. (S) 1981, 5, 372-373.

52. Dufour, S.; Castets, P.; Pickett, J. A.; Hooper, A. M. Tetrahedron 2012, 68, 5102-5108.

https://doi.org/10.1016/i.tet.2012.04.037

53. Crombie, L.; Houghton, R. P.; Woods, D. K. Tetrahedron Lett. 1967, 8, 4553-4557.

https://doi.org/10.1016/S0040-4039(01)89554-X

54. Pandey, R. C.; Dev, S. Tetrahedron 1968, 24, 3829-3839.

https://doi.org/10.1016/S0040-4020(01)92590-6

55. Sonawane, H. R.; Bellur, S. N.; Sudrik, S. G. Indian J. Chem. 1992, 31B, 606-607.

56. Doyle, M. P. Acc. Chem. Res. 1986, 19, 348-356.

https://doi.org/10.1021/ar00131a004

57. Doyle, M. P. Chem. Rev. 1986, 86, 919-940.

https://doi.org/10.1021/cr00075a013

58. Bartelt, R. J.; Weisleder, D.; Momany, F. A. Synthesis 2003, 1, 117-123.

https://doi.org/10.1055/s-2003-36253 
59. Ireland, R. E.; Marshall, J. A. J. Org. Chem. 1962, 27, 1615-1620. https://doi.org/10.1055/s-2003-36253

60. Joly, R.; Warnant, J. Bull. Chim. Soc. Fr. 1958, 367-369.

61. Boeckman, R. K.; Blum, D. M.; Ganem, B.; Halvey, N. Org. Synth. 1978, 58, 152-157. https://doi.org/10.15227/orgsyn.058.0152

62. Muto, S. E.; Bando, M.; Mori, K. Eur. J. Org. Chem. 2004, 1946-1952. https://doi.org/10.1002/ejoc.200300812

63. Bhanot, O. S. Indian J. Chem. 1967, 5, 127-128.

64. Leonard, N. J.; Schimelpfenig, C. W. J. Org. Chem. 1958, 23, 1708-1710. https://doi.org/10.1021/jo01105a034

65. Stork, G.; Ganem, B. J. Am. Chem. Soc. 1973, 95, 6152-6153. https://doi.org/10.1021/ja00799a072

66. Gawley, R. E. Synthesis 1976, 12, 777-794. https://doi.org/10.1055/s-1976-24200

67. Mori, K. Tetrahedron Asymm. 2005, 16, 685-692. https://doi.org/10.1016/i.tetasy.2004.11.077

68. Evans, D. A.; Ennis, M. D.; Mathre, D. J. J. Am. Chem.Soc. 1982, 104, 1737-1739. https://doi.org/10.1021/ja00370a050

69. Nahm, S.; Weinreb, S. M. Tetrahedron Lett. 1981, 22, 3815-3818.

70. Mori, K. Tetrahedron Asymmetry 2005, 16, 1721. https://doi.org/10.1016/i.tetasy.2005.03.027

71. Yan, Q.; Kong, D.; Li, M.; Hou, G.; Zi, G. J. Am. Chem. Soc. 2015, 137, 10177-10181. https://doi.org/10.1021/jacs.5b06418

72. Chavan, S. P.; Khatod, H. S. Tetrahedron Asymm. 2012, 23, 1410-1415. https://doi.org/10.1016/i.tetasy.2012.09.008

73. Chavan, S. P.; Dhondge, V. D.; Patil, S. S.; Rao, Y. T. S.; Govande, C. A. Tetrahedron Asymm. 1997, 8, 2517-2518. https://doi.org/10.1016/S0957-4166(97)00284-X

74. Justik, M. W.; Koser, G. F. Molecules 2005, 10, 217-225. https://doi.org/10.3390/10010217

75. Itani, H.; Ito, H.; Sakata, Y.; Hatakeyama, Y.; Oohashi, H.; Satoh, Y. Bioorg. Med. Chem. Lett. 2002, $12,799-802$.

https://doi.org/10.1016/S0960-894X(02)00018-5

76. Sudrik, S. G.; Nanjundiah, B. S.; Sonawane, H. R. Indian J. Chem. 1997, 36B, 1103-1112.

77. Spielmann, K.; de Figueiredo, R. M.; Campagne, J-M. J. Org. Chem. 2017, 82, 4737-4743. https://doi.org/10.1021/acs.joc.7b00419

78. Reetz, M. T.; Westermann, J.; Kyung, S-H. Chem. Ber. 1985, 118, 1050. https://doi.org/10.1002/cber.19851180322

79. Joshi, B.; Seshadri, R.; Charkravarti, K.; Bhattacharyya, S. Tetrahedron 1964, 20, 2911-2919. https://doi.org/10.1016/S0040-4020(01)98512-6

80. Joseph, T.C.; Dev, S. Tetrahedron 1968, 24, 3809-3827. https://doi.org/10.1016/S0040-4020(01)92589-X

81. Daunis, J.; Jacquier, R.; Lopez, H.; Viallefont, P. J. Chem. Research (M) 1981, 5, o639-0649.

82. Abouhamza, B.; Allaoud, S.; Karim, A. Molecules 2001, 6, M236. 
https://doi.org/10.3390/M236

83. Jimenez-Alemana, G. H.; Schöner, T.; Montero-Alejo, A. L.; Brandt, W.; Boland, W. Arkivoc 2012, (iii), 371-378.

https://doi.org/10.3998/ark.5550190.0013.326

84. Chaudhary, A.; Sood, S.; Das, P.; Kaur, P.; Mahajan, I.; Gulati, A.; Singh, B. EXCLI Journal 2014, 13, 1216-1225.

85. Daunis, J.; Jacquier, R.; Lopez, H.; Viallefont, O. J.Chem. Research (S) 1981, 5, 45.

86. Teisseire, P.; Plattier, M. Recherches 1974, 19, 167-172.

87. Malanco, F. L.; Maldonado, L. A. Synth. Commun. 1976, 6, 515-519. https://doi.org/10.1080/00397917608082634

88. Andrianome, M.; Delmond, B. J. Org. Chem. 1988, 53, 542-545. https://doi.org/10.1021/jo00238a013

89. Andrianome, M.; Haberle, K.; Delmond, B. Tetrahedron 1989, 45, 1079-1088. https://doi.org/10.1016/0040-4020(89)80018-3

90. Crawford, R. J.; Erman, W. F.; Broaddus, C. D. J. Am. Chem. Soc. 1972, 94, 4298-4306. https://doi.org/10.1021/ja00767a044

91. Wilson, S. R.; Philips, L. R.; Natalie, K. J. J .Am. Chem. Soc. 1979, 101, 3340-3344. https://doi.org/10.1021/ja00506a034

92. Cookson, R. C.; Parsons, P. J. J. Chem. Soc. Chem. Comm. 1978, 19, 821-822. https://doi.org/10.1039/c39780000821

93. Leopold, H.; Volker, B. Liebigs Ann. Chem. 1972, 757, 33-68. https://doi.org/10.1002/ilac.19727570106

94. Adams, D. R.; Bhatnagar, S. P.; Cookson, R. C. J. Chem. Soc. Perkin Trans. 1 1975, 1502-1506. https://doi.org/10.1039/p19750001502

95. Lseger, P.; Thomsen, I.; Torssell, K. B. G. Acta Chem. Scand. 1990, 44, 806-813. https://doi.org/10.3891/acta.chem.scand.44-0806

96. Motoyoshiya, J.; Miyajima, M.; Hirakawa, K.; Kakurai, T. J.Org. Chem. 1985, 50, 1326-1327. https://doi.org/10.1021/jo00208a043

97. Friesen, R. W.; Blouin, M. J. Org. Chem. 1996, 61, 7202-7206. https://doi.org/10.1021/j0960894z

98. Sugiura, M.; Ashikari, Y.; Nakajima, M. J. Org. Chem. 2015, 80, 8830-8835. https://doi.org/10.1021/acs.joc.5b01217

99. Eljamili, H.; Auhmani, A.; Dakir, M.; Benharref, A.; Kossareva, E.; Pierrot, M. Acta Cryst. 2001, E57, 0904-0905.

https://doi.org/10.1107/S1600536801014374

100. Eljamili, H.; Auhmani, A.; Dakir, M.; Benharref, A.; Kossareva, E.; Pierrot, M. Acta Cryst. 2001. E57, 0925-0927.

https://doi.org/10.1107/S160053680101457X

101. Narula, A. P. S.; Dev, S. Tetrahedron 1977, 33, 813-816.

https://doi.org/10.1016/0040-4020(77)80198-1

102. Lassaba, E.; Chekroun, A.; Benharref, A.; Chiaroni, A.; Riche, C.; Lavergne, J. P. Bull. Soc. Chim. Belges 1997, 106, 281-288.

103. Benharref, A.; Chekroun, A.; Lavergne, J. P. Bull. Soc. Chim. Fr. 1991, 738-741.

104. Chiaroni, A.; Riche, C.; Benharref, A.; Lassaba, E.; Baouid, A. Acta Cryst. 1996, C52, 2504-2507. 
https://doi.org/10.1107/S0108270196005756

105. Chekroun, A.; Jarid, A.; Benharref, A.; Boutalib, A. J. Org. Chem. 2000, 65, 4431. https://doi.org/10.1021/j0991848c

106. Fdil, N.; Ait Itto, M-Y.; Ait Ali, M.; Karim, A.; Daran, J-C. Tetrahedron Lett. 2002, 43, 8769-8771. https://doi.org/10.1016/S0040-4039(02)02072-5

107. Chiaroni, A.; Chekroun, A.; Benharref, A.; Pais, C.; Lavergne, J. P. Acta Cryst. 1992, C48, 17201722.

https://doi.org/10.1107/S0108270192005316

108. Lassaba, E.; El Jamili, H.; Chekroun, A.; Benharref, A.; Chiaroni, A.; Riche, C.; Lavergne, J.P. Synth. Comm. 1998, 28, 2641.

https://doi.org/10.1080/00397919808004833

109. Chiaroni, A.; Riche, C.; Lassaba, E.; Benharref, A. Acta Cryst. 1996, C52, 3240-3243. https://doi.org/10.1107/S0108270196008797

110. Loubidi, M.; Agustin, D.; Benharref, A.; Poli, R. C. R. Chimie 2014, 17, 549-556. https://doi.org/10.1016/i.crci.2014.01.023

111. Morlot, J.; Uyttebroeck, N.; Agustin, D.; Poli, R. ChemCatChem 2013, 5, 601-611. https://doi.org/10.1002/cctc.201200068

112. Eljamili, H.; Auhmani, A.; Dakir, M.; Lassaba, E.; Benharref, A.; Pierrot, M.; Chiaroni, A.; Riche, C. Tetrahedron Lett. 2002, 43, 6645-6648. https://doi.org/10.1016/S0040-4039(02)01407-7

113. Ourhriss, N.; Benharref, A.; Saadi, M.; El Ammari, L.; Berraho, M. Acta Cryst. 2013, E69, o275. https://doi.org/10.1107/S1600536813001700

114. Oukhrib, A.; Benharref, A., Saadi, M.; Berraho, M.; El Ammari, L. Acta Cryst., 2013, E69, 0739. https://doi.org/10.1107/S1600536813010040

115. Ourhriss, N.; Benharref, A.; Saadi, M.; Berraho, M.; El Ammari, L. Acta Cryst. 2013, E69, o724. https://doi.org/10.1107/S1600536813009070

116. Benharref, A.; Ourhriss, N.; El Ammari, L.; Saadi, M.; Berraho, M. Acta Cryst. 2013, E69, o9330934.

https://doi.org/10.1107/S1600536813013457

117. Benharref, A.; El Karroumi, J.; El Ammari, L.; Saadi, M.; Berraho, M. Acta Cryst. 2013, E69, 01261. https://doi.org/10.1107/S160053681301903X

118. Lassaba, E.; Benharref, A.; Giorgi, M.; Pierrot, M. Acta Cryst. 1997, C53, 1139-1141. https://doi.org/10.1107/S010827019700365X

119. Benharref, A.; El Karroumi, J.; El Ammari, L. Saadi, M.; Berraho, M. Acta Cryst. 2013, E69, o1037o1038. https://doi.org/10.1107/S160053681301502X

120. Auhmani, A.; Kossareva, E.; El Jamili, H.; Reglier, M.; Pierrot, M.; Benharref, A. Acta Cryst. 2000, 30, 525.

121. Benharref, A.; Chekroun, A.; Chiaroni, A.; Pais, M.; Riche, C. Acta Cryst. 1991, C47, 1945-1948. https://doi.org/10.1107/S0108270191003189

122. El Haib, A.; Benharref, A.; Parrès-Maynadié, S.; Manoury, E.; Urrutigoïty, M.; Gouygou, M. Tetrahedron Asym. 2011, 22, 101-108. https://doi.org/10.1016/i.tetasy.2010.12.013 
123. El Haib, A.; Benharref, A.; Parrès-Maynadié, S.; Manoury, E.; Urrutigoïty, M.; Gouygou, M. Tetrahedron Asym. 2010, 21, 1272-1277.

https://doi.org/10.1016/j.tetasy.2010.04.024

124. Chaudhary, A.; Das, P.; Mishra, A. Mol. Divers. 2012, 16, 357-366.

https://doi.org/10.1007/s11030-012-9372-3

125. Auhmani, A.; Kossareva, E.; Eljamili, H.; Reglier, M.; Pierrot, M.; Benharref, A. Synth. Comm. 2002, 32, 699-707.

https://doi.org/10.1081/SCC-120002507

126. Oukhrib, A.; Benharref, A.; Saadi, M.; Berraho, M.; El Ammari, L. Acta Cryst. 2013, E69, o5890590.

https://doi.org/10.1107/S1600536813007642

127. Ourhriss, N.; Giorgi, M.; Mazoir, N.; Benharref, A. Acta Cryst. 2005, C61, 0699.

https://doi.org/10.1107/S0108270105033470

128. Hossini, I.; Anoir Harrad, M.; Boualy, B.; Ait Ali, M.; El Firdoussi, L.; Karim; A.; Valerga, P.; Puerta, M. C. Molecules 2011, 16, 5886-5895.

https://doi.org/10.3390/molecules16075886

129. Hossini, I.; Anoir Harrad, M.; Boualy, B.; Ouahrouch; A. Chem. Mater. Res. 2014, 6, 110-114.

130. Hossini, I.; Anoir Harrad, M.; Boualy, B.; Ait Ali, M.; El Firdoussi, L.; Karim; A. Green Sustainable Chemistry 2011, 1, 111-115.

https://doi.org/10.4236/gsc.2011.13018

131. Mazoir, N.; Maya, C. M.; Berraho, M.; Benharref, A.; Bouhmida, N. Acta Cryst. 2009. E65, 04. https://doi.org/10.1107/S1600536808039998

132. Mazoir, N.; Dakir, M.; Tebbaa, M.; Loughzail, M.; Benharref, A. Tetrahedron Lett. 2016, 57, 278280.

https://doi.org/10.1016/i.tetlet.2015.11.103

133. Mazoir, N.; El Ammari, L.; Bouhmida, N.; Benharref, A.; Berraho, M. Acta Cryst. 2009. E65, o126901270.

https://doi.org/10.1107/S1600536809017127

134. El Karroumi, J.; El Haib, A.; Manoury, E.; Benharref, A.; Daran, J. C.; Gouygou, M.; Urrutigoïty, M. J. Mol. Catal. A: Chem. 2015, 401,18-26.

https://doi.org/10.1016/i.molcata.2015.02.010

135. Benharref, A.; Mazoir, N.; Lassaba, E.; Daran, J. C.; Berraho, M. Acta Cryst. 2011, 67, o58.

https://doi.org/10.1107/S1600536810050610 


\section{Authors' Biographies}

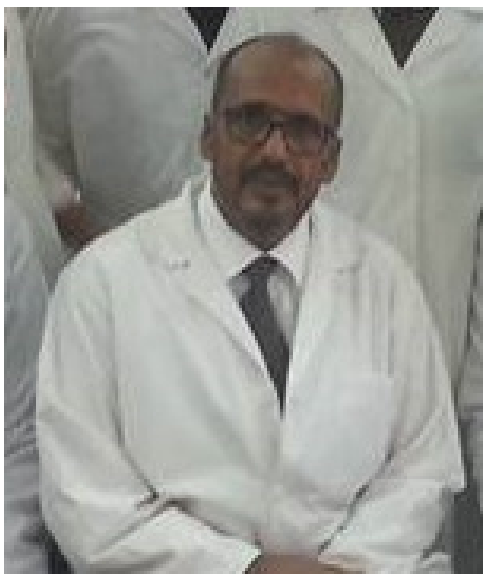

Prof. Ahmed Benharref was born in Eljadida (Morocco) in 1951. He obtained his doctorate at U.S.T.L/Montpellier France in June 1980. In 1980 Prof. Ahmed Benharref incorporated as a postdoctoral member at USTL Montpellier France. He has been Professor B grad in 1999 and Professor C grad 2002. He has been director of the Laboratory of Biomolecular Chemistry, Natural Substances and Reactions of the University Cadi Ayyad-FSSM (Morocco) since 2006. His research interests cover organic chemistry and natural products.

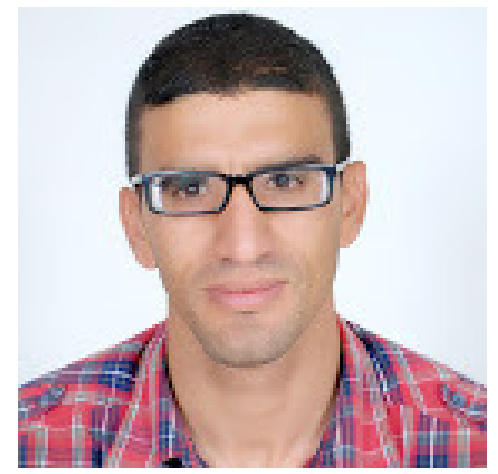

Dr. Abdelouahd Oukhrib was born in 1986 in Marrakech (Morocco). He received his Ph.D in organic chemistry, catalysis and organometallic from Paul Sabatier University of Toulouse-France and Caadi Ayyad University of Marrakech, Morocco under the supervision of Professors Martine Urritigoity and Ahmed Benharref in April 2015. He is a postdoctoral fellow at LCBSNR FSSM (Morocco) with Professor Ahmed Benharref since June 2015. His research interests are: catalysis by transition metals, organic catalysis, asymmetric synthesis and phosphorus ligands.

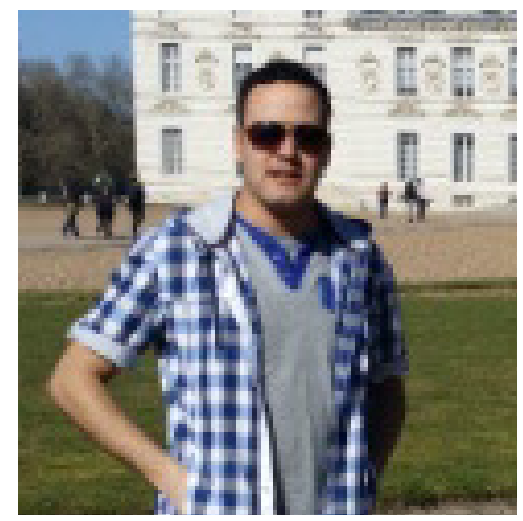


Dr. Mohamed Zaki received his Ph.D. degrees in organic chemistry of natural product from Hassan II University of Casablanca, Morocco and Orleans University, France under the supervision of Professors Sabine Berteina-Raboin and Mohamed Akssira. His research interests cover the chemistry of natural products, especially the isolation, purification and structural elucidation of pharmacologically active compounds. 